\section{RESEARCHES}

EDITOR: Benjamin Penny

EDITORIAL ASSISTANT: Misty Cook

EDITORIAL COMMITTEE: Graeme Clarke,

Iain McCalman, Tesssa Morris-Suzuki,

Fiona Paisley, Nicholas Thomas.

\section{EDITORIAL ADVISORS:}

Tony Bennett, Gri $\approx$ th University

Dipesh Chakrabarty, University of

Chicago

James K. Chandler, University of Chicago

W. Robert Connor, National Humanities

Center

Saul Dubow, University of Sussex

Valerie I. J. Flint, University of Hull

Margaret R. Higonnet, University of

Connecticut

Caroline Humphrey, University of

Cambridge

Lynn Hunt, University of Pennsylvania

Mary Jacobus, Cornell University

Cover illustration: Advertisement for 1940 Tokyo Olympics, back cover, Travel in Japan, 3.I (i937).

ISSN: 1440-o669

\section{W. J. F. Jenner, Australian National University}

Peter Jones, University of Edinburgh

E. Ann Kaplan, State University of New York at Stony Brook

Joan Kerr, Australian National University

Dominick LaCapra, Cornell University David MacDougall, Australian National University

Fergus Millar, University of Oxford

Anthony Milner, Australian National University

Meaghan Morris, University of Technology Sydney

Martha Nussbaum, University of Chicago

Paul Patton, University of Sydney James Walter, Gri $\approx$ th University Iain Wright, Australian National University 


\section{RESEANCHES}

ASIA AND MODERNITY

\section{CONTENTS}

Editorial

John Clark

Asian modernisms

Rozanna Lilley

Souveniring history in Hong Kong

Morris Low

Japan, modernity and the Tokyo Olympics 33

Ana P. Labrador

The projects of nationalism: celebrating the centenary in Philippines

contemporary art

Sang Ye

Beam Me Up

New CGR staff

New HRC visitors

HRC activities

Forthcoming conferences

From the desk of the Librarian 


\section{EDITORIAL}

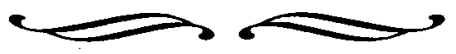

This issue of Humanities Research is devoted to the Asia-Pacific Triennial, a project initiated by the Queensland Art Gallery nearly ten years ago, to exhibit, document, and research the dynamic contemporary art of the Asia-Pacific region. This exhibition was the first of its kind in Australia and indeed remains unique in the world in bringing together Asian and Pacific artists.

Australia's cultural engagement with Asia has, in the past, been conceived as art history, both through exhibitions and the development of collections. The visual arts of Asia have been presented to Australians as a variety of cultures with a past rich in tradition. The dynamics of change, identities, and even twentieth-century cultural dislocation as revealed through contemporary art have only recently attracted attention and are highlighted by the Asia-Pacific Triennial. The Queensland Art Gallery has a strong commitment to building collections and exhibiting exhibitions of the art of the twentieth century. In determining ways in which the Gallery could contribute to the exhibition and collection of art of the region, the Asia-Pacific Triennial was conceived. In many ways the Gallery saw the development of the Triennial as a project waiting to be done. It broke the pattern of art museums' preoccupation with the past; defined a way, in both intellectual and organisational terms, in which Australia might construct a relevant forum for the presentation of Asian and Pacific contemporary art; and reaffirmed the Gallery's commitment to international programs of current international and domestic relevance.

200,000 visitors to the first two exhibitions in 1993 and 1996 and with an equal number anticipated for the Third Triennial exhibition opening on 9 September 1999 make this event one of the most popular among contemporary art events and the international response to the Triennial now reveals it as one of the five major art events in the world. The philosophy of the Triennial is inclusive and based on equal participation with art professionals throughout the region, almost 600 of whom-artists, writers, and curators-have been involved thus far in the project. In the course of developing the Triennial, the Gallery has also undertaken to present a series of exhibitions on the premodern and modern art of Asia and established a major collection in world terms of contemporary Asian art with a generous donation from the Myer Foundation and Michael and Ann Myer, in memory of Ken and Yasuko Myer. Our large library collection and databases on contemporary Asian art are extensively used by scholars. 
One of the aims of the Triennial has been to open debate in a cross-disciplinary way, including on issues of modernity and contemporary culture. The Gallery is therefore delighted that this scholarly issue of Humanities Research is being published. The Queensland Art Gallery has a strategic alliance with the Centre for Cross-Cultural Research, and the Deputy Director of the Queensland Art Gallery, Dr Caroline Turner, who manages the Triennial project, represents the Gallery on the National Committee of the Centre. We look forward to further major collaborations with both the Centre for Cross-Cultural Research and the Humanities Research Centre. $\propto$

DOUG HALL

Doug Hall is the Director of the Queensland Art Gallery 


\section{ASIAN MODERNISMS}

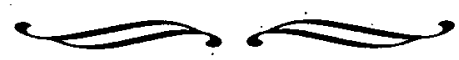

I. LOCATION:

At the end of the rggos it is relatively facile-for someone in Euramerica ${ }^{1}$ - to consider that various kinds of modern art work and artist from the non-Euramerican world have been accepted within it or have begun to be so. This seems to be particularly the case for Asian artists who have been seen at Les Magiciens de la Terre, ${ }^{2}$ at the Venice and São Paulo Biennales, and who are increasingly the subject of country ${ }^{3}$ or area-specific 4 shows or the major component of others. ${ }^{5}$ Such acceptance might also be taken to mean the incorporation of modern Asian art into the bounding intellectual paradigms of modernity and its histories which were supposedly invented in Euramerica: the position of the centre may have moved, but it is still the centre.

This essay does not accept either of these premises: Other positions can be briefly but directly brought into focus if we consider two Asian artists of Indian origin and the intellectual constructions around them. Anish Kapoor is an artist of Indian origin residing in London, who has been exhibited at the Venice Biennale in the British pavilion and is the subject of 'major' critical overviews by leading Euramerican curators and critics. ${ }^{6}$ N. N . Rimzon is an Indian artist residing in India who has been exhibited abroad but who has not been the subject of such a Euramerican catalogue. 7 The one is subject to Euramerican discourses which privilege themselves by the incorporation of difference. The other is subject to no such Euramerican gaze but remains, however formally, cognate and qualitatively related to the work accepted in Euramerica, as 'Indian' or in another discourse. Yet the latter has been seen in other sites outside both India and Euramerica, in for example Australia. This differentiation is between a vertical, unicentral model of art assimilation to Euramerican canons, and a horizontal, polycentral discourse between differently constituted centres, none of which claim to assimilate, nor indeed reconstitute, a . canon.

The difference of position derives ultimately from Euramerica's claim to have invented, and therefore to retain purchase on, modernity. This claim, whilst true in a rather simplistic developmental history, disappears the moment it is accepted that modernity invents itself everywhere it is required for a new relativization of the pasts of any given culture or group of cultures. The principal condition is that these cultures need toand are capable of-carrying out this relativization. It is a relatively easy step from this position to the future-oriented, 
projective relativization of modernism, or, further, to the involuted and eclectic rerelativization of modernity itself some call post-modernism. In the quite precise language of fashion and the street it is also called 'retro'. ${ }^{8}$ Seen this way modernity belongs to Asian artists because they work in societies and cultural discourses which require it. Modernity does not operate by the privilege of transfer from Euramerica or by the valuation of Asian modern art works and artists through their being accepted in Euramerica. Even before we approach the phenomenon of globalization, it is sensible to see how basic this difference of approach to modernity must be to one which privileges Euramerican origin.

\section{AFFILIATION}

But if modernity belongs to Asian art cultures because of their own demands, what kind of modernity is it? How did it come into being? How is it to be recognized from inside any particular Asian art culture or from without? If modernity is not owned by 'The West', does that mean the kinds of modernity found in, say, some Asian art cultures are different, new, or radically other?

The affiliation of such modernity may be constructed in at least three ways, the full implications of which are yet to be explored. One is to see it as contestatory, as in a dialectical relation to that which has occasioned or imposed modernity, "The West'. This is the colonial / post-colonial dimension of modernity, where modernity arises as a trajectory of subaltern counterappropriation or rejection and revolt. It implies, at least theoretically, a lack of authenticity or own demand driving Asian modernity because external stimulus is a necessary cause.

A second affiliation is to group modernities in a family of species which have derived from an $u r$-species. This is a model of affiliation where the branchings of a tree are seen to derive from common ancestors whose different sub-branchings represent (in a Darwinian evolutionary model of development ${ }^{9}$ ) the adaptations of the species to different conditions in different localities. A variant of this model is to accept the notion of species branching but to see these (in Gould's revisions ${ }^{\text {10}}$ ) as not in an hierarchical tree but in various bunchings of variation from the same original set of species which exist in parallel and not in a single hierarchy.

A third model of affiliation is to see modernity in art along the lines of different languages in dialogue under conditions of heteroglossia (as in Bakhtin ${ }^{\mathrm{I}}$ ). The dialogistic relation of such art discourses, that is their perpetual mutual relativization, may be interpreted as a fundamental condition of modernity. Affiliation is given because of common relativization, however it is achieved. Relativization can operate through the modes provided by colonial domination (India), internal self-development (Japan), 
and various kinds of quasi-sovereignty which seek to maintain the unitary identity of discourses even as they are broken down by contact from without (China).

In art history it has been relatively easy to overlook the different implications of these models of affiliation, because of the transfer of styles and their ideological constructs from 'The.West' to Asia. The transfer and overlaying of technical and symbolic values has taken attention away from the meaning of these transfers from within, and from the way authenticity has been created for a wholly new and constructed 'tradition' at this interface.

'Tradition' has often been hermeneutically opposed to 'modernity' when the 'traditional' has only been made possible by the 'modern'. But even as the 'modern' has been relativized by its transfer from 'The West', so the neo-traditional has been secondarily relativized by its constructed discursial difference from the 'modern'. Thus have modern Asian art discourses been constructed not along the lines of single 'East/West' split but at least by the process of primary and then secondary relativization-which I choose to call 'double othering'. ${ }^{12}$ This process can act as a relativization or 'othering' ${ }^{13}$ between a distancing of the neo-traditional Kannon the Compassionate Mother by Kano Hôgai, I888, from its 'Japanese' pasts, and further by its separation from the position of nearcontemporary 'Western-style' work like Kannon riding on a Dragon, by Harada Naojirô, 1890 .
3. HISTORIES:

Relativization of the past may be the historical position of modernity whose marker is the caesura in local discourses created by the wholescale transfer of 'Western' academy realism. Such a position has tended in the discourse of interpretation to render the onset of modernity as a radically historical disjunction. But on closer examination of the historical record in the discourse of art works ${ }^{14}$ it may easily be seen that modernity in several Asian art cultures such as Japan or India did not start with the transfer of 'Western' realism, and indeed had a long antecedence in many proto-modern features of art discourses and in the structures of the art world. One cannot also ignore the longevity of the linkages between the pre-histories of modernity in Asia and Euramerica. There is thus neither a caesura in cultural relations nor an absolute rupture in the way art discourses are related to their pasts. It seems that part of the reason why there is a tendency to create such interpretive caesura is a reflection or reduplication of the levels of binary structures habitual to the Euramerican world, such as imperial/metropolitan and colonial/local. This world has not been noted for its creation of discursial spaces defined between multiple centres and histories.

Furthermore, what one might call the habitual Euramerican interpretive mode has tended to see the inward movement of academy realism in a linear series of stages 
such as transfer, assimilation, and transformation. This view has concealed or de-privileged the various kinds of relativization implicit in such processes for an Asian art world. It has concealed how many features of modern and modernist modes of art discursial change were present inside these transfers. Perhaps the largest shift in art historical interpretation required for art history by modern Asian art is one away from the notion of transfer marked by the dissemination of models of stylistic development. Interpretation, whether exogenous or endogenous to any art discourse, should move to understanding a range of processes of relativization as imbricated within the complex term modernity / modernism / post-modernism. In this complex, any particular stylistic model or congruence is probably the least signifying element for the endogenous art discourses involved. The discursial space has to be left for a kind of co-option by local movements of an international one, and I would argue this is often found even very early in the transfer of realism. The co-option is not principally of the local by the central which would be the habitual (and still colonial) perspective. Such a position also possibly accounts for the perverse late-or post-modernist pleasures to be derived both endogenously and exogenously from I99os' Chinese 'popism' such as in the work of Zhang Xiaogang, a discourse which cynically manipulates a surface conventionality in order to sequester-I would argue - - a subversive parody safely within. ${ }^{15}$

\section{NATIONS}

For most Asian cultural discourses the modern began with the relativization of the past provided by the historical break of colonial or neo-colonial rule. As importantly it also began by the reaction against this in the form of an anti-colonial movement, and independence struggle towards the founding of a new state. However hegemonic the new state became in claiming domain over many kinds of society and cultural discourse within it, such states claimed to have founded the nation, to have integrated many discourses under its umbrella, and in most cases to have provided the leader of the people. The modernist striving for a desired future articulated between a leader and a people became a frequent subject for pictorial representation. This has historically been so much the case that one might postulate the thematic of modern Asian art to have been the allegorizing of the new nation through representing the new leader, and often of the very people who supported him. There is no doubt that as these male figures seek to articulate the masculinist privilege of serving the nation, ${ }^{16}$ so alongside them the female figure of the mother, or of multiple types of women as a repository of a variety of national values, or of a leader of the masses in the selfsacrificing figure of a toiling intellectual, acts as a feminising counterpart, ${ }^{17}$ even if this counter allegory can only rarely be described as feminist in intention.

Two conditions seem to have changed the possibility for this type of national 
allegory. One is the success of the movements under or against colonialism, where nationalism survived as a strategy for creating a repertory of ideal figures in a national imaginary under the conditions of a rapidly de-colonizing world. This can provide a kind of semantic exhaustion where the use and re-use of a particular metaphor, like Chairman Mao as Great Helmsman, turns into a saturated metonym, a kind of image coinage where value - or metaphorical weight-resides in the currency system not in any particular image. A second, and usually consecutive, condition is found where the colonial or the reaction against it only survives as a dim echo in a national imaginary now preoccupied with negotiating the post-colonial terms of its relation to a globalizing world. Thus stand the agonized, repeated faces of Philippine peasants in works by Alvorado Nunelucio looking out in the individualized frames of their images. ${ }^{18}$ Through the slightly hallucinatory effect of their black outlines and primary colours they flicker, in a way like alternative TV pictures, to subvert the very fractionating forces which place them in a world economy and split them off from their former lateral solidarity in the possibility of a Philippine 'nation'.

\section{MEDIATORS}

Art history, at least any art history of modern art, cannot at least escape the possibility it will serve as a cultural critique, even if it is not explicitly. so intended. Any exogenous or endogenous construction of a modern, modernist, post-modernist or simply contemporary art in Asia is going to privilege some kinds of art against others. But in a world brought into close communication within and between art cultures, the figures who have normally provided for these kinds of assessment in various functional domains-critics, curators, journalists, art historians - with modern art are always serving to re-position the 'new'.

The endogenous role of a critic, curator, or dealer in mediating and sometimes forming a group of conceptual perspectives around a cohort of disparately arranged artists is well known in Euramerica. It has also been a significant feature of Asian modernity, such as the role played at different times by Geeta Kapur in India, ${ }^{19}$ Li Xianting in China $^{20}$ or Nakahara Yûsuke in Japan. ${ }^{21}$ The important feature of such critics, however well informed they may be about international and exogenous art movements or by their own personal experience, is that they work from inside a set of cultural discourses which are their own centre. But the late twentieth century has seen the advent of more specifically 'interface' critics, curators, and dealers who mediate supposedly scarce knowledge and works from the endogenous to the exogenous levels. There is no doubt this particular position has played a significant role in the mediation of particularly East Asian art cultures to international art exhibitions, and here the role of Nanjô Fumio ${ }^{22}$ and 
recently of Hou Hanru in China is prominent. ${ }^{23}$ Whilst there can be no doubt such mediators, or 'doorkeepers ${ }^{24}$ play an important role in inserting different types of Asian art into Euramerican discourses which otherwise might ignore them, they also manifest a minority opinion or a selective representation against the very complexity of the endogenous discourses they purport to represent to the exogenous. In other words, for an art history of modernity which includes Asia as one range of non-Euramerican practices it would be fallacious to assume this could wholly or even partially be based on the art introduced from such mediators to the international level, even under a shifting rubric of 'contemporary practice'. ${ }^{25}$ The hard but rewarding work of looking from inside at each endogenous discourse is the base for such an art history of other modernities, not the post facto hypothesizing of such a history from such works as have been articulated on exogenous levels.

Some will argue that the global, exogenous level of practice, of the distribution of works and of the career-cycling of artists has long ago penetrated down to the local endogenous level. This is an unexceptional objection. Many artists, some the most rooted in their endogenous discourses such as Rabindranath Tagore, have continuously paid attention to international levels, even as these were earlier structured by the very world colonialism they were trying to see a way for their cultures to escape from. If the modern involves relativization of the past, and modernism the elevation to the plane of a formal subjectivity of an orientation to different futures, and if we were to attribute hermeneutic sovereignty to the global level, then that relativization would disappear or become a mere simulacrous imitation of itself. This would be to reproduce - even from a supposedly progressive position-the structure of central super-ordination over the localnow abstracted onto a 'global' level-which the rich variety of practice made possible by modernism had the potential to resist, subvert, or at least circumvent. Whatever we conclude to be the role of globalizing forces in the late twentieth century, an Asian history of modern art would first have to construct what conceptually and pragmatically links its own discourses. $\propto$

JOHN CLARK

John Clark teaches in Art History and Asian Studies at the University of Sydney and recently published 'Modern Asian Art'.

This article will appear in the History of the Scientific and Cultural Achievements of Humanity (UNESCO/Routledge, forthcoming, 200o), edited by Caroline Jones.

\section{NOTES}

'This terminology, although perhaps unfamiliar, is necessary. Once the nontechnological cultural products of 'The West' were adopted, adapted, and transformed outside 'The West' the location of their geographical origin no longer constituted a 
privileged civilizational autonomy. One pernicious legacy of direct colonialism is that the cultural products transferred to the world from 'The West' are somehow always to be denied their authenticity to those who adopted them under its duress in places not in 'The West', at least seen from the position which I shall now locate in Euramerica or characterize as Euramerican. For fuller exemplification, see myModernAsian Art (Sydney: Craftsman House \& Honolulu: University of Hawaii Press, 1998).

${ }^{2}$ Jean-Hubert Martin (ed. \& curator), Les magiciens de la terre (Paris: Centre Georges Pompidou, 1989 ).

${ }^{3}$ One example is Gao Minglu (ed.) Inside Out, New Chinese Art (Berkeley:University of California Press, 1998).

4 Poshyananda, Apinan et al., Traditions / Tensions: Contemporary art in Asia (New York: Asia Society Galleries \& Sydney: The Fine Arts Press, 1996).

5 Hou Hanru and Hans Ulrich Olbrich, Cities on the Move (Ostfildern-Ruit: Verlag Gerd Hatje, 1997).

${ }^{6}$ Homi K. Bhabha and Pier Luigi Tazzi, Anish Kapoor (London: Hayward Gallery \& Berkeley: University of California Press, 1998); Germano Celant, Anish Kapoor (London: Thames \& Hudson, r996). That by Celant barely refers to Kapoor's Indian origins.

${ }^{7}$ For early Rimzon material see A. Dube, catalogue essay for Seven Young Sculptors (New Delhi: Kasauli Art Centre, ${ }^{9} 8_{5}$ ). See also Victoria Lynn, 'The art of N.N. Rimzon', Art \&Asia Pacific, 3, 2 (1996).

${ }^{8}$ Art historically speaking, modernity, modernism, and postmodernism do not form a series of clear-cut tripartite stages, but tend to overlap, particularly if there is a relative freedom to eclectically modify styles whose sources do not yet operate a bounding hegemony, such as the 'syncretic' architecture of early Meiji Japan.

${ }^{9}$ Darwin's position was as follows: 'Thus modern forms ought, on the theory of natural selection, to stand higher than ancient forms. Is this the case? It seems that this answer must be admitted as true, though difficult of proof', in Charles Darwin, The Illustrated Origin of Species, (abridged and introduced by Richard Leakey from sixth edition of $18_{7}$ including comments which update Darwin's theories or his evidence, London: Faber \& Faber, 1979), p. 174.

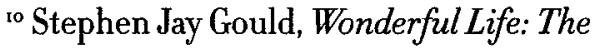
Burgess Shale and the Nature of History (London: Penguin Books, 1989), p. 47, "The maximum range of anatomical possibilities arises with the first rush of diversification. Later history is a tale of restriction, as most of these early experiments succumb and life settles down to generating endless variants upon a few surviving models'.

"I Since it seems so directly indicative of the problems raised here, please allow a somewhat lengthy citation from Bakhtin's 'Discourse in the Novel', found in M.M. Bakhtin, The Dialogic Imagination, (tr. C. Emerson, \& M. Holquist, Austin: University of Texas Press, I98I), pp. 284-85: 'But internal dialogization can become such a crucial force for creating form only where individual differences and contradictions are enriched by social heteroglossia, where dialogic reverberations do not sound in the semantic heights of the discourse (as happens in rhetorical genres) but penetrate the deep strata of discourse, dialogize language itself and the world view a particular language has...., my italics.

${ }^{12}$ For a discussion of this term, see my 'Yôga in Japan: Model or Exception? Modernity in Japanese art, 185os-1940s: An international 
comparison', Art History, I8.2, (June 1995), pp. $253^{-8} 5$.

${ }^{13}$ On 'othering', see my 'Gendai Ajia no Bijutsu gensetsu ni okeru "Taka" [Othering in Modern Asian Art discourses]', translated into Japanese in a volume edited by Shimamoto Kan, to appear in 1999 from a Tezukayama Gakuin workshop paper of 1996 .

${ }_{14}$ Modern Asian Art, Chapter Two on 'Prehistories'.

${ }^{15}$ See my 'Histories in the Modern', in Graeme Murray, Meg Syme and June Knight (eds), Reckoning with the Past: Contemporary Chinese painting (Edinburgh: Fruitmarket Gallery, 1996), Pp. 17-20.

${ }^{16}$ See the discussion of 'Chairman Mao goes to Anyuan,' in Julia Andrews, Painters and Politics in the People's Republic of China: r949-1979 (Berkeley: University of California Press, 1994), pp. 338-42.

${ }^{17}$ For a feminist understanding of Ravi Varma see Geeta Kapur, 'Ravi Varma's Unframed Allegory' in R.C. Sharma (ed.), Raja Ravi Varma: New perspectives (New Delhi: National Museum, 1993).

${ }^{8}$ Alvorado Nunelucio's work 'Duta Indi Bala' [Land not bullets] is reproduced in the catalogue of the FirstAsia-Pacific Biennale (Brisbane: Queensland Art Gallery, 1993), p. $3^{1 .}$

${ }^{19}$ Among Geeta Kapur's important earlier writings are Pictorial Space: A point of view on contemporary Indian art (New Delhi: Lalit Kala Akademi, 1977), Contemporary Indian Artists (Souza, Kumar, Padamsee, Husain, Khakhar, Swaminathan; New Delhi: Vikas Publishing House, I978); and Place for People, (text for exhibition, Jehangir Art Gallery, Bombay; New Delhi: Rabindra Bhavan, $\mathrm{I} 98 \mathrm{I}$ ).
${ }^{20} \mathrm{Li}$ Xianting's activities may be glimpsed in English through his historical essay in V.C Doran (ed.), China's New Art post-rg8g (Hong Kong: Hanart TZ Ltd., 1993), and the essay, 'The Imprisoned Heart', Art \& Asia Pacific, I. 2 (1994).

${ }^{21}$ For an indication of his position see Nakahara Yûsuke et al, Europalia 8g: Japan in Belgium (Gent: Museum van Hedenndaagse Kunst, I989).

${ }^{22}$ Nanjô Fumio and Dana Friis-Hansen, Transculture (Tôkyô: The Japan Foundation \& Fukutake Science and Culture Foundation, 1995). Nanjô was very active in the 1980 in introducing Japanese contempoary art abroad. See, in particular, Kathy Halbreich, Kômoto Shinji, Nanjô Fumio, Thomas Sokolowski, Against Nature: Japanese art in the rg8os (New York: New York University GreyArt Gallery, 1981); Kondô Yukio, Nanjô Fumio, Peter Weiermaier, Japanische Kunst der Achziger Jahre (for the Frankfurter Kunstverein, Edition Stemmle, I99o).

${ }^{23}$ Hou Hanru was the Chinese adviser for Les Magiciens de la Terre and has since been active as a curator of modern Chinese art in Europe working from Paris. See his essays 'Departure Lounge Art', Art \& Asia Pacific, r. 2 (1994), 'Beyond the Cynical: China avantgarde in the 199os', Art \&Asia-Pacific, 3.I (i996), 'Towards an "Un-Unofficial Art": deideologicalization of China's Contemporary Art in the I9gos', Third Text, 34 (Spring I996), 'Entropy; Chinese Artists, Western Art Institutions: A new internationalism', in J. Fisher (ed.) Global Visions: Towards a new internationalism in the visual arts (London: Kala Press, 1994), 'De "décrire la réalitié" au "théâtre du monde". Lart Chinois depuis 1979'. (tr. J. Lacoste) in Harry Belleter (ed.), Face à l'Histoire (Paris: Centre Georges 
Pompidou, 1996). See also Cities on the Move, and his conversation with Gao Minglu in Inside Out.

${ }^{24}$ On 'doorkeeping' see my 'Art and its "others"-recent Australian-Asian visual exchanges', Maryanne Dever (ed.),Australia and Asia: Cultural transactions (Surrey: Curzon Press, 1997) and also Chapter Eleven of my ModernAsianArt.
${ }^{25}$ Thus catalogues like Cities on the Move, in a tendency followed by the recent catalogue Gilda Williams (ed.), Cream (London: Phaidon, I998), which declares itself to be 'a portable exhibition in a book' increasingly resemble telephone books where the artists' works become a kind of conceptual address and the name of the artist a fantastic, - unfathomable number. 


\title{
SOUVENIRING HISTORY IN HONG KONG
}

\author{
In the final phases of late capitalism, history itself appears as a commodity.
}

Susan Stewart

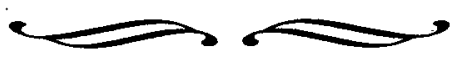

$\mathrm{I}_{\mathrm{t}}$

think it would be fair to say that we all experienced Hong Kong's transition to Chinese sovereignty. From the steady drone of the car radio, to the evening television news or those incessant conversations about 'what will happen when China takes over', the 'handover' was a matter of constant exposure until the repetition rendered it part of the fabric of our lives. I somewhat reluctantly joined those who went to watch, as though being there might make a difference, or at least implicate me in its aura. In the end I think the sense of voyeurism was intensified by attending the full-dress performance. But so too was the feeling that I had heard it all before.

\section{BOREDOM}

Hong Kong people were repeatedly polled, interviewed, and questioned about their attitudes to the handover. Endless administrative efforts were invested in objectifying people's complex, ambivalent, and frequently contradictory feelings about a process that was always presented as a fait accompli. From January 1987 , for instance, Asian Commercial Research conducted a poll, the results of which were known as the 'Happiness About June $3^{\circ}$ ' index. This quantification produced varied results which appeared to chart a reasonably cheery story. The registered low of $32 \%$ in August 1996 had climbed to $62 \%$ by June r 997. The relative absurdity of such measurements was, however, made clear by the completely different responses registered by other polls. Thus a study conducted on 2 July r 997 claimed widespread 'indifference' about sovereignty transferral as its result $-5^{8.3} \%$ of $5^{60}$ people interviewed by Hong Kong University's Social Science Centre stated that they had no special feelings about the return to China. ${ }^{2}$ Doubting the methodological utility of directly inquiring about people's attitudes to the handover, I never joined the rush of journalists and market research employees engaged in this task. However, Hong Kong Chinese friends and acquaintances made no secret of the fact that they were 'bored' both by the endless questioning and media saturation accompanying the events. ${ }^{3}$ 
There is an element of fatalism involved here. This fatalism recognizes that just as it is not within anyone's power to alter what happened in the past, so too it is not possible to alter the future. In fact, Tam reports that many locals likened the handover, and the calculations about the future that it necessarily entailed, to a gambling table where different players place their bets, some winning, and some losing. ${ }^{4}$ This fatalism is evident in numerous Cantonese set expressions. One might hear mo si (it doesn't matter, there is nothing to report) or, generally from older people, yau mat ye ho gong a? (what is there to talk about?). Younger people might opt for mo mat ye chi gik (nothing exciting). Alternatively, jau hai gam la (it's like this) conveys that pragmatism for which Hong Kong people are stereotypically well-known. People I know, though, just opted for the English term 'bored', employing it as an interpretative category to convey an embracing sense of unease and irritation. Boredom, I argue, was more than a dreary accident or a trivialization of a momentous occasion. It was, in many ways, the habitual mood of the handover until the quantity took on a quality of its own, becoming, in Heideggerian terms, '... a boundless etcetera of indifference'. 5 The threat to narrative involved in such indifference requires our rapt attention.

Studies of boredom amongst adolescents have tended to the conclusion that teenage lack of attention can be correlated with enforced participation in activities that are 'other-controlled'. ${ }^{6}$ While it is important to reject any implied infantilization of Hong Kong people, it is also necessary to remember that the paternalisms of British colonialism and of Mainland chauvinism, which renders locals as Xianggang tongbao or younger, never equal siblings,? conspire to do precisely that. To understand boredom as partly a function of political powerlessness we need only note that individuals in Hong Kong were never seriously consulted by either Britain or China throughout the negotiations over the sovereignty transferral. A sense of coercion and entrapment was, therefore, inevitable. But boredom also, as Spacks argues in her study of the literary history of the term, ${ }^{8}$ is characteristically employed as a measure of dense psychological entanglements, and of disruptions of desire.

History was certainly paraded before Hong Kong people as an alien factor, a countdown which relegated them to the role of spectators, a count-down so numbingly persistent that the endless advertisement of time effectively froze it into an endless present. ${ }^{9}$ The public clocks which registered the passing of each second to a zero point at midnight on $3^{\circ}$ June, where time began afresh, as either last judgement or Utopia, the bureaucratic nightmares involved in replacing the stripes of the Union Jack with the gold stars of the Chinese National flag, the erasure of Queen Elizabeth from postage stamps, the pages simply turning on the calendar; these were the necessary efforts to 
articulate the coming of a new regime through counting. Evanescence and finitude were the order of the day. In another context, Stewart has perceptively noted that it is precisely this counting that reduces difference to similarities'. ${ }^{\circ}$ After all, everyone knew that the movement of the second hand toward midnight was inevitable, and that the situation of which that was an index had already, in most salient respects, happened. ${ }^{x}$ If time weighed heavily on the bored throughout the handover, if it was an object of resentment, even resistance, this should come as no surprise.

My previous mention of Heidegger was not incidental. My argument, to this point, to some extent shadows his remarks about boredom. Heidegger conceived of boredom, or more exactly, the condition of being bored as a fundamental mood of human being. It is an emotional paralysis that springs from the repression of anxiety, an anxiety that forcibly tears people away, through a foreboding of homelessness, from habitual coping. In this framework, boredom is a sterile calm that constitutes a refusal to engage in the contemplation of nothingness. This anaesthetizing refusal, whether listless or frenzied, sustains technological drive. It is cowardice in the face of ontological uncanniness. ${ }^{12} \mathrm{He}$ describes boredom as a mood in which we are 'equally removed from despair and joy', a mood wherein 'everything about us seems so hopelessly commonplace that we no longer care whether anything is or is not ...' ${ }^{\mathrm{r} 3}$
In many ways such a description is apt. Hong Kong people had plenty of reasons to feel anxious in 1997. The handover cast them in a role beyond their power to fully direct or control. They neither chose or made the worldly stage we all watched on TV. Displacement, unease, homelessness were utterly over determined. To refuse to experience this loss, to dissipate care, to assert ontic familiarity in the face of uncanniness are all comprehensible given the political circumstances. Where I part company with Heidegger is in his indictment of such responses as sheer timidity. Here, though, we need to exert a little care. Heidegger was concerned that ennui would replace angst as the dominant contemporary disposition. His remarks were thus directed at profound or deep boredom; to a pervasive indifference to worldly existence as a whole. ${ }^{\mathrm{I} 4} \mathrm{The}$ boredom expressed by Hong Kong people during the handover was, by way of contrast, highly specific and precisely targeted.

This specificity was lodged in what, for want of a better term, we might think of as a valued cultural style. I refer here to cynicism. According to Simmel, cynicism is wont to flourish in situations where the movements of money generate 'absurd combinations of personal and objective values'. ${ }^{15}$ The cynic knows that everything has a market value and is, as a consequence, 'mocking and frivolous'. We are, once again, in danger of rehashing caricatures, caricatures I have elsewhere dismissed as reductively conservative. ${ }^{16}$ 
Yet these caricatures have a life and are; as we shall later see, frequently revivified by Hong Kong people engaged in the task of societal self-examination. If Simmel figures the stock market as the nursery of cynicism, many locals would only agree. Cynicism is, I contend, affectively linked to boredom because both of these attitudes are expressed by those engaged in a project of levelling the illusion of any difference in values. Both therefore carry a certain ethical weight and an inherent aggression. They also declare the bearer of these attitudes as someone with the entitlement to judge and substantiate a self-protective disengagement, otherwise known as 'cool'. The cynical and the bored tacitly insist on the incoherence of experience, on the lack, finally, of point.
Cynicism is, in other words, a form of cultural capital. To be bored is to declare one's cosmopolitanism and sophistication and this cosmopolitanism is, somewhat paradoxically, at the heart of Hong Kong people's most treasured sense of the value of their own metropolitan distinctiveness In some ways we might figure this as a carefully orchestrated self-presentation, a pose. But the satiric emphasis of the performance marks an unwillingness to validate any set narrative and this persistent rejection of plot, climax, teleology, denouement has potentially radical implications as critique.

Originally, Heidegger's concern with moo derived from his interest in philosophic inquiry, cast as a mood of awe and wonder. ${ }^{17}$ The Hong Kong Tourist

Figure I

Wonders Never Cease, global marketing campaign rg95 g6. Reproduced with kind permission of Hong Kong Tourist Association.

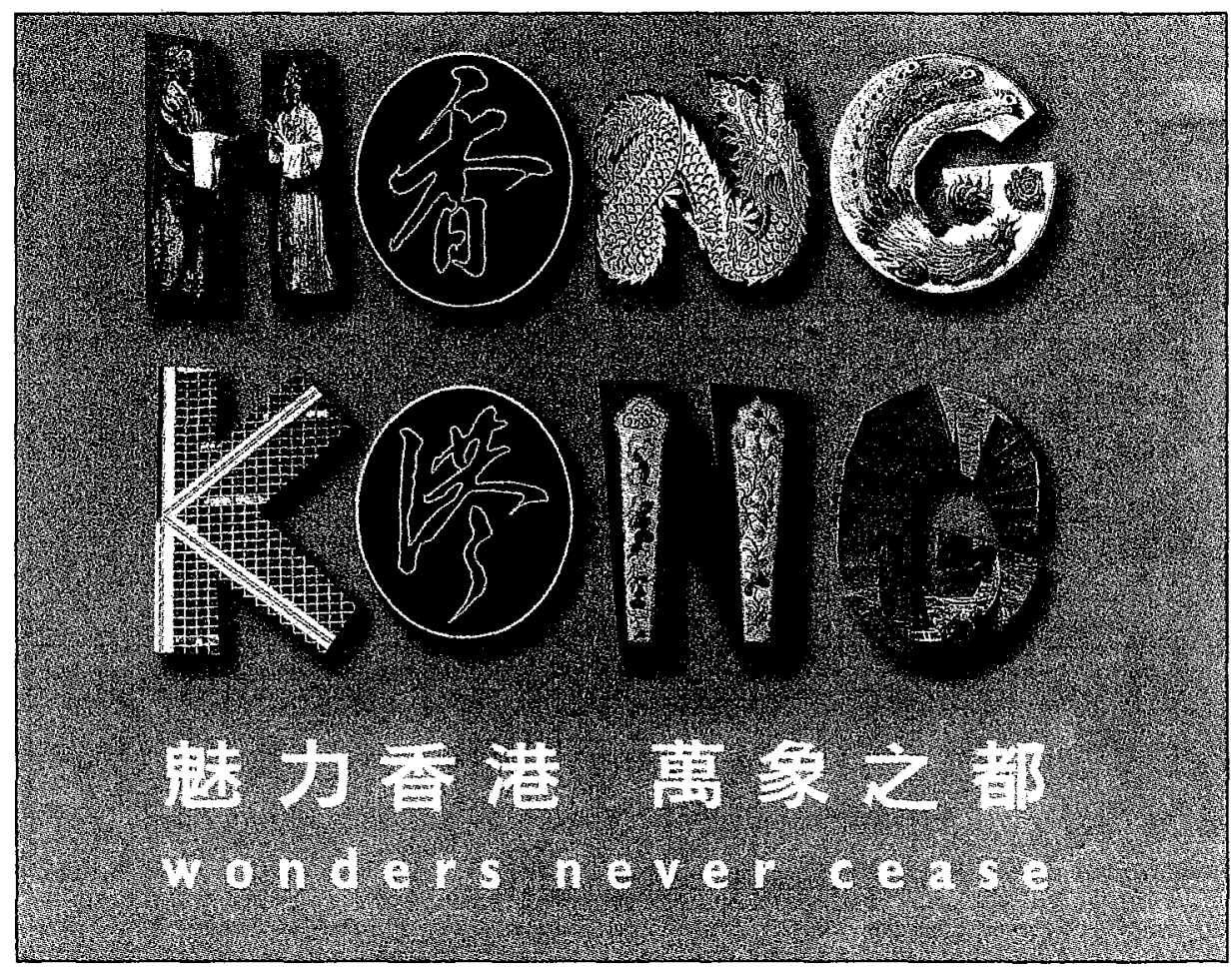


Association made every effort to encourage this mood in their handover publicity campaign. Under the slogan 'Wonders Never Cease' they promised the visitor roo glossy days of marvel and fascination, running from I July, the day following the sovereignty transferral, to 8 October. According to the poster, this spell would be woven via an emphasis on tradition (see figure I). Cantonese opera, dragons, the majestic red sails of sampans on the harbour and, of course, banquets were the ingredients they summoned. Not everyone, however, was convinced. This strategic emphasis on innovation and novelty, the pressure to make the old new, thereby producing a product which surpassed the expanded repetition of the same, was a flop. The ornamental poverty of repackaging simply failed to convince'wonder drinks' and 'wonder meals' offered at a 'discount' by luxury hotels are a prime example -leaving the sensation of an oddly gratuitous formal shell, the content of which was utterly indifferent. ${ }^{18}$

Not only did tourists stay away in droves, thousands of residents scheduled their leave to avoid the tinsel of speeches and fireworks, and the tedium of answering hackneyed questions posed by any of the 8 ooo journalists who applied for accreditation to cover the ceremonies, ${ }^{19}$ choosing 'handover holiday' packages in Thailand or Singapore instead..$^{20}$ Those who did stay were not necessarily model participants. The Better Hong Kong Foundation intended to set a Guinness world record for mass karaoke singing as part of the \$HKıoo million 'Hong Kong 97 Spectacular' staged during the reunification celebrations at Victoria Harbour. Full-page newspaper advertisements were placed, extolling spectators to 'join the chorus' for nine minutes of collectivity. A program was included with lyrics to songs which conjured Utopian longing-Tomorrow Will Be a Better Day, Children of the Dragon and China Dream were among the selection. The live broadcast on television and radio revealed, however, that few of the goo,ooo spectators gathered around the harbour to watch the fireworks bothered to pay lip service to this fantasy. As one young office clerk expressed it: 'I know people are supposed to be crazy about karaoke but I think there is a limit'. ${ }^{2 x}$ A commissioned research company did their best to inflate the numbers by taking into account people who were at home or elsewhere. Their efforts proved futile. As it turned out, Guinness had no category for karaoke. The organizers submitted their thirty-two float flotilla, including a giant thirty storey 'pearl', instead. ${ }^{22}$

The possibilities for collective experience during the handover were, I suggest, progressively attenuated by sheer saturation. Picture the following. A middle-aged woman enters Yue Hwa Chinese Products Emporium. If she had been born on I July she would have been entitled to a $30 \%$ handover discount. Disappointed by the cruelties of fate, she moves on to a perfumery located up the escalator. Here, she sniffs a new French 
scent called 'Hello Goodbye'. She looks at the $\$ \mathrm{HK}_{2} 8$ o price tag and at the label featuring the Union Jack and the Chinese National Flags entangled. She decides to stick with Diorissimo. Made thirsty by the humidity, she considers a beer. Flicking through a magazine she spies an ad for Delaney's-The Irish Pub. She looks at the image of a smiling Chairman Mao with a schooner of Guinness in hand and at the slogan 'One Country, Two Pubs'. Here, she studies her magazine in greater depth noting that she has missed the 27 June Special Administrative Region Flagcarrying Ceremony by Taxis and Public Light Buses. However, she could still make the 2 July Angels Spreading Flowers to Greet Hong Kong, Everybody Cheering Up to Celebrate Reunification, with aerobatic flying displays, parachute demonstrations and song and dance performances at Sha Tin Race Course. Refreshed, she decides to go home. On the way she accidentally wanders through a handover carnival, and watches a ten year old girl play a shoddy fairground game called 'Smooth Transition'. Inside her apartment, she switches on her computer and erases the bookmark for China Wide Web, unable to any longer tolerate twenty-four hours of daily handover news and the incessant contemplation of enveloping sign-objects demanded by her environment. ${ }^{23}$ So, she phones her sister in London who tells her that she has just visited Chinatown's latest restaurant 'I997' where she had a lovely meal of 'One Country, Two Systems duck' and 'handover rice'.

\section{SOUVENIRS}

Clocks, calendars, T-shirts, caps, pens, watches, mugs, ashtrays, cufflinks, and numerous other items were available for purchase in July r 997 as handover souvenirs. Department stores, chemists, street sellers, and speciality stores all competed to produce goods, tailored to specific market niches, which would capture the moment. Almost everything was susceptible to packaging as a souvenir. Reebok offered commemorative Pump Fury shoes (funky sneakers with the Chinese characters for nine and seven embroidered on the tongue); $\mathrm{CNN}, \mathrm{CNBC}$, TVB, and the China News Service produced commemorative videos, some available for sale and some designed as corporate gifts; Kowloon Motor Bus Company advertised a limited edition model bus bearing the number 1997 and a message: ' $\mathrm{KMB}$ and you - together we share the joy and pride'; record companies rushed to compile patriotic albums with titles like 'Hong Kong Good Songs for 1997'. Prices varied, but invariably contained some combination of the number ninety-seven. I bought a special edition of Monopoly, approvingly admired by the Customs Officers as I exited Hong Kong. The woman ahead of me in the queue had a special edition Chinese Barbie. I felt a twinge of envy. The urgency. of the generic structure and of the generic repetition, the deliberate superfluousness of this seemingly endless stream of giftwrapped remembrance, the apparent necessity to see and buy the same thing 
over and over again, produced an exaggerated display of the values of consumer culture. ${ }^{24}$

The image I just conjured was of tourists exiting Hong. Kong, suitcases laden down with the weighty baggage of remembrance, eager to rush home and triumphantly exhibit their spoils to friends and family. We imagine that these travellers will shortly, after the rush of curious conversation has subsided, find a place for Chinese Barbie or their 1997 key rings on a mantelpiece which also displays their trinkets and postcards from Rome, or Paris, or Laos, or Japan. Eventually these objects may be relegated to dustier confines, crowded together in a box under the bed, to be occasionally taken out and admired like so many pornographic photographs usually hidden from public sight. ${ }^{25}$ This is a familiar view, a hazy panorama if you like, of tourists appropriating and thereby diminishing, or at least, perverting the Other. While this scenario may well be accurate, the funny thing about the handover was that the logic of its monumentality transformed everyone, visitors, and locals alike, into tourists. ${ }^{26}$ This has much to do with the flamboyant temporality of the sovereignty transferral, a temporality so insistently focussed on midnight $3^{\circ}$ June 1997 , that time itself was rendered an exotic object. Seeking out that object, souvenirs aimed to magically. transport all of us to that moment of deathly origin. ${ }^{27}$

Souvenir producers knew this and consequently their goods were frequently targeted at local consumers eager to commemorate their own lives, or, more specifically, their own location in time. The fact that they were not only 'there' but 'here then' was confirmed in the operation of the souvenir. This operation of linking self to a particular time was overtly declared by advertisements for 'message cameras' which, evidently, 'make a memorable time more exciting' by adding a caption to the bottom of photographs (see figure 2). A number of captions are there for the choosing-for a new birth, 'It's a Boy!' or, in the slightly disappointing case of a girl, 'She's so Cute!'; for a birthday, 'It's a Celebration!'; for a holiday, 'What a Vacation!'; for marriage, 'A Wedding Moment'; and, just in case if anything was not covered by these happy stories suitable for inclusion in the family album, 'It's Party Time!' could serve as an all purpose guiding description. The handover added another episode to these closely edited and capitalized triumphant life-cycle narratives. ${ }^{28}$ 'A Significant Moment 1997' would appropriately direct viewers to the solemnity of the occasion. As if to mock the gravity of the text, the example photograph is modelled on a child's birthday party. A group of teenage Hong Kong Chinese are celebrating the sovereignty transferral. Arms affectionately around one another, surrounded by streamers and balloons, they wear party hats and handover T-shirts, jolly sentences emblazoned across their chests-'I Love r997, 'ig97 Party Party', 'Happy r997', Hong Kong r997'. With the 
FIGURE 2

Watson's Camera Advertisement. Reproduced with the kind permission of A.S. Watson Group (HK)

Limited.

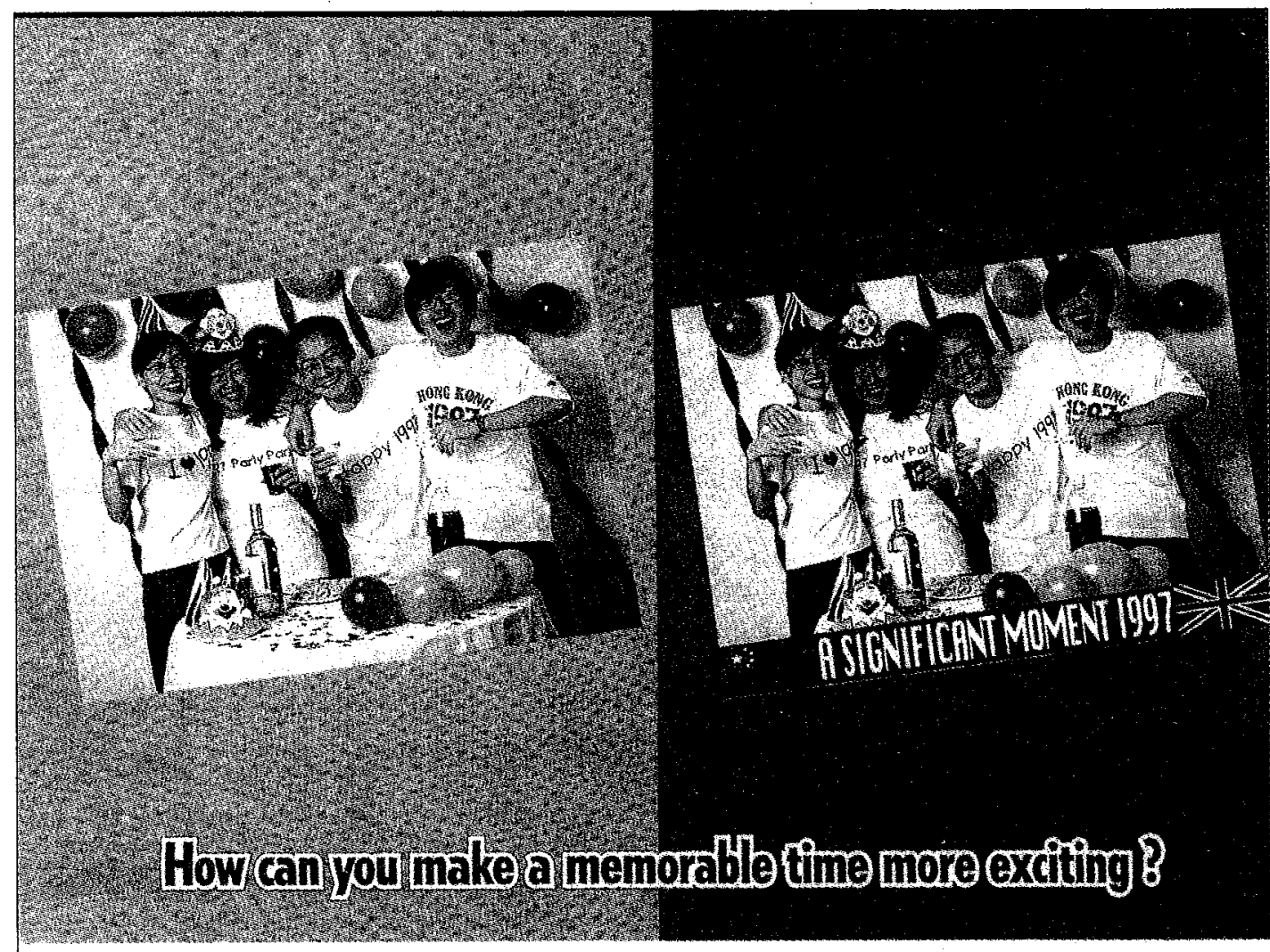

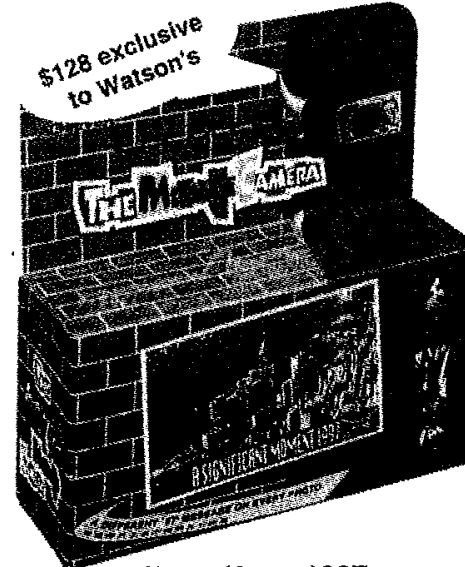
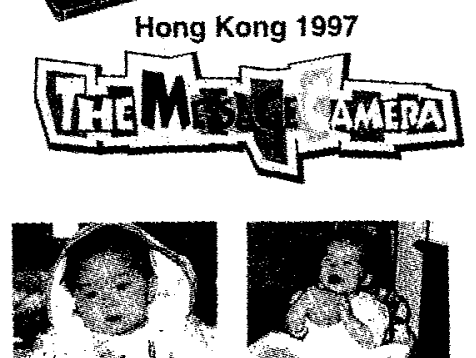

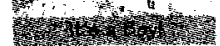
it's a Boy

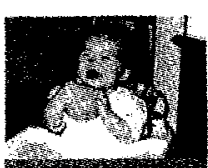

It's a Girl
What can make the handover more memorable? A message camora of course!

This single use, $35 \mathrm{~mm}$ camera with built-in flash camera can only be purchased at

Watson's stores. With this special camera you can print different messages on

your photographs to make them even more memorable. Basides the special 'Hong Kong 1997 message, there are six other models available for you to make those special moments in your life even more personal.

Special moments take on a new dimension with Watson's message camera,available for only HK\$128. So get down to your local Watson's store today, purchase a message camera and start making those unforgettable moments more exciting.
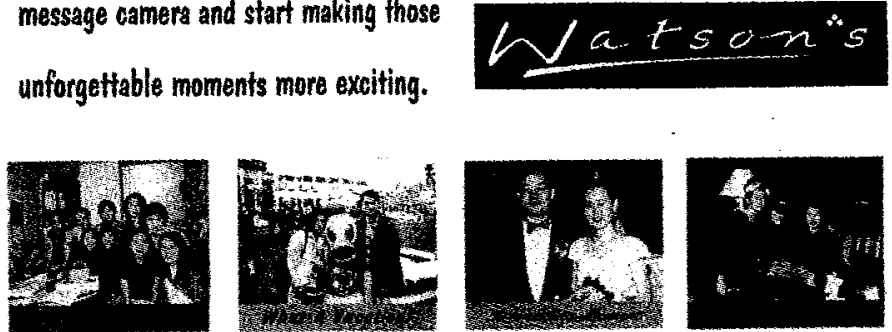

Happy Eirthday
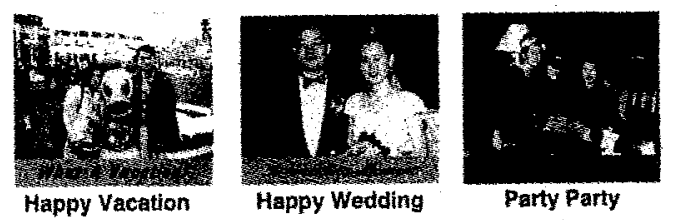
aid of some soft drinks and a plate of potato crisps, this wholesome group insist that the handover is fun, that it can be slotted into a preordained domestic trajectory, as 'natural' and as fulfilling as birth or marriage. They also flaunt the modernity of Hong Kong people. Until the I980s most citizens of the territory did not even know their birth dates, as calculated by a Western calendar. Today, cakes and candles are absolutely de rigueur. ${ }^{29}$ Message cameras promised to provide their purchasers with thematic clarity, with a narrative closure that domesticated the handover as one of a series of conventionally recognized rites of passage; contributing to an up-beat formulation of autobiography and condensing History into a series of replica histories.

What I am arguing here is that souvenirs, such as message cameras, enacted a will to authenticity, a space, if you like, to belong in the midst of the boredom of the insistent monumentality and predictability of handover narratives which, whatever political colouring they took on, could not help but supply the postcolonial corpse. In a sense, it does not matter that souvenirs frequently appeared to repeat the blandest of sentiments. We are in the realms of what Jameson describes as the necessary simultaneity of the Utopian and the ideological in mass culture.$^{3^{\circ}} \mathrm{I}$ have already alluded to the repetitious sterility of dominant narratives about 1997; I do not want the denunciation of this sterility to be my structuring gesture. Equally, I do not wish to engage in an aestheticizing project of entirely celebrating the souvenir as Utopian potential. Let's consider this Utopianism in greater concrete detail.

Jameson, if I read him correctly; views the Utopian as that which is critical of the social order. Handover souvenirs were often that and, sometimes, in quite direct ways. Thus East Wind Company offered for sale a wooden box with a quasi-colonial crest. Inside was a concise history of the abuses of British imperialism and a lump of granite, a direct reference to Lord Palmerston's now infamous I 84 I statement as British Foreign Secretary that Hong Kong was nothing but a 'barren rock'.$^{\text {r }}$ One might note though that the language of criticism employed against British colonialism was precisely the language of Chinese nationalism. Of more interest were satirical souvenirs because they refused a precise political location. This was particularly the case with objects, or sometimes just advertisements for objects (framing being all), that satirized imperial melancholy. 'Grab your piece of Hong Kong history before Britannia loses it completely!' (see figure 3), encourage the sellers of 'the last authentic colonial flags' made under government licence.

Britannia; draped in the Union Jack, wears a Viking helmet as she prepares to plunge a sword into a small terrier (suspiciously similar to the Patten household's treasured family pets, Whisky and Soda) with a cardboard cut-out yellow mane around its neck. The deflationary tone of this pantomime tableau, its undermining of 
Wagnerian impulses (a hand-written 'lion' and an arrow point to the dog), humorously underlines the fact that the British 'empire' is long since dead and buried and simultaneously relies on the embarrassed surge of melancholy evoked by the final nail in the coffin.

Two of the most successful souvenir entrepreneurs, Jon Resnick and Guy Nicholls, made persistent mockery of the handover. Their first product, a T-shirt bearing the words "The Great Chinese Take-away', was snapped up by those who felt derisive or just enjoyed the quip. Cutting down to size was the name of the game. Their second effort was a terse comment on the asphyxiating evacuation of content during the handover. The product was, literally, nothing - an empty container with 'canned colonial air' written on it. During an interview, Nicholls claimed that they had wanted to sum up

\section{FiguRE 3}

Last Authentic Colonial Flags Advertisement. Long Island Company.

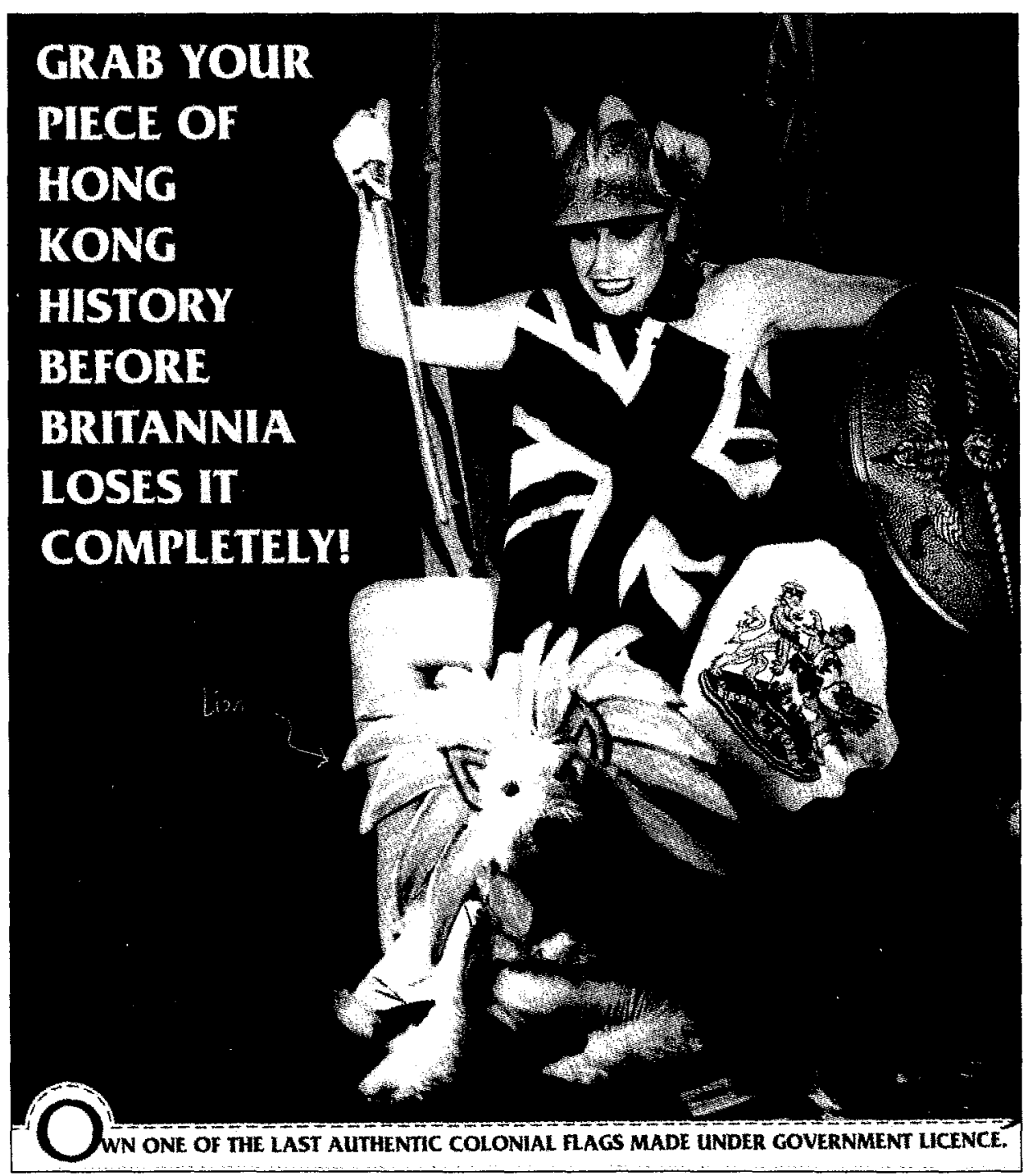


FigURE 4

Bus stop advertisements featuring Gong Li and Tung Chee-Hwa. Photographed by Rozanna Lilley.

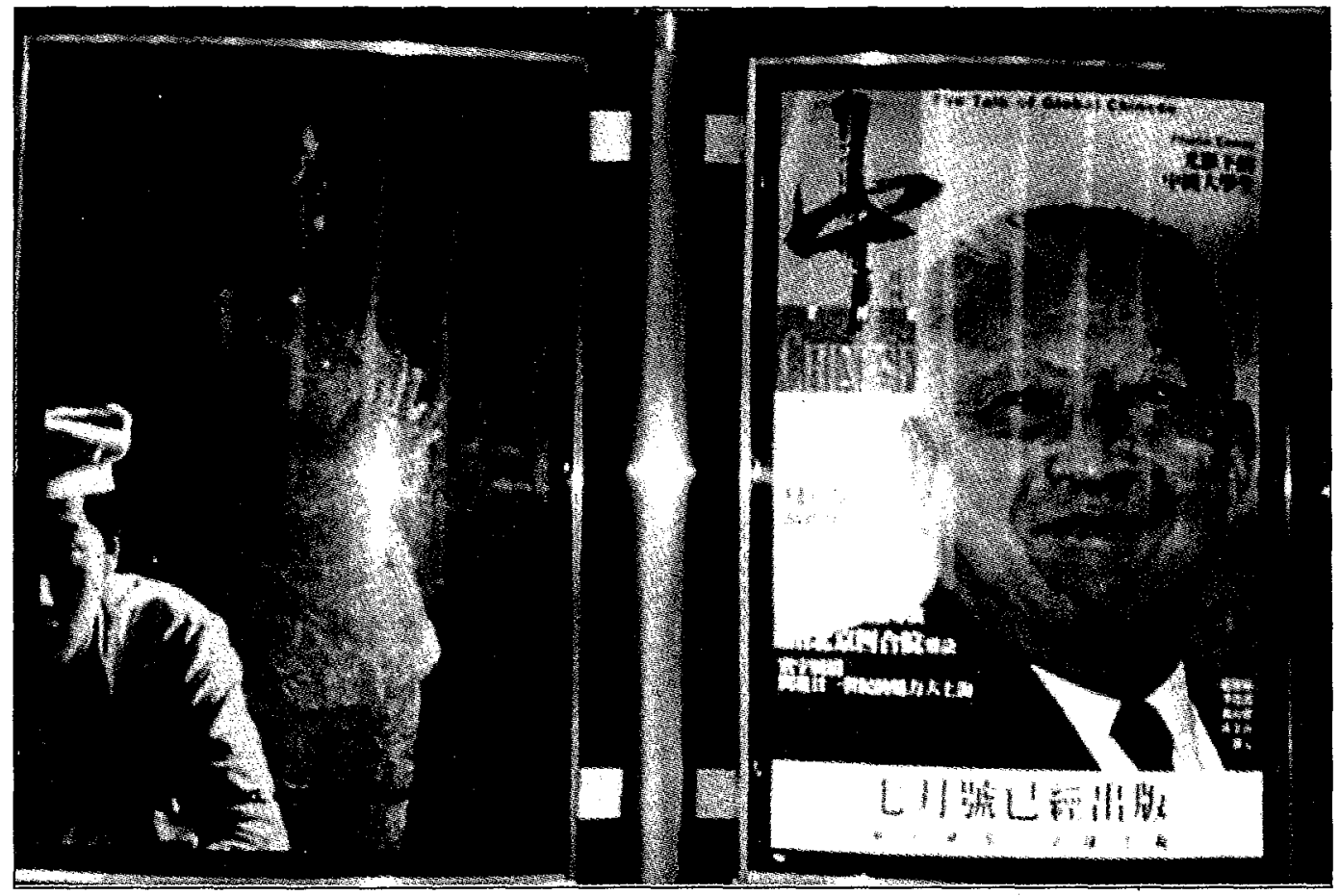

'the whole "End of Empire" thing'. He added: 'Open it at your risk and if you breathe deeply, perhaps you'll get a faint whiff of cucumber sandwiches, white bread (crusts cut off), pink gin. All those elements that combine to make Ioo\% pomposity' ${ }^{32}$ As was the case with our flagtouting Britannia, canned colonial air relied on both mobilizing and satirizing that pomposity. It also commented on the relentless commodification of 1997 , saying you might as well spend your money on nothing as on all those other trinkets (remember the craze for pet rocks?) and, laughing, people bought it.

If canned colonial air directly commented on aspects of the predictability of the handover (the formulaic genre of melancholy revealed as such), other souvenirs provided a garish antidote to all the slick packaging and glossy images that characterized its presentation, whether on television or adorning the city as neon dragons draped across skyscrapers, flamingo and fish lanterns embellishing public parks, bus stops brilliant with a diptych of media personalities Tung CheeHwa and Gong Li (see figure 4), the actress and the Chief Executive caught in the alliance of stardom for the pleasure of passers-by. Existing alongside all that careful management of image and style, many souvenirs, such as the lucky dragon which uncurled from a brightly coloured soft plastic egg, clutching the Chinese flag in one of its embryonic hands and the bauhinia flag of the Hong Kong Special Administrative Region in the other, the skyline and harbour stamped across its 
belly, ${ }^{33}$ provided a flourishing alternative language, wilfully insisting on the right to be shoddy, garish and cheap. ${ }^{34}$

Before we become entirely entranced with the Utopian potential of souvenirs, whether as direct critique or as the demand for aesthetic pluralism, we need to consider, too, their necessary participation in the dominant logic of Hong Kong society-making money. Handover collectibles were seen by their purchasers as an investment, the certainty of their value increasing making them a better bet than the stock market. Some buyers were after a quick return; others were prepared to hoard for future gain. Tickets and stamps were particularly prone to this logic. People queued for hours to buy commemorative tickets issued by the Mass Transit Railway which offered unlimited rides from midnight on $3^{\circ}$ June until services finished on I July. To ensure the increased value of these tickets, most were never used. ${ }^{35}$ Reports that a ticket, numbered I997, from the first Shanghai to Hong Kong train sold for $\$ \mathrm{HK}_{55}, \mathrm{Ooo}$, and just five days after it had been bought for $\$ H K I$, Igl, provided evidence of the potential returns to be made $:^{36}$ Staff at 125 post offices throughout Hong Kong worked on Sunday to meet the rush of philatelists and speculators eager to buy 'sovereignty-neutral' stamps, the skyline having replaced the British monarch's head. On the first day of Chinese rule, stamps bearing the image of Queen Elizabeth II were already changing hands for more than ten times their initial value and hawkers outside the General Post Office flogging Official First Day Cover commemorative envelopes were reaping similar rewards. ${ }^{37}$

Hong Kong hawkers were not the only ones experiencing the glorious sensation of getting rich quickly. In mainland China too, history buffs were preparing to capitalize on the craze for handover stamps. In Shenzhen more than 6000 people queued for a midnight frank on a commemorative stamp bearing a portrait of the late Deng Xiaoping, regally poised against the office blocks of Hong Kong..$^{8}$ The stamp's value rose from eight yuan to fifteen yuan over the course of a few days. ${ }^{39}$ Commenting on the collapse of the always fragile opposition between consumer and collector, a Guangzhou buyer stated that his major purpose in purchasing Hong Kong stamps was to have them 'as a souvenir' but that he was also attracted by the certainty that their value would 'not go down, only up'.40

The Guangdong Post and Telecommunications Bureau sold sets of 'Return of Hong Kong' souvenir cards, complete with compact discs of patriotic music. Shops in Guangzhou reported a brisk trade in handover coins, pens, ashtrays and penholders. Bakeries were whipping up giant moon cakes, containing ninety-seven eggs, patterned with flags. ( $^{4^{1}}$ Everyone, it seemed, was in on the act. However, while the mainland Chinese trade in souvenirs revealed important similarities with Hong Kong, it also 
underlined essential differences. In Hong Kong souvenirs were produced both by government organizations and by privately owned businesses. Endless tales circulated about individual entrepreneurs aiming to produce the artefact which would capture the imagination of a public both hungry for and tired of the handover. In the Mainland, only authorized firms, approved by two government offices, were officially allowed to produce souvenirs.4² Furthermore, most souvenir buyers were work units and companies, keen to display their patriotic fervour, not individuals. ${ }^{43}$ In this sense, then, both the production and the consumption of souvenirs performed the stereotypical distinction between the Mainland and Hong Kong, insisting on the gap between a socialist economy and a putatively laissez-faire one, between a severe lack of choice and an abundance of it, between the driven necessity of demonstrating loyalty to the Party and the right to claim indifference.

In using the word 'performed' here I am refusing the apparently static qualities of souvenirs and suggesting that the strand of critical theory which understands photography as a complex movement from presence to absence can usefully be more widely applied.44 The souvenir, whether as photograph, video footage, or three dimensional object, gives pleasure in being private. From the banal to the satiric or the exquisite, this bric-a-brac has been largely overlooked in writing about Hong Kong's handover, even though the sheer proliferation of goods thus packaged pointed to a manic collectomania. This is because souvenirs are generally deemed to be trivial expressions of commercialization, as though all the effort expended in forming those 'miniature museums of our archived selves' 45 is only a sign of crassness. Eloquently refuting this view are Stewart's remarkable observations on the objectification of desire instantiated by the souvenir and the collection. This objectification is, by her reading, achieved by 'collapsing distance into proximity to, or approximation with, the self.$^{6}$ The souvenir thus partakes in the structure of the fetish. By reducing the public and the monumental into the miniature, and thereby rendering history as private time, the part comes to replace the whole as the latter's substitute or signature. ${ }^{47}$ Somewhat differently to Stewart's souvenirs, which spiral continually inward as they generate narratives reaching only behind, $4^{8}$ handover souvenirs were also turned outwards towards the future. To phrase this differently, I might observe that the souvenirs with which I have been concerned here are objects arising not only out of the insatiable demands of nostalgia but also out of the equally ravenous requirements of hopeful anticipation about all that reunion with China might bring, demands and requirements which make these objects necessarily partial evocations.

It is this very partiality, this inability to achieve closure, which ensured the affective intimacy of handover souvenirs. 
Earlier I referred to the stereotypical qualities of handover narratives, their anxious repetition of the same points, their pessimisms and optimisms alike being perceived as impersonal, alienating and, ultimately, boring. I also discussed the relentless commodification of the handover, a commodification of which souvenirs must count as an example. Souvenirs, I argued, achieved a number of effects ranging from the satiric to the nostalgic, from the Utopian to the profitable. All those T-shirts and caps and cufflinks might, at first glance, look like a pile of junk. But it was a pile from which consumers could retrieve something to display or to wear. What all of these effects had in common was the creation of an intimate specificity which momentarily negated the generality and alienatory scale of sovereignty transferral. ${ }^{49}$

\section{B RIC-A-B RAC}

Let us return now to the issue of boredom as the habitual mood of the handover. An embracing rubric of dissatisfaction, an allpurpose index of discontent, an insistence on cosmopolitan distance from the tedium of repetition and the dreariness of nonengagement, boredom is a word with a definite capacity to blur. Its utility as a description of Hong Kong people's attitudes to the handover rests precisely on that capacity. Boredom is a term that absorbs and organizes different anxieties together, suggesting that, deafened by the noise of the media, language was too used up and worn out through the exertions of repetition to register anything other than grim duty. ${ }^{5 \circ}$ It is tempting to argue that this saturation and repetition drained the handover of its Utopian impulses and rendered it merely meretricious; to see boredom as a negation allowing no space for creativity.

We should resist this temptation, not exactly because it is wholly wrong but because it evacuates complexity, leading tc a mental diagram, or better still reflex, wherein the connections between boredom, apathy, and materialism become so stunningly direct that caricature can be the only end result. Hong Kong people labour under the burden of those caricatured connections and it is irresponsible to contribute to them, just as it is irresponsible to ignore this weighty baggage. Instead, I suggest we shift our angle of vision, seeing claims to boredom not as a dead weight but as an enunciation of political and social vulnerability, an enunciation that, in the context of Hong Kong's handover, constituted a disruption to repetitive narrative. Such disruptions are a necessary precondition of creativity. This creativity, which is in large degree a demand for authenticity, for a lived relationship to History forged through the domestication of the monumental in the intimacy of downsizing, has been partially effected, I have argued, in the production and consumption of those most trivial and seemingly 'boring' artefacts, souvenirs.

In the midst of predictions about the triumph of socialism in the figure of 
reunification on the one hand, and the necessary transformation of all of China through the example of democracy and the free market on the other, souvenirs performed another transition altogether. The intense commodification and frequently jingoistic packaging involved in the conception and marketing of these objects might be said, quite properly, to repeat the logic of consumer capitalism. My point is that they also exceeded these teleologies. As personal objects of mourning and celebration, as whimsically irreverent or even caustically cynical commentaries, souvenirs performed the transformational function of converting the distant and the overwhelming into the intimate. That transformation might, too, be described as profoundly ideological. But one of the peculiar things about serendipitous shopping is that you never know whether you are going to take home trash or treasure, or what future pleasures either might elicit. $\propto$

\section{ROZANNA LILLEY}

Rozanna Lilley is an Assistant Professor teaching in the newly established Cultural Studies Program at Lingnan College in Hong Kong.

\section{ACKNOWLEDGMENTS}

Thanks to Annette Hamilton for encouraging me to attend the handover, Neil Maclean for editorial assistance, Yao Souchou for discussing boredom with me, and Richard Eves for infrastructural support. The research for this paper was undertaken when I was a Macquarie University Research
Fellow in Anthropology. A Macquarie University Research Grant funded my trip to Hong Kong during 1997 . The time to write this paper was provided by a Postdoctoral Research Fellowship at the Centre for CrossCultural Research, The Australian National University. Revisions were undertaken at Lingnan College, Hong Kong.

\section{NOTES}

' South China Morning Post, 26 June 1997. The "media references in this paper are restricted to English-language sources. Readers should be aware that Hong Kong is served by a large variety of Chinese-language newspapers and magazines. Unfortunately, an analysis of all of these is beyond either my scope or my capabilities. Readers should also be aware that the vast majority of readers of the two major English newspapers, the South China Morning Post and the Hong Kong Standard, are Hong Kong Chinese.

${ }^{2}$ South China Morning Post, 3 July 1997.

${ }_{3} \mathrm{My}$ argument is that boredom was experienced by many people across the socio-economic spectrum in Hong Kong. I accept, though, that self-conscious expressions of boredom may have been more elaborate amongst the elite. To suggest that many Hong Kong people were bored is not to deny the simultaneous presence of numerous other affective responses including excitement, delight, and fear at the prospect of Chinese rule. My aim here is not, presuming such a project was possible, an exhaustive account of all of the responses to the handover. Rather, I hope to provide some suggestive linkages between being bored and buying souvenirs.

4 Siumi Maria Tam, 'Eating Metropolitaneity:

Hong Kong identity in yum cha', The Australian Journal of Anthropology, 8.3 (1997), 29I-306, p. 304. 
${ }^{5}$ Martin Heidegger, Ralph Manheim (trans), $A n$ Introduction to Metaphysics (New Haven and London: Yale University Press, 1959), p. 46.

${ }^{6}$ Susan Shaw, Linda Calwell and Douglas Kleiber, 'Boredom, Stress and Social Control in the Daily Activities of Adolescents', Journal of Leisure Research, 28.4 (1996), $274 \div 92$.

7 Tam, 'Eating Metropolitaneity', p. 305.

${ }^{8}$ Patricia Spacks, Boredom: The literary history of a state of mind (Chicago and London: The University of Chicago Press, I995), p. x.

9 Guy Debord, Society of the Spectacle (Detroit: Black and Red, $\left.198_{3}\right)$.

${ }^{\text {ro }}$ Susan Stewart, On Longing: Narratives of the miniature, the gigantic, the souvenir, the collection (Baltimore and London: The Johns Hopkins University Press, 1984), p. I4.

"Ackbar Abbas, 'Hong Kong: Other histories, other politics', Public Culture, 9 (1997), 293313, p. 304 .

${ }^{12}$ Leslie Thiele, 'Postmodernity and the Routinization of Novelty: Heidegger on boredom and technology', Polity, 29 April I997, 489-517.

${ }^{13}$ Heidegger, Introduction to Metaphysics, p. I.

${ }_{14}$ Thiele, 'Postmodernity and the Routinization of Novelty', P.5or.

${ }^{15}$ Georg Simmel, Tom Bottomore and David Frisby (trans) from a first draft by Kaethe Mengelberg, The Philosophy of Money, (Boston, London, Melbourne and Henley: Routledge and Kegan Paul, 1978), p. 256.

${ }^{16}$ Rozanna Lilley, Staging Hong Kong: Gender and performance in transition (Surrey: Curzon Press, 1998).

${ }^{17}$ Thiele, 'Postmodernity and the Routinization of Novelty', p. 509 .

${ }^{18}$ Frederic Jameson, Signatures of the Visible (London and New York: Routledge, Chapman and Hall, r99o), Pp. I7, $9^{1}$.
${ }^{19}$ Sydney Morning Herald, 31 May 1997.

${ }^{20}$ South China Morning Post, 25 June 1997. My interest in this paper is largely confined to Hong Kong Chinese. However, I contend that both the intense levels of publicity surrounding the handover and the tendency for commentary about the event to be offered within the framework of a repetitious series of fixed narratives left everyone-tourists, expatriates, and localsfeeling frequently bored. A longer version of this analysis, forthcoming as a chapter in an edited collection on consumption in Hong Kong, deals at some length with these repetitious narratives.

${ }^{21}$ South China Morning Post, 2 July 1997.

${ }^{22}$ South China Morning Post, 5 July 1997

${ }^{23}$ Charles Levin, 'Translator's Introduction', in Jean Baudrillard, Charles Levin (trans), For a Critique of the Political Economy of the Sign (St. Louis, Telos Press, I98I), 5-28, p. 23.

${ }_{24}$ Jameson, Signatures of the Visible, p. I9; and Stewart, On Longing, pp. 6, г68.

${ }^{25}$ Jameson, Signatures of the Visible, p. II.

${ }^{26}$ Ackbar Abbas, Hong Kong: Culture and the politics of disappearance (Hong Kong: Hong Kong University Press, 1997), p. 65.

${ }^{27}$ Stewart, On Longing, p. 165 .

${ }^{28}$ Carol Mavor, 'Collecting Loss', Cultural Studies, II.I (1997), III-37, p. I26.

${ }^{29}$ James Watson, 'McDonald's in Hong Kong: Consumerism, dietary change, and the rise of a children's culture', in James Watson (ed.), Golden Arches East: McDonald's in East Asia (Stanford, California: Stanford University Press, 1997), 77-109, p. 103.

${ }^{30}$ Jameson, Signatures of the Visible, p. $3^{\circ}$.

${ }^{31}$ South China Morning Post, 24 June 1997.

${ }^{32}$ South China Sunday Morning Post, 6 July I997. 
${ }^{33}$ Sydney Morning Herald, 6 June 1997.

34 Jameson, Signatures of the Visible, p. 218.

${ }^{35}$ South China Morning Post, 23 June 1997.

${ }^{36}$ South China Morning Post, 3 o June 1997.

${ }_{37}$ South China Morning Post, 2 July 1997; and Sydney Morning Herald, 28 January 1997.

$3^{8}$ South China Morning Post, $3^{\circ}$ June 1997.

39 South China Morning Post, 3 July 1997.

40 South China Morning Post, 3 o June 1997.

"South China Morning Post, 3o June 1997.

${ }^{42}$ South China Morning Post International Weekly, 27 July 1996.

${ }^{43}$ South China Morning Post, 26 June 1997.

44 Carol Mavor, Pleasures Taken: Performances of sexuality and loss in Victorian photographs (Durham and London: Duke University Press, I995), p. 4 .
45 Mavor, Pleasures Taken, p. I2I.

$4^{6}$ Stewart, On Longing, p. xii.

${ }^{47}$ Stewart, On Longing, p. 137.

${ }^{8}$ Stewart, On Longing, p. 135.

${ }^{49}$ See Daniel Miller, 'Consumption as the Vanguard of History: A polemic by way of introduction', in Daniel Miller (ed.),

Acknowledging Consumption: A review of new studies (London and New York:

Routledge, r995), I-57, p. 3I. I use the word 'momentarily' because the whole complex issue of people's lived relationship to these artifacts is beyond the scope of this study. The general question of whether or not these souvenirs were displayed in domestic or public spaces and of what narratives these objects elicited must await further research.

$5^{\circ}$ See Heidegger, An Introduction to

Metaphysics, p. $5^{\mathrm{I}}$. 


\section{JAPAN, MODERNITY AND THE TOKYO OLYMPICS}

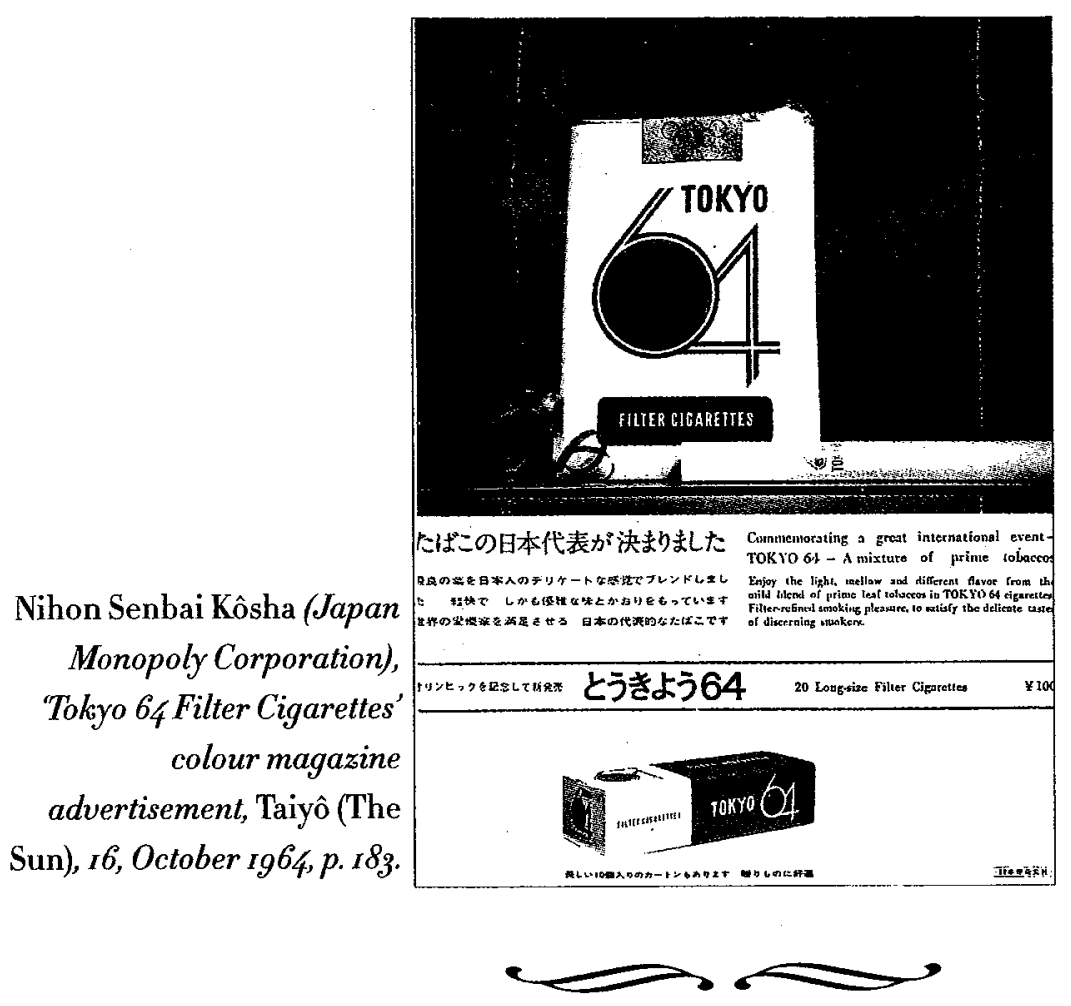

$\mathrm{H}$ modernity? This essay is an attempt to challenge the idea that modernity was simply viewed as an import from the West by specifically examining representations of Japan in major sporting events.' These representations often attempted to promote a syncretic image of Japan as a hybrid culture, one which borrowed from other nations and yet remained distinctive. Japan's industrialization unleashed modernizing social forces which eroded some local cultural differences but at the same time helped create a national identity. This identity was paradoxically linked not only with the nation's ability to borrow from other nations, internationalize and modernize, but also with the preservation of cultural traditions. In sport and other arenas, we see a code-switching between local and global worlds, a fluidity in identity, and a modernity of their own. ${ }^{2}$

The bodily experience of modernity in Japan has been shaped by the discourses of colonialism, militarism, and democracy. As Yoshio Sugimoto argues, these are not mutually exclusive. The cleaning of classrooms by students, group exercises reminiscent of army drills, emphasis on correct bowing and posture, and even etiquette regarding the blowing of noses contribute to what he describes as part of the friendly authoritarianism which 
pervades Japan today. ${ }^{3}$ By examining sport, we can gain some understanding of how this body culture evolved. In the name of sport and regional or global bonding, perceptions of racial and ethnic difference were sometimes downplayed. By looking specifically at Japan's participation in the Far Eastern Olympics of Ig23, the lead up to the cancelled r94o Tokyo Olympics, and the Games eventually held in 1964 , we can identify contending discourses of nationalism and internationalism.

Many Japanese publications were published in English as a form of cultural diplomacy to promote Japan in the West. By examining images of Japan in such publications, others consumed by the Japanese, and the images which visitors to Japan themselves went away with, we can glimpse an understanding of the greater transformations that Japan was undergoing. The film and photographs referred to in this essay are manifestations of certain visions of national culture and the role of tradition in it. Sporting images in the mass media helped define national identity for many Japanese.

Through the Olympics, Japan again embraced a modernity with prewar origins. ${ }^{4}$ In her recent book on Japan's Competing Modernities, Sharon

Minichiello stresses how ideas of modernity in prewar Japan pertained to progress, science, and rationality. 5 The 1940 Olympics which were to be held in Tokyo, and the 1964 Olympics which were, were both important moments in
Japanese history. They provide a window into the Japanese experience of modernity, and the tensions and contradictions inherent in it. In the years leading up to the Pacific War and those immediately after, there was a blending of both internationalism and nationalism in the discourses surrounding Japanese identity. As we shall see, in the immediate postwar period, the emphasis is on the former. The success of the Tokyo Olympics promoted a vision of 'Japaneseness' which emphasized the nation's modernity. Published accounts by foreign visitors reinforce this.

\section{BODY AND NATION}

In the late nineteenth century, foreign instructors helped introduce Western sports into the elite educational system in Japan. ${ }^{6}$ Differences in athletic ability were viewed as reflecting not only physical differences but differences in national strength. By promoting sport, they could improve the bodies of the Japanese. Sabine Frühstück has suggested that from the Meiji period (1868-1912) and the years leading up to the Pacific War, Japanese bureaucrats and intellectuals, physicians and scientists increasingly attempted to use scientific knowledge to form wellfunctioning and well-regulated bodies which could be mobilized for the nation.?

Yoshimi Shunya has examined Meiji schools as the space within which the nation was created and instilled in the bodies of children. Students underwent 
militaristic exercise drills and participated in athletics meets, a disciplinary technique which helped them form a sense of belonging to the state. ${ }^{8}$ Indeed, physical education was, for the Japanese and others, a way of linking the individual bodies of citizens to the welfare of the nation. ${ }^{9}$ There is still evidence of Meiji body culture in Japanese schools today.

Ikari Seiya argues that internationalism was a major characteristic of sport in the years after World War I and through to the I93os. The popularization of sports is evident from the pages of newspapers which still remain. In terms of Westerninspired sport activities in the late 1920 s and $3^{\circ}$, baseball was overwhelmingly the most popular, followed by sports such as athletics and swimming. ${ }^{10}$

\section{FAR EASTERN OLYMPICS}

Major sporting events add to national prestige, promote the interests of competitor nations through association with the performances of athletes, and create comparisons with other competitor nations. They provide cultural pleasure and impress visitors, and provide an effective instrument of propaganda. The historian Graeme Davison has argued that while celebrations such as the Olympics are opportunities to assert group identity and unity, on close inspection someone is excluded and something is being denied. ${ }^{\mathrm{II}}$ The Far Eastern Olympics, a series of major sporting events in which Japan, China, and the Philippines participated, were certainly a case of just that.
The Far Eastern Olympics were the idea of physical directors of the Manila and Shanghai YMCAs, who organized the Far Eastern Athletic Association with Japan to support the games. The games were held from 1913 to $19^{2} 7$ every two years, and after I930, every four years, alternating with the better-known world Olympic Games. As can be seen in media coverage of the Far Eastern Olympics held in Osaka, Japan, in I923 (see figure r), such athletics events provided the Japanese with a concrete example of Asian solidarity. Although the magazine pictured was written almost entirely for Japanese readers, a short

\section{FigURE I}

Track Event at the Sixth Far Eastern Olympics, Osaka, Japan, Ig23. Cover image, The Asahi Sports, I.5, May Igz3.

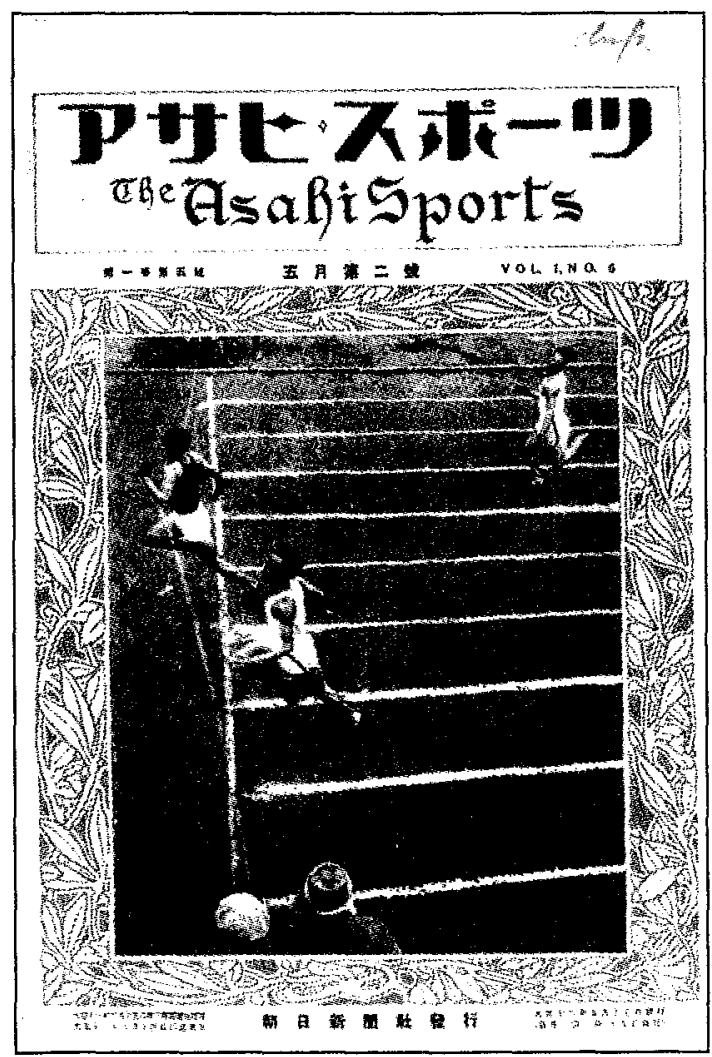


message of welcome could be found on the inside page, in English.

To the Philippino [sic] Champions, contestants in the Sixth Far Eastern Championship Games: The promotion of understanding and friendship between nations to-day can spring only from the open-hearted efforts made by each of the nations. For this reason we are gratified at knowing that the effectiveness of the friendly rivalry of sport and its essentiality in the cause of international peace are becoming recognized throughout the world. ${ }^{\text {I2 }}$

Maintaining this solidarity against the backdrop of Japanese territorial expansion strained relationships. Grant Goodman has written of the Far Eastern Olympics of I934. Japan sponsored Manchurian participation in the games that were to be held in Manila on 12-19 May. Japan insisted on the admission of the new informal colony of Manchukuo (formerly known as Manchuria) which, if successful, would have served to legitimate and recognize the new puppetstate. Japan had previously participated in the games and considerable press coverage had been devoted to it. China threatened to pull out of the games if Manchukuo was admitted. The 1934 Far Eastern Olympics went ahead without participation by Manchukuo, but shortly after the games were over, Japan and the Philippines agreed to dissolve the Far Eastern Athletic Association which was responsible for the games and in its place formed the Amateur Athletic Assocation of the Orient. This new organization included Manchukuo but excluded
China. ${ }^{13}$ This episode reflects the increasing politicization of sport in the r93os.

\section{FASCIST BODY CULTURE?}

Florence Taylor, an Australian who visited Japan in the I93os, could not help but link the body culture of Japan with that of Italy. In her book $A$ Pot-Pourri of Eastern Asia: With comparisons and reflections (1935), Taylor provides us with a sense of the importance of the health and well-being of the body and how that was seen as reflecting national might and military preparedness. A photograph in her book entitled 'Gymnastics in Italy' shows hundreds of men dressed in white undergoing a mass exercise drill. It bears the following caption:

In comparison, Australia trains her men and women in sports and in life-saving, which are worthy, but not nearly comprehensive enough to cope with defence demands. The onlookers should be trained as well. No success comes to a country just by chance. As with individuals, countries attract success by their thoughts and actions. ${ }^{14}$

This is preceded by a small illustration of young female Japanese archers in amongst the text, accompanied by a caption which describes how in Japan, 'according to' convention every step and every movement is governed by strict etiquette. Calm and complete control of mind and body are considered of greater importance than accuracy in shooting' ${ }^{15}$

Germany, Italy, and Japan do seem to have shared certain attitudes to the body which 
emphasized mass drills for both the civilian population and armed forces, and linked disciplining of the body and mobilization of the nation, but these attitudes were not unique to these nations. We can say, however, that sport in Italy played an important role in carrying out the Fascist Party's aims of patriotism and military fitness. At the outbreak of World War II, a major athletic stadium, the Forum Mussolini, was being completed for the I944 Olympic Games, which were cancelled. In Germany, physical education programs emphasized military objectives. Hitler youth clubs provided training in a range of sports including boxing, wrestling, swimming, and athletics. ${ }^{16}$ In Japan, Young Men's Leagues (seinendan) were also a way of promoting such activities. A 1937 publication on these organizations, written for a Western audience, suggested that while we might compare them to the YMCA, boy scout groups and Hitler Youth,

\begin{abstract}
There is no nation in the world that does not possess something prominently peculiar to its own land, which can hardly be copied by any other nation. And as these things are, in most cases, products of so-called racial instinct, quite natural and spontaneous, they always play one of the most fundamental roles that are essential to the development of national life, though even the nation itself sometimes has not a very clear idea of their significance. ${ }^{17}$
\end{abstract}

We should be careful not to stereotype attitudes to the body in Japan, for, as Florence Taylor suggested, countries such as Australia could benefit from such ideas as well. Even in Japan itself there were differing attitudes and intense debate on race in the years leading up to the Pacific War. ${ }^{18}$ And there is no consensus on whether we can label Japan as 'fascist'. 9

SPORT AND EMPIRE

In Japan: Her Cultural Development (r939), Kaji Ryûichi commented on the

FIGURE 2

Image of mass-drill in I93os Japan. The Society for International Cultural Relations, Sports, second impression (Tokyo: The Society, Ig3g).

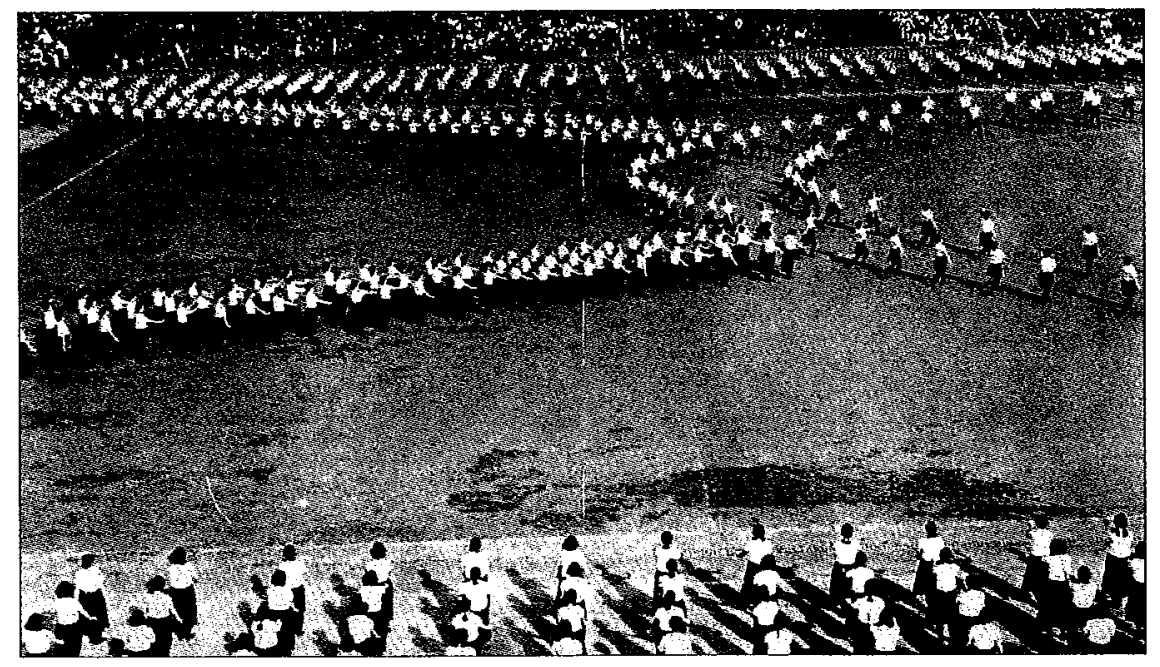


progress made by Japanese athletes and the need for political and economic advances as well:

Encouraged by international sport circles and improved by the coaching of foreign experts, Japanese athletes have made such progress in recent years that they often set new world records in track and water events. This means an advancement not only of Japanese, but also of world sport.... Of course such activity must not be limited to the cultural sphere, but must also be undertaken politically and economically. ${ }^{20}$

The first sentence is repeated as a caption to photos on the opposite page. It

diplomatically acknowledges the benefits of a modernity which owes much to other cultures, and the internationalism of sport, but nevertheless reminds readers of Japan's rights to protecting its national interests. The images show tennis courts, swimming pools (where the Japanese were excelling), and a mass exercise drill. While Japan acknowledges the benefits of internationalism, concerns regarding national ambitions are not far away. As Tani Barlow has reminded us, colonial and modernist discourses are often in collusion in Asia. ${ }^{21}$

In another English-language publication published by the same governmentfunded organization, The Society for

\section{Figure 3}

Boys Dressed in kendô (Japanese fencing) gear, r93os. The Society for International Cultural Relations, Sports, second impression (Tokyo: The Society, (939).

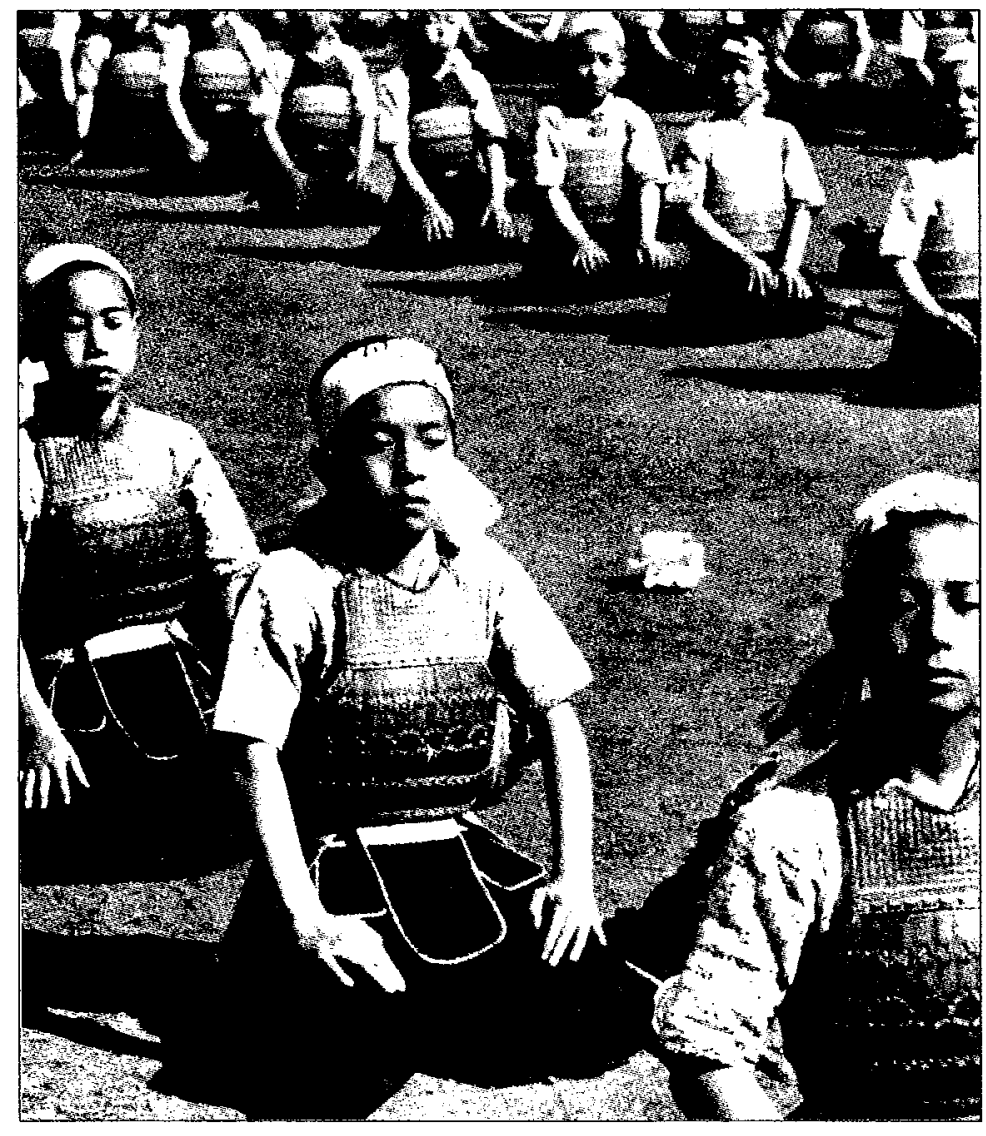


FiguRE 4

Japanese Hurdlers, 193os. The Society for International Cultural Relations, Sports, second impression (Tokyo: The Society, Ig39).

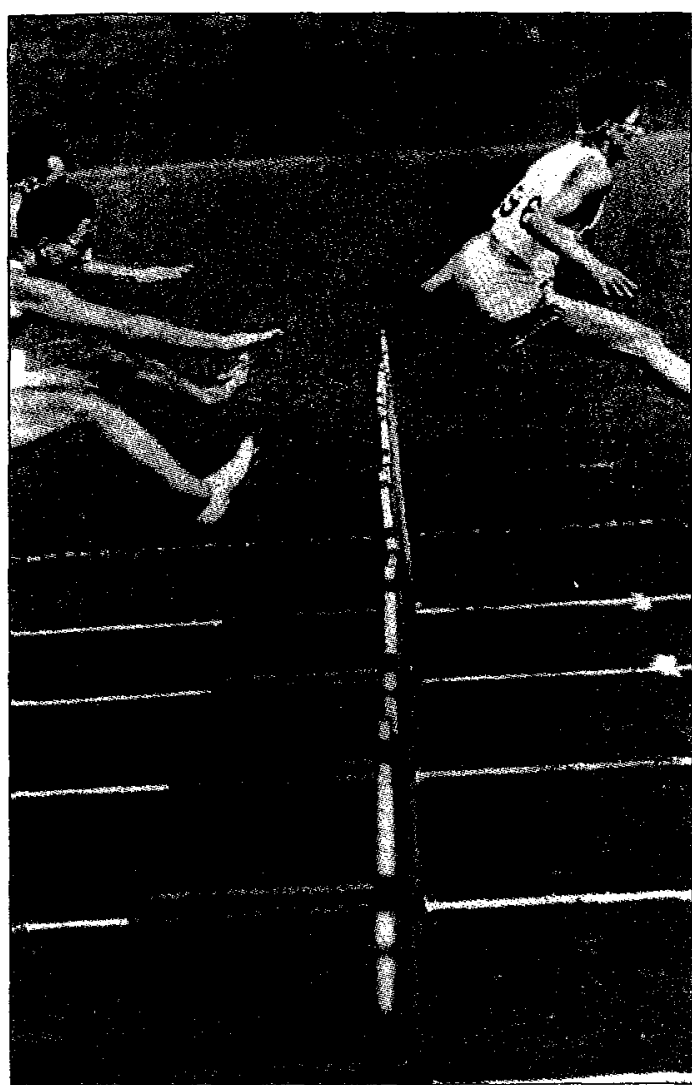

International Cultural Relations, that very same year, images of traditional sports.are juxtaposed with those of more recently introduced sports (see figures $3 \& 4$ ). The book entitled Sports was part of a series of heavily illustrated books on Japanese life and culture produced as part of a major effort at promoting Japanese culture in the USA and elsewhere in the years prior to the Pacific War. Captions to the images inform us that 'schools, factories, offices and other social institutions are trying to encourage physical culture through massdrills' (see figure 2) and that Kendô, Japanese fencing (see figure 3), was 'a moral code of the samurai and developed not only as a feat of the sword but as a means of spiritual cultivation'. While Japanese swimming, 'with the adaption of foreign strokes to the old Japanese forms' is seen as more of a hybrid sport, the result has 'come to be internationally famous'. Descriptions of Japanese sport reflect the growing militarization of physical culture in Japan, and the understanding that the Japanese drew on other cultures, preserved some of its traditions, and succeeded. ${ }^{22}$

The Japanese government has made extensive use of sports and culture for the pursuit of national purposes. Proposals to hold the Olympics in Tokyo can be viewed as part of Japanese 'cultural policy', with government officials seeking to use sporting events for the purposes of national policy and to reinforce Japan's right to compete with the world in territorial expansion.

\section{940 TOKYO OLYMPICS}

We cannot view the 1964 Olympics in isolation, for despite the changes Japan had undergone, the ghost of the cancelled I940 Tokyo Olympics (see cover) remained in the memories of many Japanese. The original proposal to schedule the Olympics in Tokyo directly after the 1936 Berlin Olympics, seemed to bond Germany and Japan. Tokyo was awarded the Olympics the day prior to the opening of the Games in Berlin in $193^{6}$, but by $193^{8}$, Japan's conflict with China and shortages in building materials, especially steel, meant 
that it had little option but to withdraw from hosting the Games. ${ }^{23}$

Kanô Jigorô (I860-I938) a pioneering figure in the development of jûdô and the Olympic movement in Japan reflected how Japanese could embrace both the old and new. He adapted techniques from various schools of the martial art of jûjutsu to form the basis of his new jûdô, a sport more grounded in the modern science of physiology and dynamics. He established the Japan Amateur Sports Association in IgIr as the body to select Olympic representatives, and he was instrumental in winning the 1940 Olympics for Tokyo. ${ }^{24}$

The Japanese Government also strategically planned to hold the International Exposition of Japan in $194^{\circ}$ at Tokyo and Yokohama, in order to commemorate the 2,60 oth anniversary of the accession to the throne of Emperor Jimmu, the first Emperor of Japan. The exposition would highlight 'the great achievements of Emperor Jimmu and his illustrious successors who have ruled over Japan in an unbroken line for twenty-six centuries. ${ }^{25}$ This was at a time of war with China and because of the political situation at the time, like the Olympics, did not come to fruition. It would not be until the postwar period when the first Tokyo Olympiad would be held.

The Olympics and Expo were major international events which, if held in 1940 , would have served to legitimate the Japanese empire. Almost a quarter of a century later, the Olympics served a different purpose-an opportunity to welcome Japan back to the family of nations and to celebrate its postwar reconstruction and economic growth. Both the prewar and postwar plans to hold the Olympics are evidence of the syncretism of Japanese culture in which a type of code-switching occurs.

Representations of Japanese identity can be fluid, and alternate between one rooted in Japanese (and Asian) traditions and one more closely linked with the West. ${ }^{26}$

\section{TECHNOLOGICAL DEVELOPMENT}

The Olympic Games were not only a celebration but also a stimulus for further technological development. Shin Mizukoshi has written of how the $194^{\circ}$ Olympics encouraged engineers to develop television technology in the hope of telecasting Japan's glory. The Olympics were to be but one of a number of national events which would feature television technology, from the late 193 os to the I940s. These included the Kôha Teishin Tenrankai' ('Asian Communications Exhibition'), 'Shisô Senden Tenrankai' ('Ideological Propaganda Exhibition'), and 'Kagayaku Gïutsu Tenrankai' (Brilliant Technology Exhibition'). ${ }^{27}$ While one might not immediately link the Olympics with technology and propaganda, in Japan's case there is a clear relationship.

The same confidence which prompted Japan's proposal to host the Olympics in I94o can also be seen in the development of railways. In prewar Japan, trains served 
as agents for Japanese expansion. A part of Japan's expansionist policy for Asia was the first 'bullet super-express' which was running by 1939 . Visitors to Manchukuo could apparently travel the $944 \mathrm{~km}$ between Dairen and Harbin in 12:5 hours by riding the 'stream-lined, ultra modern super-express “Asia”'. Reports describe it as having provided roomy, air-conditioned comfort for passengers, 'the last word in speed and comfort'. Maximum operating speed was said at the time to have been ${ }^{40}$ $\mathrm{km} / \mathrm{hr} .^{28}$ The early attempts to develop television (communications) and the very real expansion of railways (mass transporation) were part of attempts to establish in Japan the 'modern apparatus of circulation'. ${ }^{29}$ Such technologies worked to increasingly globalize the Japanese, introduced new forms of modernity, facilitated social cohesion and at the same time aided the movement and migration of people from Japan to other parts of the empire.

The dream of linking Japan via a highspeed train network continued into the postwar period. The construction of the new railway line was pushed forward, with the result that a commercial service started on I October 1964, the same year as the Olympic Games in Tokyo. Both served to heighten national prestige. $3^{\circ}$ The Japanese National Railways opened the new Tôkaidô Shinkansen (literally the ' Tôkaidô New Trunk Line') between Tokyo and Osaka ten days prior to the opening of the Olympic Games. The train has often been referred to as the 'bullet train' because of its high speed. ${ }^{3 r}$ The new Tôkaidô line was seen as a symbol of the modernization of Japanese railroads, and in a broader sense, Japan itself. Japan would take its rightful place in the 'sun', and the railways 'their rightful place alongside road and airline services' ${ }^{32}$ The coming of the second bullet train heralded a period of renewed Japanese confidence and was, in many respects, a manifestation of postwar Japanese techno-nationalism. Many agreed that the shinkansen embodied 'Utopian concepts which those modernizing an existing line can at best realize partially'. ${ }^{33}$ That it was realized just prior to the opening of the Olympics, at a time of high economic growth, is no historical accident.

The view from a shinkansen window became a central visual experience for travellers, an impressive reminder of Japan's modernity, especially its technological prowess. ${ }^{34}$ The train facilitated national cohesion, bringing even isolated regions and communities into contact with each other. Sport, too, brought people together, and one of the most successful examples of this was the I964 Tokyo Olympics.

\section{I9.64 TOKYO OLYMPICS}

The Olympics are not only opportunities for sporting fans to enjoy performances by athletes from throughout the world, they are also significant moments of representation and display.35 The noted Japanese director Ichikawa Kon captured 
those moments in his well-known film Tokyo Olympiad, sg64 (1965) for the Tôhô Film Company. Like Leni Riefenstahl's film of the $193^{6}$ Olympic Games Olympia (1938) which celebrated the body and the Nazi state,$^{36}$ it too had a message to convey to the rest of the world. By examining Ichikawa's portrayal of the Olympics, we can come to understand how the Games served a number of purposes for the Japanese. Japan had travelled a long way since its defeat in the Pacific War. The very same emperor who had broadcast his country's surrender less than two decades before, now greeted the countries of the world with pride. The historian Stephen Large has written that such events helped to sell the emperor to the Japanese public as the 'human emperor' ${ }^{37}$ Ichikawa's film further promoted the idea that the imperial household had adapted to postwar Japanese democracy by making connections between the previously sacred body of the emperor, the private moments of individual spectators, the sporting achievements of athletes and the masses who saw the film at the cinema.

For both those watching the Olympics in I964, and those participating, the Tokyo Olympics conjured up mixed feelings. These were embodied in the torch bearer, Sakai Yoshinori, who was born the day after the atomic bomb blast in Hiroshima in r945. After lighting the Olympic flame in the main stadium, pigeons symbolizing peace were released to signal a new Japan. The new Japan was intent on rebuilding industries and concentrating on economic goals. The success of the women's volleyball team showed how the pressure to succeed was great. The high achieving spirit of many Japanese was reflected in both sport and in industry. It was as if the Olympics were a metaphor for what Japan had become.

The opening of the film is particularly powerful, juxtaposing as it does old and new facets of Japan. It begins with a bright sun (read Japan) and the destruction of old buildings to make way for the new (read postwar modernization). Like

Riefenstahl's film, there is an attempt to create linkages with classical Greek culture. In Ichikawa's production, a shot of Greece reminds viewers of the origins of the Olympics, and then we are transported back to Japan with another shot of a rising sun. The Olympic torch travels through Istanbul, Beirut, Tehran, Lahore, New Delhi, Rangoon, Hong Kong, and other countries. We then are reminded of Japan's past with an aerial view of Hiroshima's A-Bomb Dome. Young and old Japanese faces greet blonde foreigners coming off a Pan American jet. The torch is carried through an old Japanese town, tiled roofs of old houses flagging traditional Japan, helped along by a glimpse of bunraku puppet heads.

We return to signs of Japan's emerging modernity with the jostling and bustle of Japanese waiting to greet the foreigners in Tokyo for the Olympics. An image of Mount Fuji fills the screen, with what appears to be a vehicle zooming across the 
foreground. The car signals youth and speed, just like the international athletes visiting what clearly is a modern Tokyo. The raising of flags reinforces the image of an international event, as does the parade of countries in the opening ceremony. This internationalist theme can also be seen in Riefenstahl's Olympia, for Nazi Germany, like postwar Japan, was keen to convince the world of its peaceful intentions. $3^{8}$

The camera captures the face of Emperor Hirohito, his son Prince Akihito, and the face of an unknown old man overcome with emotion. Like the Japanese viewers of the film, he no doubt was conscious of how far the Japanese had come. While visions of the past might well have been going through his mind, a shot of a Seiko clock indicating that it was $2 \mathrm{pm}$ firmly locates us back into the present. Economic concerns are not far away. Is this an early example of indirect cinematic merchandizing? The opening of the Olympics by the Emperor, the arrival of the torch bearer, the lighting of the flame, and the release of pigeons, all serve to create a cathartic sense that we are witnessing something quite special.

Each scene seems to serve the purpose of making us aware of the coexistence of tradition and modernity. While this might be disorienting for some Japanese, such as the old man, there appears to be no looking back. The only old building remaining is that of a building in Hiroshima which serves as a reminder that Japan had been a victim. The only image of
Japan as an aggressor that we are left with is as a competitor in sport. The film provides an idealistic, easy-to-understand metaphor for Japan's reconstruction, its return to the international community, and subsequent high economic growth.

Much of the remainder of the film focusses on the athletes, their performances, and national affiliations. We could be anywhere, and perhaps that is a hidden message as well. There appears, at first, to be no radical difference that might set Asian modernity apart from that in the West. We are, however, occasionally reminded that we are in smoggy, fastdeveloping Japan, a land of tradition where some women still wear kimono. There still seems to be some traces of exotic Japan, but much of it is a thing of the past. Japan was achieving the standardization and uniformity of industrialized nations elsewhere. Gone are the mass drills of wartime. In postwar Japan, considerable effort was being made to make sport more 'scientific' and less ideologically-based.

We gaze at the bodies of athletes in a way somehow different from that of Riefenstahl's Olympia. Gone is the eugenicist quest for a perfect body, and instead we see bodies of all shapes excelling in competition. We witness the excitement of the men's roo metre freestyle swimming race, and then glimpse more of the countryside thanks to a cycling event. Women's volleyball is one of the few opportunities for us to see the 
raising of the Japanese flag, before the film closes with a ceremony and fireworks. Japan actually won sixteen gold medals, the third largest number after the USA and the Soviet Union. Japanese success served to reinforce growing pride in their achievements, in both sport and the world of trade.

The Japanese who attended the Olympics, the hordes of people who viewed Ichikawa's film, and those who were passengers on the shinkansen, all were treated to a visual spectacle which destabilized previous modes of perception. They were presented with images framed by the sporting arena, screen, or high-speed train window.39 For those who watched the film years later on television, the film served to transform the Japanese memory of the Olympics into a visual archive of filmed or remembered moments.

To commemorate the Olympics, Fuji Photo Film Co. published an album of selected photographs from that year's annual photo contest sponsored by the company. The themes for the contest were 'Youth of Japan' and 'Scenery of Japan'. While large group photographs of bodies in action were plentiful, the previous emphasis on recording mass formations was replaced by depictions of 'youthful energies, $4^{\circ}$ blurred images, smiling faces and bodies out of synchronization with each other. The photographs were used to decorate the rooms of the Olympic Village, and members of Olympic teams and officials were presented with copies of the album. Fuji Film's publication provided in book-form what Ichikawa sought to achieve on film. Both are powerful statements about how the Japanese saw themselves in the postwar period. Ichikawa, and the photographers who were selected for Fuji's album sought to change perceptions of the Japanese by framing the body in images which emphasized individualism, something which they associated with democracy and the West.

\section{RECONSTRUCTING TOKYO}

How has space changed the way the Japanese have experienced modernity? Yoshimi Shunya has explored the structural transformations of urban culture in the process of modernization, focussing especially on sakariba, parts of Tokyo where people enjoyed going to the theatre, viewed exhibitions, went shopping, and ate and drank. He argues that the shift of interest for young people from Asakusa to Ginza in the I92os (and Shinjuku to Shibuya during the I97os), reflected similarities in the sense of spatiality, the people who gathered there, and reflected the commercialization of the lives of urban dwellers. ${ }^{4}$

The ${ }_{19} 64$ Summer Olympics also changed the way in which people used the space of Tokyo. It was both a chance to introduce to the world Japan's reconstructed capital city and a stimulus to further transform areas of Tokyo adjacent to the Olympic 
site. Homes and businesses were relocated for the creation of 'Olympic

Thoroughfares'. Omotesandô-dôri, the main street going through Harajuku, was widened and made into a tree-lined boulevard which many Tokyoites refer to as their version of the Champs Élysées in Paris. Harajuku became a magnet for foreigners and Western fashion. The changes which Tokyo underwent were facilitated by the fact that Azuma Ryûtarô was governor of Tokyo from 1959 until after the Games, and also Chairman of the Japan Olympics Committee..$^{2}$

In a way, the 1964 Games were a substitute for the cancelled r940 Olympics. The continuities between wartime Japan and postwar Japan can be seen in the appropriation of army land for sporting events. What had been a drilling ground for the Japanese army became a main base of operations for the Allied Occupation and renamed 'Washington Heights'. Much of Washington Heights became an athletes' village during the Olympics and was returned to the people in the form of Yoyogi Park.43

A constant reminder of the Olympic years is the National Gymnasium complex (consisting of two buildings) designed by Tange Kenzô. Tange was one of the main authors of 'Tokyo Plan ig6o' which proposed to prepare Tokyo for the Olympics and solve some of the city's urban problems. The roofing of the main building was at once both reminiscent of Mt. Fuji and symbolic of modern Japanese architecture which drew on traditional Japanese design motifs. 44 While many of the changes to the landscape imbued the space of Tokyo with a Western-inspired modernity, the building was a potent reminder of Japanese culture, albeit distilled.

The redevelopment of Tokyo included an expanded road system, new parks, improved water supply system, bullet train, monorail line, expansion of subways, more hotels, and the Olympic site itself. The need to transport overseas visitors arriving in Japan swiftly to their destinations meant the creation of extra infrastructure which later benefited all Japanese. The Haneda Monorail Line opened less than a month before the Games and carried visitors from Tokyo's main airport to link up with the Yamanote Loop railway line. Similarly, the bullet train (shinkansen) dates from around the same time; a lasting reminder to all visitors to Japan of the country's modernity: its efficiency and technological know-how. 45

\section{RESPONSE OF OVERSEAS VISITORS}

In Olympic Diary: Tokyo 1964, Neil Allen provides a day-by-day account of his experience of the Games. His first entry for Tokyo is dated Sunday, 4 October and begins with a poem by the Emperor Meiji which highlights how Japan has long been the site where things both foreign and native came together: 
In my garden

Side by side

Native plants, foreign plants,

Growing together..$^{6}$

Allen then relates how disorienting being in Tokyo was. The Olympic site was like 'a private lung of its own', outside of which was the sprawling metropolis, the maze of streets, where 'someone who could not speak Japanese might well be lost for days'. ${ }^{47}$ In his final entry, almost three weeks later on 24 October, Allen sums up his experience with the following words:

The Japanese organization has been superb. The television aids, the electronic gadgets, the thousands of voluntary helpers and the eagerness of the ordinary public of Tokyo have seen to that. But there has been some inflexibility and we saw it again this evening when those who made rules were really asking for trouble..$^{8}$

Allen leaves us with a sense of Japan as a modern nation, with a large population which enthusiastically supported the Games, but which has little tolerance for those who do not conform to regulations.

Christopher Brasher's account Tokyo Ig64: A diary of the XVIIth Olympiad is dedicated to the British athletic team. It focuses on their performances, with little mention of Tokyo. He, like Allen, refers to the bustle of the city, 'the traffic is appalling, building is going on everywhere, Tokyo is an ugly city'. Within this city where 'the taxi-drivers do drive like kamikaze pilots' he compliments the Japanese on having created peace and tranquility in the form of the Olympic Village.49 He draws on various stereotypes of Japanese culture, to frame his impressions of the bustling city. The reference to kamikaze taxidrivers is repeated a few pages later, with a comment on how they commit seppuku (suicide) $!^{\circ}$ He describes the opening ceremony as 'the most brilliantly organized spectacle ever held in international sport ${ }^{\prime}{ }^{1}$ and devotes the remainder of the book to 'the proper business of the Games-sport between the nations of the world' ..$^{2}$ Like Allen, he congratulates Japan on its impeccable organization of the Games, but as can be seen by the contents of the book, 'the staging of the Games is, after all, no more than a setting for the athletes'. ${ }^{53} \mathrm{He}$ describes how in the closing ceremony, nationality is forgotten.

\section{GENERIC BODIES/FLUID IDENTITIES}

For postwar Japan, the 1964 Olympics helped to internationalize Japan as it emerged from defeat and reconstruction. Japanese and overseas visitors alike realized the poignancy of that moment in Japanese history, aware that Japan was still very much in the process of becoming a modern nation. Shortly after the Games ended, an issue of the illustrated Japanese magazine Mainichigurafu (Mainichi Graphic) proclaimed that "'The World is One' is not a mere phrase but living reality'.54 Japan's internationalism was pushed to the fore. Symbolic of this was a set of black and white postcards issued by the Tokyo Legal Affairs Bureau which 
emphasized the equality of all people. A generic person of no visible nationality (although obviously a man) is shown (see figure 5), as if to illustrate the universality of the human experience, as alluded to by Brasher's account.

In Japan, strict binary constructions such as tradition versus modernity are called into question. What we are rather uneasily left with is a type of ideological instability. This instability can be seen in advertising strategies. At a recent HRC conference, Yoshimi Shunya argued that in the years following the games, in the late 1960 s and r97os, advertisements for electric appliances such as television sets, refrigerators, and washing machines emphasized the influence of Japanese culture (in terms of choice of colour, craftsmanship and affinity with nature) despite the products owing much to
Western know-how. This reflects a consciousness among the Japanese that although they often borrowed ideas from elsewhere, considerable time and energy were expended in making the ideas their own. From the i 98 os, electronics became decontextualized from national space. Instead, users of technology moved around the world. 55 This is perhaps just as well, as technology labelled 'Japanese' was increasingly being manufactured offshore and there were no barriers as to who could consume the products.

\section{CONCLUSION}

This essay has shown that elements of nationalism and internationalism, ${ }^{5}$ tradition and modernity, authoritarianism and democracy have been part of Japanese attitudes to the body since late last century. Participation in the Olympics involved the

\section{FI GURE 5}

'All people are equal under the law...', Jinken yôgo (The Protection of Human Rights) black and white picture postcard series (Tokyo: Tokyo Legal Affairs Bureau, no date).

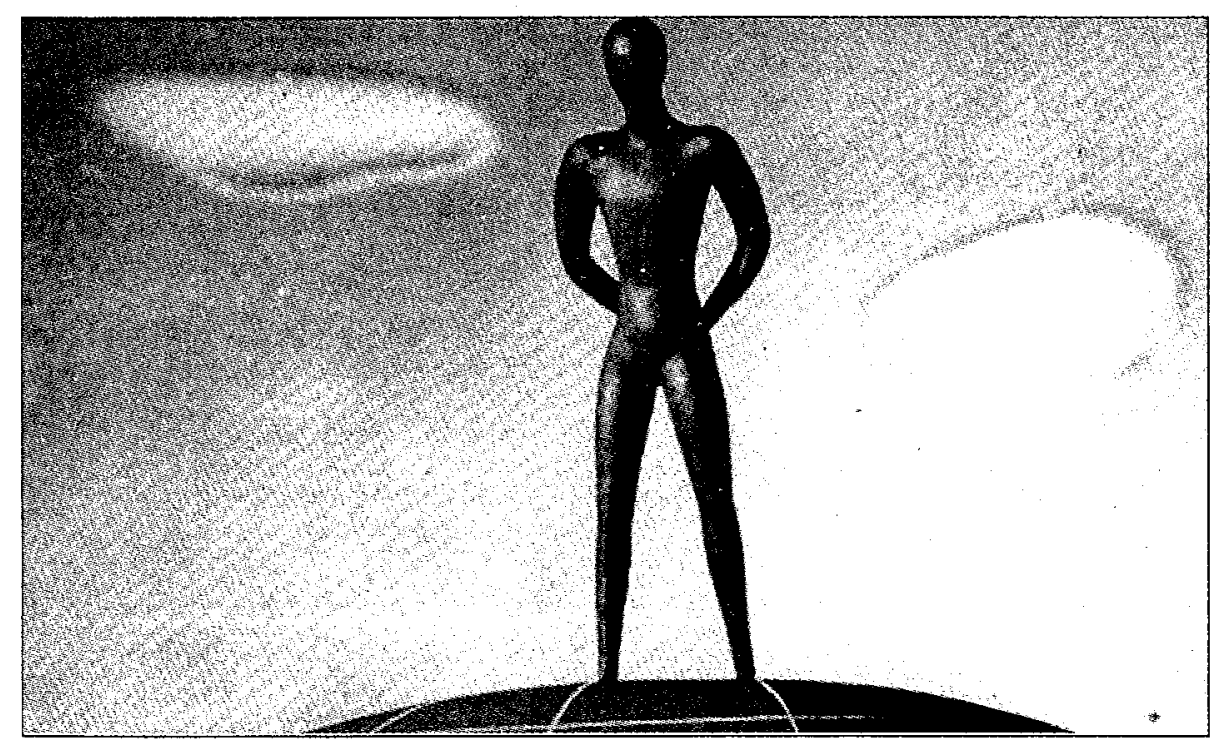


introduction of sports and obeying rules of competition. Through these rules and regulations, the Games helped create a world culture of the body where nationality was a sub-text. ${ }^{57}$ The 1964 Tokyo Olympics enabled Japan to present a new image to the world, one more inkeeping with its postwar priorities. It also spurred on the development of Tokyo, transforming it into a city, a space with modern infrastructure.

The Olympics ostensibly helped draw the line between the hardship of the immediate postwar years, and a more prosperous future, courtesy of high economic growth. Advertising images, photographs, films, and even the view from the train window, all referred to in this essay, were powerful modes of representing modernity in Japan.$^{8}$ These representations and written accounts of the 1964 Tokyo Olympics reveal to us how the Japanese were readmitted to the family of nations. But as we have seen, many Japanese and foreigners left the Games knowing that the Japanese were somehow different, for the modernity which emerged was of their own making, one which successfully coupled both local and global worlds. We are coming to realize that there are many modernities in Asia, and that the world is not all the same. As Tani Barlow has found, Asian modernities 'perform their own recodings of the discourses of modernity'.59

Media representations of the Olympics provide a window to understanding how host nations portray themselves. In the case of Japan, identity seems somewhat fluid. What will the Sydney 2000 Olympics say about Australian identity? The 1956 Melbourne Olympics provided Australia with an opportunity to perform on the international stage, and to define itself. ${ }^{60}$ Since that time, the forces of globalization have changed the way Australians view themselves. ${ }^{6}$ How will the Sydney Olympics be remembered? As the foreign visitors to the 1964 Olympics reported, it is often not so much 'place' but individual moments (of sporting excellence) which may stay in the memory. Will this be the case in 2000 ? By examining images of the sort described in this essay, we can understand how the mass media help us to frame the past and our identity in ways we are just beginning to understand. $\infty$

\section{MORRIS LOW}

Morris Low is Senior Lecturer in Asian Studies at the University of Queensland. He is a historian of Japan and has published extensively in the history of science and technology. This essay is part of a larger project on the history of Japanese visual culture and representations of masculinity.

\section{ACKNOWLEDGMENTS}

I am grateful to two anonymous readers whose constructive comments helped me to substantially revise this paper.

\section{NOTES}

' Tani E. Barlow (ed.), Formations of Colonial Modernity in East Asia (Durham, N. Carolina: Duke University Press, 1997). 
2 Jean Comaroff and John Comaroff,

'Introduction' in Jean Comaroff and John

Comaroff (eds), Modernity and Its

Malcontents: Ritual and power in

postcolonial Africa (Chicago: University of

Chicago Press, 1993), xi-xxxvii, esp. p. xii, for a discussion of modernity.

3 Yoshio Sugimoto, An Introduction to Japanese Society (Cambridge: Cambridge University Press, 1997), pp. 253-54.

4 Barlow, Formations of Colonial Modernity in East Asia.

${ }^{5}$ Sharon A. Minichiello, 'Introduction' in Sharon A. Minichiello (ed.), Japan's Competing Modernities: Issues in Culture and Democracy, rgoo-rg3o (Honolulu: University of Hawaii Press, I998), pp. I-2I, esp. p. 2.

${ }^{6}$ Ikari Seiya, 'Supôtsu: Kokusaika to taishûka' in Minami Hiroshi (ed.), Shôwa bunka: rg25rg45 (Tokyo: Keisô Shobô, r987), 504-27.

${ }_{7}^{7}$ Sabine Frühstück, 'Unveiling the Nerve of the Nation: Neurasthenia, Public Health, and the Building of Japan', unpublished paper originally presented at the Association for Asian Studies annual meeting, Washington D.C., 1998 .

${ }^{8}$ Yoshimi Shunya, 'Undôkai no shisô: Meiji Nihon to Shukusai bunka' ('The Athletics Meet: The festival culture of Meiji Japan'), Shisô, 845 (r994), 137-62.

9 Susan Brownell, Training the Body for China: Sports in the moral order of the People's Republic (Chicago: University of Chicago Press, 1995), p. 46.

${ }^{10}$ Ikari, 'Supôtsu: Kokusaika to taishûka'.

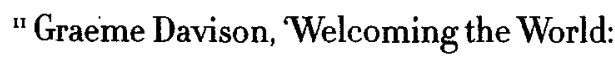
Melbourne in I956', in Juliana Engberg (ed.), r956: Melbourne, modernity and the $X V I$ Olympiad (Bulleen, Victoria: Museum of Modern Art at Heide, 1996), 49-57, p. 49.

'2 'Welcome', The Asahi Sports, May r923, p. 2.
${ }^{13}$ Grant K Goodman, 'Athletics as Politics: Japan, The Philippines and the Far Eastern Olympics of I934', Pilipinas, 2o, Spring 1993 , $55^{-66}$.

${ }_{14}$ Florence M. Taylor, $A$ Pot-Pourri of Eastern Asia: With comparisons and reflections (Sydney: Building Publishing, 1935), p. 208e. It has been suggested that the surfing individualism which Taylor was referring to also co-existed with regimentation and discipline which Taylor admired in the Japanese. See Ed Jaggard, The Australian Surf Lifesaver as a National Symbol, r9206o', in David Day (ed.),Australian Identities (Melbourne: Australian Scholarly Publishing, I998), $5^{8-72, \text { p. } 62 .}$

${ }_{55}$ Taylor, A Pot-Pourri of Eastern Asia, p. 208.

${ }^{16}$ Kenneth R. Dutton, The Perfectible Body: The Western ideal of physical development (St. Leonards, NSW: Allen and Unwin, 1995), pp. 205-9; Deobold B. Van Dalen, Elmer D. Mitchell and Bruce L. Bennett, $A$ World History of Physical Education (New York: Prentice-Hall, 1953), pp. 240-41, 342, 58o.

${ }_{77}$ Shimomura Torarokuro, Matsuda Kaizo (trans), Seinendan: Young Men's Leagues of Japan (Tokyo: Federation of the Young Men's Leagues of Japan, 1937), p. r.

${ }^{18}$ Tessa Morris-Suzuki, 'Debating Racial Science in Wartime Japan', Osiris, $\mathrm{r} 3$, in press.

${ }^{19}$ See Herbert P. Bix, 'Rethinking "EmperorSystem Fascism": Ruptures and continuities in modern Japanese history'; Gavan McCormack, 'Nineteen-Thirties Japan: Fascism?', Bulletin of Concerned Asian Scholars, 14, 2 (1982), 2-19, 20-33.

${ }^{20}$ Kaji Ryûichi, Japan: Her cultural development (Tokyo: Society for International Cultural Relations, 1939), P. 57. Japanese names are given in Japanese order throughout this paper unless the author has resided abroad for an extensive period. 
2x Tani E. Barlow, 'Editor's Introduction', Positions, I, I (I993), v-vii.

${ }^{22}$ The Society for International Cultural Relations (Kokusai Bunka Shinkokai), Sports, second impression, KB.S. Foto Series on Japanese Life and Culture, Vol. I (Tokyo: The Society, I939), pp. ii-iii.

${ }^{23}$ Edward Seidensticker, Tokyo Rising: The city since the Great Earthquake (New York: Alfred A. Knopf, r99o), pp. 102-103.

${ }^{24}$ Inoue Shun, 'Budô: Invented tradition in the martial arts' in Sepp Linhart and Sabine . Frühstück (eds), The Culture of Japan as Seen Through its Leisure (Albany: State University of New York Press, r998), 83-93.

${ }_{25}$ 'International Exposition of Japan in $194^{\circ}$ to be held at Tokyo and Yokohama to Commemorate 2,6ooth Year of Founding of Japanese Empire'; The Japan Trade Review, I1.2, (March I938), 37-44, esp. p. 37 .

${ }^{26}$ Miriam Silverberg, 'Remembering Pearl Harbor, Forgetting Charlie Chaplin, and the Case of the Disappearing Western Woman: A picture story', Positions, I.I (I993), 24-76, pp. $40-41$.

${ }^{27}$ Shin Mizukoshi, 'Social Imagination and Industrial Formation of Television in Japan', Bulletin of the Institute of Socio-Information and Communication Studies, University of Tokyo, March I996, I-14.

${ }^{28}$ 'A Historical Outline of the Development of Manchurian Railways', Contemporary Manchuria, 3.3 (July 1939), 36-6r. Also see 'Manchuria's Super-Express "Asia", Contemporary Manchuria, Vol.2, no.I, 45-6o.

${ }^{29}$ Nicholas Mirzoeff, An Introduction to Visual Culture (London: Routledge, 1999), p. 29.

${ }^{30}$ O. S. Nock, Railways of the World, Vol. 5 : Railways of Asia and the Far East (London: Adam and Charles Black, I978), p. I99.
${ }^{3}$ Kamitsuka Akihiro, 'Reform of the Red-Ink Railroad', Japan Quarterly, 33.I (JanuaryApril I986), 25-30.

$3^{2}$ Aoki Kaizo, 'The National Railways', Japan Quarterly, 8.I (January-March I96I), Io6-I3, esp.p. II3.

${ }_{33}$ Article by G. Freeman Allen and R.K. Evans in Modern Railway (October I963), cited in "The Future on Rails', Japan Quarterly, I1.4 (I964), 407-ro, esp. p. 410.

34 Yoshimi Shunya, 'The Cultural Politics of the Mass-Mediated Emperor System in Japan', paper presented at the conference Dialogue with Cultural Studies, Institute of SocioInformation and Communication Studies, University of Tokyo, I996, for a discussion of how an ordinary train ride can be a highly visual experience, with advertisements for weekly mass magazines suspended from the ceiling above the heads of passengers.

35 Davison, Welcoming the World', p. 49.

${ }^{36}$ Susan Sontag, 'Fascinating Fascism', New York Review of Books, 22, I (1975), reprinted in Susan Sontag, Under the Sign of Saturn (New York: Doubleday, I980), 73-105, for a discussion of the film.

37 Stephen S. Large, Emperors of the Rising Sun: Three biographies (Tokyo: Kodansha International, 1997), p. I $9^{2 .}$

${ }^{38}$ Andrew Bonnell, 'Director's Cut', The Australian's Review of Books, 4. 5 (June I999), $5,6,27$.

${ }^{39}$ Lynne Kirby, Parallel Tracks: The railroad and silent cinema (Exeter, Devon: University of Exeter Press, 1997), pp. 250-51, for a discussion of the convergence between trains and the cinema.

$4^{\circ}$ Fuji Photo Film Co. Ltd., Japan: Tokyo Olympic Year (Tokyo: Fuji Photo Film, 1964). I would like to thank Peter Davidson for providing me with a copy of this book. 
${ }_{4}^{4}$ Yoshimi Shunya, 'Urbanization and Cultural Change in Modern Japan: The case of Tokyo', Tôkyô Daigaku Shakai Jôhô Kenjyûjo Kiyô, 48 (December 1994), 139-55; Yoshimi Shunya, Toshi no doramaturgii: Tôkyô sakariba no shakaishi (Tokyo: Kaibundô, 1987).

$4^{2}$ Roman Cybriwsky, Tokyo: The changing profile of an urban giant (Boston: G.K. Hall, 199I), pp. 9I-92.

${ }^{43}$ Cybriwsky, Tokyo, p. 9 I.

${ }_{44}$ Cybriwksy, Tokyo, pp. $9^{1}-9^{2}$.

45 Cybriwsky, Tokyo, p. 93.

${ }^{46}$ Neil Allen, Olympic Diary: Tokyo 1964

(London: Nicholas Kaye, I965), p. 6.

${ }_{47}$ Allen, Olympic Diary, p. 6.

${ }_{4}^{8}$ Allen, Olympic Diary, p. 99.

${ }^{49}$ Christopher Brasher, Tokyo 1964: A diary of the XVIIIth Olympiad (London: Stanley Paul, I964), p. r.

${ }^{50}$ Brasher, Tokyo rg64, p. 4.

${ }^{5}$ Brasher, Tokyo rg64, p. 17.

${ }^{52}$ Brasher, Tokyo Ig64, p. 19.

${ }_{53}$ Brasher, Tokyo rg64, p. 104.
${ }^{54}$ Mainich gurafu (Mainichi Graphic), special issue, 3 November I964, p. I7o. Thanks to Peter Davidson for kindly providing a copy.of this publication.

${ }^{55}$ Yoshimi Shunya, "'Made in Japan": Cultural politics of "Home Electrification" in Postwar Japan', paper presented at the 'Electronic Identities in East Asia' conference, Humanities Research Centre, The Australian National University, February 1998.

${ }^{56}$ T.J. Pempel, 'Contemporary Japanese Athletics: Window on the cultural roots of nationalism-internationalism', in Sepp Linhart and Sabine Frühstück (eds), The Culture of Japan as Seen Through Its Leisure (Albany: State University of New York Press, I998), $13-37$.

${ }^{57}$ Brownell, Training the Body for China, pp. 37, 3II.

${ }^{8}$ Mirzoeff, An Introduction to Visual Culture, p. 65 .

59 Barlow, 'Editor's Introduction', v-vii.

${ }^{60}$ Davison, Welcoming the World', p. $5^{\circ}$.

${ }^{61}$ Robert Holton, 'Globalization and Australian Identities', in David Day (ed.), Australian Identities (Melbourne: Australian Scholarly Publishing, 1998), 198-2Ir. 


\section{THE PROJECT OF NATIONALISM: \\ CELEBRATING THE CENTENARY IN \\ PHILIPPINES GONTEMPORARY ART}

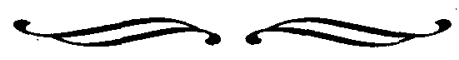

T he celebration of the Philippine Centenary was a major event, particularly so because of the substantial funding provided for it by the national government as well as the establishment of a body, the National Centennial Commission (NCC), to oversee its programs over a two-year period. Activities commenced in 1996 the centenary of the beginning of the Philippines' revolution against Spanish colonial rule. Popularly known as the Philippine Centennial, $1898-1998$, the biggest commemoration occurred on Independence Day, 12 June $1998 .{ }^{\circledR}$

The Philippine Centennial can be characterized as an event consisting of multiple nationalist projects and intersected by plural agendas. Ultimately its goal may be perceived as a reification of the belief in the nation-state. Nevertheless the nationalist projects were interpreted differently by the citizens of the Philippines whose allegiances are similar but whose practices are not. This makes for an interesting study regarding the effect of the Philippine centennial celebrations on the process of making art in the country's urban areas. More particularly, I am keen to see how representations of nationalist sentiments are reinforced through financial support as well as ritualized actions and occasions. In this essay, I will provide examples to support my notion of the ways in which stereotypes of images are recontextualized and beliefs change despite the desire to fix them through political motivation and historical accounts. This is evident in works of art using national dress and the flag as the theme, motif, and inspiration. In addition, the Philippine Centennial can account for rehearsing. anti-colonial nationalist narratives, and excluding other forms of nationalism.

Despite the rhetoric of anti-colonialism, the complex relationship of Filipinos with their former colonizer is still evident in the sense that some actions seem to glorify the Spanish presence in the Philippines. For instance, financial support from the NCC towards refurbishing public buildings influenced by Spanish colonial architecture created a wave of nostalgia among the elite, to the extent that they began renovating their ancestral homes in the provinces. Meanwhile, local researchers were determined to establish the Filipino agency in those Hispanic- 
influenced buildings. Ambiguous colonial relationships are also evident in some contemporary artistic expressions found during the Philippines Centennial celebrations. While the official events waved the banner of patriotism as a naturalized aspect of being Filipino, these contrasted with the yearning to come to terms with the colonized past. This was made obvious by remembrances of key moments surrounding the declaration of independence in 1898 , hence the frequency in NCC programs of reenactments of events from a century ago. This is also prevalent in museum shrines of Philippine heroes: visitors are made to re-live the past through multimedia exhibitions. The search for an idiom to reconstruct pivotal moments of the nation's history seems crucial to arrive at an understanding of nation and national identity among Filipinos.

In a way, the official NCC events tried to narrow some of the possibilities of artistic expression to the extent of legitimizing mainly literal and hackneyed renderings of nationalism and national identity. Yet even in some of the narrower spaces of artistic discourse, interpretations were made in compelling ways, pointing to other possibilities of constructing images of Filipino identities.

\section{FIGURES OF ART}

Apart from the projects of the National Centennial Commission (NCC), other government institutions such as the Cultural Centre of the Philippines (CCP) and the National Commission on Culture and the Arts (NCCA) worked with the NCC on art exhibition projects. Among those at the CCP were the Igkas-Arte (Resilient Art) ${ }^{2}$ and Sining Sentenaryo (Centenary Art) exhibitions. At the NCCA galleries, a display of artists' interpretations of the Philippines flag entitled Watawat (Flag) was included in its many nation-wide programs. Many of these exhibitions were marked by monumental or installation works of art and tableaux of life-sized mannequins. Of the three I mentioned above, only Igkas-Arte was toured nationally (see figure $\mathrm{I}$ ).

FIGURE I

Tableau of Pabasa (Singing the Passion of Christ), from the Igkas-Arte exhibition, Cultural Centre of the Philipines. Photographed by Julio Sambajon.

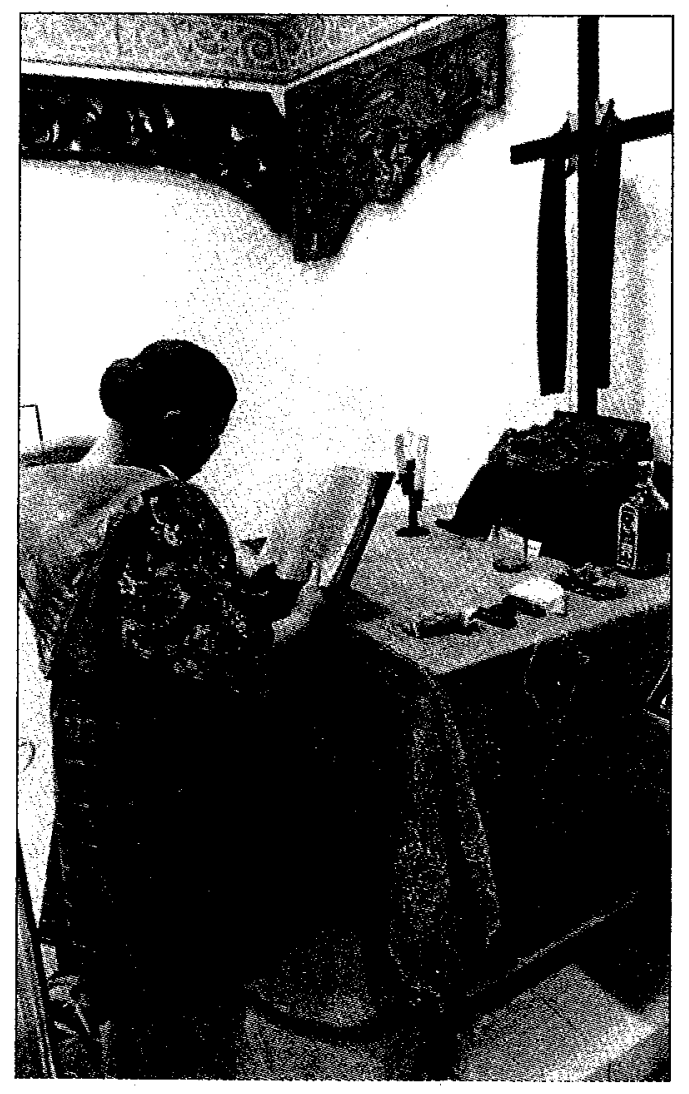


Private foundations similarly engaged in exhibition projects in collaboration with the NCC. The Art Association of the Philippines (AAP) called its annual art contest the Centennial National Painiting Competition ' 98 . Held at the Museo ng Sining (Museum of Art) in Manila, the majority of prizes were awarded to Manila-based painters at the exhibition opening. This occurred despite the AAP's first attempt to hold a national competition. On the other hand, the Metropolitan Museum of Manila (Met), organized an exhibition on a theme taken from a phrase of the national anthem. Alab ng Puso (Fire of the Heart) - perhaps to evoke the intensity of passion for nation. This phrase was interpreted by twenty-two Filipino contemporary artists in celebratory or critical works of art. Most of them conformed to the curatorial brief by creating massive or life-sized art pieces.

Not all exhibitions sought funding from the NCG, however. This demonstrates the desire of some groups to work outside the official framework of celebrating the centenary. For instance, the Far East Bank Company organized a national touring exhibition of art from its collection. ${ }^{3}$ Galeria Duemila, on the other hand, displayed human scale terra cotta sculptures by Julie Lluch at the art centre of a big shopping mall. These sculptures portray various representations of Filipino women as Lluch's ode to the history of the Philippines and Filipino women's responses to it. This is a remarkable project considering the competition of images from the commercial space of the mall. Even the NCCA used the same space to exhibit works of art for their selffunded project, entitled Diwa ng Sining (Soul of Art).

What is interesting in all these visual arts programs for the Philippine Centennial is the tendency for figurative images to take precedence over abstract or non-objective art. Produced mainly for the NCC project, most contemporary works of art were made in the likeness of human figures that stereotyped a particular Filipino iconography. For instance the depiction of figures with apparently Malay features and dressed up in Spanish-influenced costumes was common in old and contemporary works of art that were selected for exhibition. Moreover, the works of art were predominantly portraying a narrative of a dramatic historical event or an image of a hero of the revolution. Many artists tried to fit into the demands of commissions from the NCC. Among them was Bencab whose works in the last ten years have become increasingly symbolic images of Filipino women. In his last project-producing illustrations for a book on national hero Jose Rizal-Bencab's figurative drawings became popular iconography for other artists working within the official centenary programs.

Most of the abstract art was limited to the theme of the Philippines' flag, yet again reinforcing nationalist sentiments. The practice of depicting flags to connote devotion to nation is perhaps 
uncharacteristic of non-colonized countries. However, in colonized countries, flag images have served to evoke patriotic feelings or make a work identifiable as a work by someone from that particular country. But as in any national flag it is the bearer of the people's, or community's, cultural-political project. Before the formation of nation-states, armies and guilds used banners. Symbols, such as coats-of-arms were super-imposed on cloth, metal, or wood. With the rise of nation-states, colours and symbols were standardized. Red, blue, and white, for example, symbolized libertarian ideals. The number of star emblems on flags signified states, provinces, dominions, and islands. It is interesting to note, further, how certain colours are grouped on a flag among a collection of countries within the same region. In contrast to flags found in Africa whose colours are principally green, white, and yellow, those in Southeast Asia are predominantly white, blue, and red. Among the works of art incorporating the Philippine flag theme in the centennial exhibitions, I found that the challenge for artists was to denote the flag distinctively as they applied it to their representational compositions.

Notably, as I will demonstrate in a later section, the artistic process of solving a pictorial problem using the elements from the design of the Philippine flag, serves to re-contextualize it. Rather than be constrained by constitutional restrictions imposed on the alteration of the flag, Filipino artists were able to make use of it more creatively. This has rendered the flag and its emblem open to interpretation beyond the confines of the official nationalist narrative as expressed by the NCC.

The emphasis of NCC projects on reenactments of key moments in Filipino history may be understandable as they act as the representative of the nation-state and they alone can legitimize the authentic Philippine culture. There is tension, however, when there is disagreement over their interpretations compared with the interpretations of those on the ground or those who were excluded from participating in the official celebrations. Some artists believed they were not invited to exhibitions or did not win centennial-theme competitions because their work did not quite fit the standard artistic representations favoured by the NCC. Others presume they just did not have the right connections and therefore could not negotiate for grants or commissions.

Critics have suggested that methods used by the NCC may be likened to strategies employed by the Spanish colonizers. Eventually, the natives of the Philippines appropriated the same strategies to benefit themselves. A discussion of Philippines' contemporary art, especially one that connects rather directly to Spanish colonial art and its practices, is not complete without considering the response of converted Filipinos to religious art. The Roman Catholic Church has exerted influence over Philippine 
State policies that affects people's lives up to the present. What is interesting even with these constraints, however, is the creativity of the Filipinos' ripostes.

Historian Vicente Rafael, citing Reynaldo Ileto, ${ }^{4}$ claims that religious conversion was used by the Spanish to gain control over the colony. He notes:

Religious conversion was crucial to the consolidation of Spanish power in the Philippines. But as Reynaldo Ileto has convincingly shown, Catholicism not only. exercised a profound impact on the patterning of notions of authority and submission in colonial society; it also furnished the natives with a language for conceptualizing the limits of colonial and class domination. The idiom of religious conversion was crucial, then, for this reason: it shaped the terms of native surrender just as it lent itself to the articulation of popular resistance to a colonizing power. 5

In this sense, the introduction of European painting to the Philippines through religious art offered a vocabulary and a way of articulating something Filipino in a new idiom, allowing them to imagine themselves as visually empowered. This empowerment would have begun when local artists were allowed to paint without restrictions from the church, following an edict from the Spanish king Carlos III, in ${ }_{7} 85$. As Villegas disclosed:

Previously, the clergy treated religious art almost as a monopoly, commissioning works which they took care of distributing. Deregulation of their art permitted artists to paint for a larger market, paving the way for the development of secular art. ${ }^{6}$
This promoted opportunities for artistic expression, to chronicle events, and, more importantly, to gain economic advantage. Whereas in the past local artists were limited by having to work within the confines of church patronage, the secularization of art created other prospects for representation. Artists found other ways of constructing their images, much less hampered by ecclesiastical requirements of faithfully copying European models. As a result, more artists developed painting skills that satisfied the demands of a new economic class.

Members of this class engaged in vigorous commercial trade and travel in the $186 \mathrm{os}$ after the opening of the Suez Canal. The shorter route also meant that luxury goods such as art materials and European works of art were more quickly transported.

Among those who developed their painting skills locally were Vigan-based Esteban Villanueva and Manila-based Simon Flores. Self-taught painter Esteban Villanueva (I798-I878) was commissioned by the colonial government to document pictorially the Basi Revolt. $\mathrm{He}$ created fourteen scenes that featured the uprising in the Ilocos region during the early nineteenth century. The revolt ensued after the colonial government imposed a monopoly on wine manufacturing. Presently housed in the Burgos Museum in Vigan, Ilocos Sur, the Villanueva paintings have been widely ćited during the Philippine Centennial both as a chronicle of social transformation and an early example of 
'Filipino' artistic expression.7 Simon

Flores, on the other hand, enjoyed patronage from the new elite to do commissioned portraits. Having studied painting with academically-trained Spanish teachers at the Academia de Dibujo y Pintura ${ }^{8}$ (Academy of Drawing and Painting) in Manila, Flores gained a steady clientele, many of whom are represented in his paintings formally dressed and surrounded by luxurious interiors. Like Villanueva's paintings, Flores' oil portraits have survived time and tropical conditions. They are presently held in a few museums and personal collections, frequently cited during the centenary celebrations as vivid manifestations of Filipino artistry. Figurative painting particularly has enjoyed contemporary patronage for its ability to elicit nostalgia for the primordial past and incipient nationalism.

\section{SARTORIAL CENTENNIAL}

What is more important in the process of reification of a nationalist ideology is the relocation of artists such as Villanueva and Flores in Philippine art history. Devices that call attention to them, such as exhibitions and textual citations, have made it expedient to think about the many possible images that they selected to paint. Both of them, for instance, chose to depict their subjects with dignity. These were residents of the Philippines of mixed ancestry who were usually victims of colonial discrimination. At that time, the 'pure Spanish' or españoles peninsulares, were considered at the top of the racial echelon. Forms of clothing seem to be the best device to identify the artists' subjects-dress, like other aspects of everyday life, constructs the identities of the wearers. As Tarlo suggests:

Like other social phenomena, clothes are often dehistorical, naturalized, converted to myth... Yet at the same time they are detachable, thereby denying the very permanence they sometimes seem to suggest. They are both part of us and superfluous to us. What this suggests is not that clothes have any particular meaning, but that their peculiar proximity to our bodies gives them a special potential for symbolic representation. ${ }^{9}$

The visual presence of special clothes during the Philippine Centennial celebration was partly the result of a policy enforced in most government offices.

Apart from allowing occasions to dress up, employees had to wear characteristic Filipino costume. Unlike the male national costume that has been used as business attire, women's clothes departed from the traditional gala dress to allow them more freedom of movement to carry out their work.

For the men, the uniform required every Monday was the formal Barong Tagalog (or Tagalog Shirt)-a long- or shortsleeved shirt made out of transparent material, split at the sides up to the waist and buttoned at the front. Men wear this shirt hanging outside the trousers with a vest underneath. Sometimes the front of the shirt is embroidered with a design in a 
neutral colour similar to the shirt (i.e. ecru or pale blue).

The women's costume, known as Baro't Saya (Blouse and Skirt) may vary but customarily involves a loose white or ecru embroidered, transparent blouse over a slip. This is worn with a long printed or plain skirt. Although less formal looking than the Terno, the Baro't Saya is more comfortable for office wear. The Terno is still considered the archetypal national dress and has also evolved through the years from a five-piece heavily starched costume (as depicted in many nineteenthcentury paintings and prints) to a onepiece butterfly-sleeved long gown. The authenticity of this national dress is demonstrated by its display during official state functions when it has been worn by the wives of the Philippines' presidents.

Former First Lady Imelda Marcos popularized the Terno by wearing it consistently during her husband's term of office. This national costume is worn exclusively by the upper class and beauty contestants rather than by Filipino women in general. Apart from the restrictive construction of the Terno, the favouring of the Baro't Saya as popular Centennial costume satisfies the requirement of a 'Filipiniana' dress. Moreover, since the Terno seems to be closer to colonial-style clothes, the Baro't Saya fits the anticolonial sentiment consistently expressed during the Centennial celebrations. In this sense the enforcement by official policy to wear Filipiniana has brought about a process of negotiating a standard form of dress. By insisting on wearing the Baro't Saya, female government employees were directly involved in the process of reconsidering what constitutes the national dress.

These forms of dress were popularly known as Filipiniana-a term that is rich in irony because, although it is patterned after a European style of colonial dress, it is restructured to suit local residents' bodies. Towards the end of the centenary celebration, the term Filipiniana was eclipsed by the widely-used 'Centennial' to denote the national dress. Centennial clothes were still only worn on special occasions because of their impractical design and because they were antithetical to the modern, everyday clothes that most Filipinos have become accustomed to wearing.

The negotiation over national dress was also taking place in the art exhibitions for the Centennial commemoration. I have observed a correlation between images from historical paintings and the promotion of national costume in, for example, the display of nineteenthcentury paintings and prints by the Far East Bank for its national touring exhibition which seems to suggest that the choice of images was more than incidental. The organizers of the exhibitions may, perhaps, have selected works of art that depicted costume they deemed to be Filipiniana to stereotype a look that contributed to a particular Filipino iconography. Yet despite the tendency to use this criterion for other 
FIGURE 2

Brenda Fajardo, Ang Tipan Ni Ynang Bayan (The Testament of Mother Land). Photographed by Dick Baldovino.

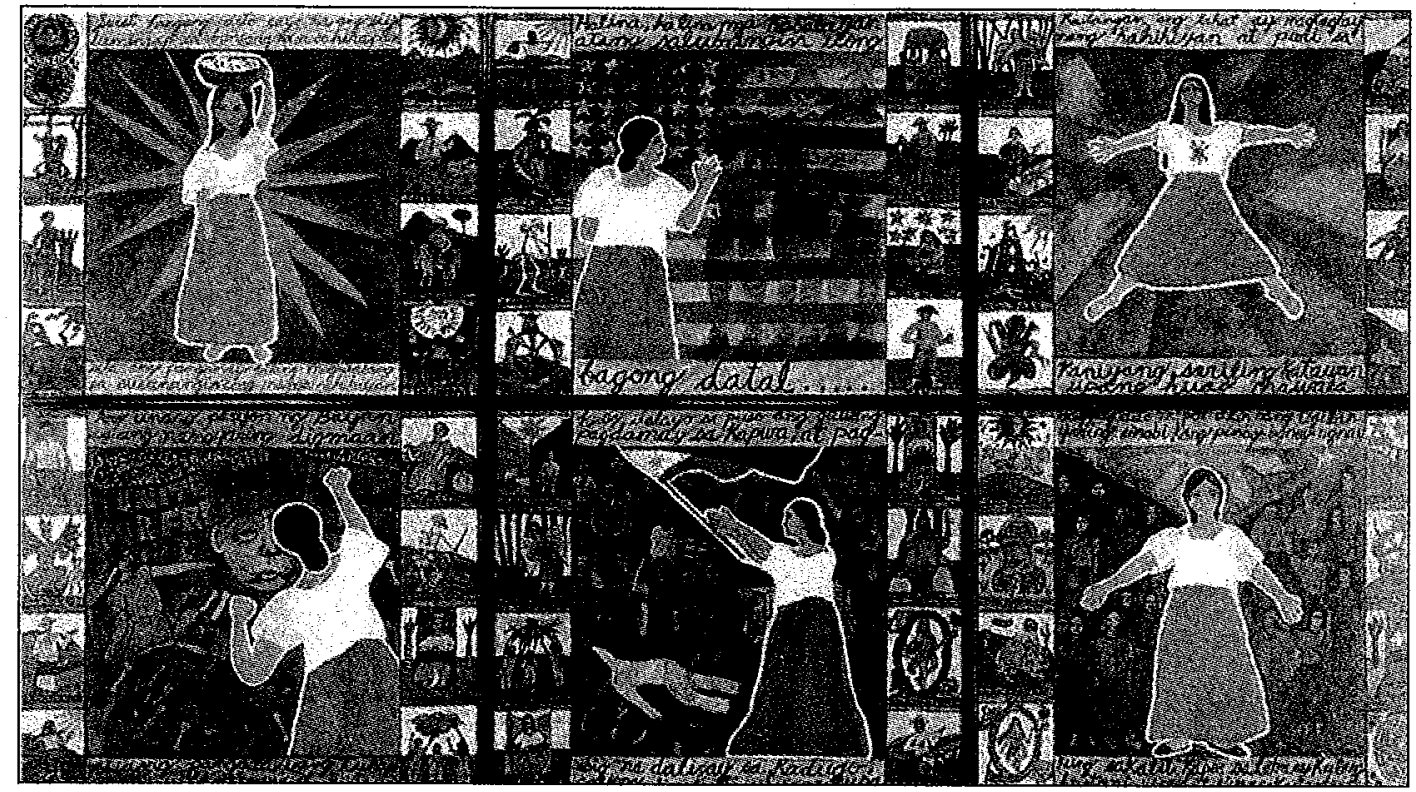

exhibitions, contemporary artists found different ways of evoking them, particularly in some of the artists' use of cloth and clothing as metaphors for constructing their own notions of national identity and expressing their anti-colonial sentiments.

In the Alab ng Puso exhibition at the Met, artists Brenda Fajardo, Ana Fer, and Pacita Abad, among others, incorporated cloth or clothing into their art. Fajardo dressed her central figure in a form of traditional peasant women's costume (a variation of the Baro't Saya) - the loose top painted white and the skirt, red - to signify Mother Land. In her insistence to dress Mother Land in Baro't Saya, Fajardo conveys her adherence to it as the true national dress (see figure 2).

Fer, on the other hand, chose to depict her cast of major characters of the revolution by painting them with identifiable features and costumes that may have resembled them in real life-their colonial clothes, as well as bearing, typify the historical visual accounts of these heroes. By featuring them in such clothes, Fer goes beyond creating stereotypes. She instead appropriates the clothes as a fashion statement, expressing the individuality of those heroes, as isolated as their life-sized cardboard cut-out, making them stand out from the rest despite their typical colonial costume (see figure 3 ).

Unlike these two artists, Abad chose to stitch together and paint pieces of cloth from different parts of the Philippines, creating an installation piece that resembles a Muslim wedding tent prevalent in southern Philippines. As a monument (at fifteen feet high and fifteen feet wide) to her twenty-year collection of 
cloth, as well as to the fabric of the

Philippines' life, she has put together an assemblage that renders the tentative veil of embroidered, transparent Centennial costume pale. It is a canopy of Abad's aspirations as she celebrates 'roo Years of Freedom', claiming the cloth monument as a national emblem that encompasses cloth designs from all over the country. Further, by putting the pieces of cloth together as a Muslim wedding tent, Abad contends that culture was very much alive before the Spanish 'discovered' the Philippines, since Islam antedated Christianity by centuries (see figure 4). In the examples above, the artists have defined and recast cloth and clothing to represent their idea of Filipinos as a social group, revealing how our minds are programmed to express something through cloth. Thomas Carlyle, the nineteenth-century British intellectual, sardonically reflected on this idea through his creation, the German philosopher of clothes, Herr Teufelsdröckh in Sartor

Resartus. He remarks:

Teufelsdröckh undertakes no less than to expound the moral, political, even religious Influences of Clothes; he undertakes to make manifest, in its thousandfold bearings, this grand Proposition, that Man's earthly interests 'are all hooked and buttoned together, and held up by Clothes.' He says in so many words, 'Society is founded upon Cloth'. ${ }^{\text {ro }}$

FIGURE 3

Ana Fer, Mga Panauhing Pandangal (Guest of Honour). Photographed by Dick Baldovino.

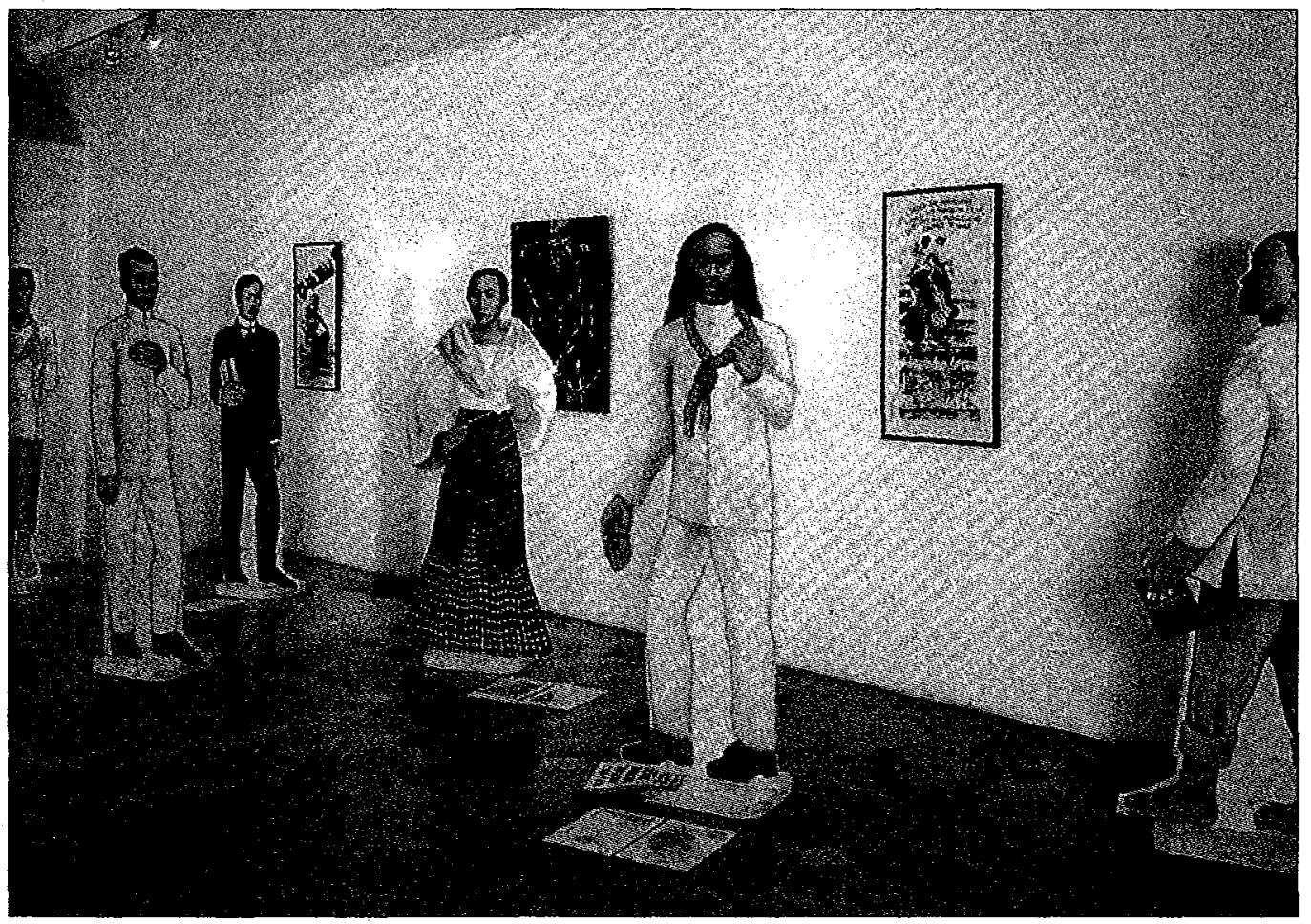


FIgURE

Pacita Abad, roo Years of Freedom - From Batanes to Jolo. Photographed by Dick Baldovino.

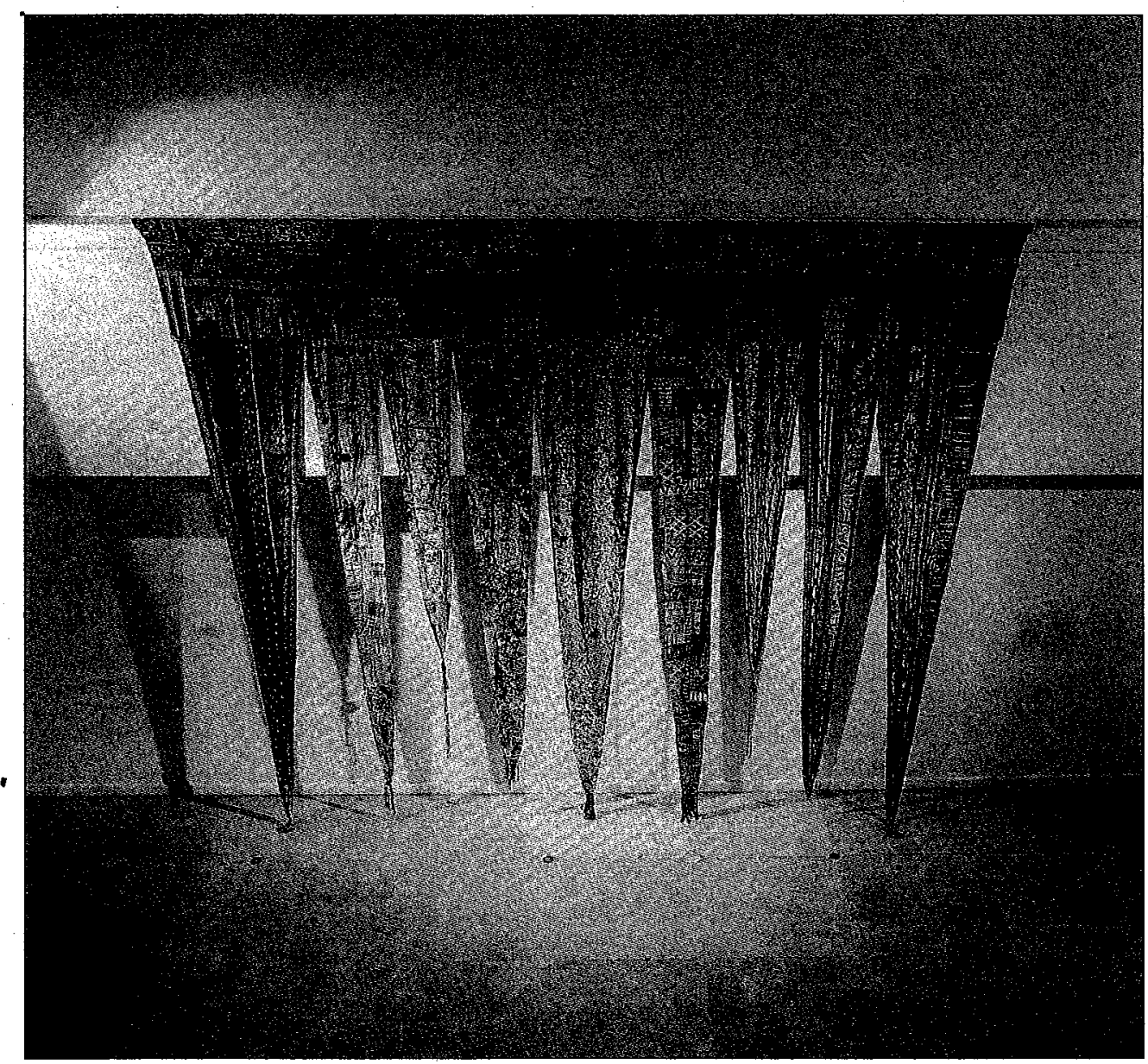

FLAG FETISH

Apart from clothing, another way by which cloth has been assembled to symbolize national identity is through flags. Unlike Abad's desire to have a truly national flag by incorporating other pieces of cloth in her patchwork tapestry, the standard colours of the Philippines officially represents the nation. A national flag is a prime example of cloth where a fixed image cannot be altered. The Philippines' flag is perhaps unique among the world's flags because it can be reversed to change its symbolism. In times of peace, the blue half is displayed above its red half and turned around with the red above the blue if the nation is at war. The white triangular patch on one side holds a central golden sun with eight rays and three golden stars at each corner. This is designed so that no matter if the blue or the red is overhead, the triangle motif remains symmetrical.

Nowhere have I encountered such excessive devotion to the flag as in the Philippines where it is honoured with a ceremony involving standing at attention and singing the national anthem. This ceremony is usually held outside government offices on Monday mornings, 
just before any theatre performance, and at the start of every last film show in cinemas. There is none of the sense of irony of wearing the emblem as the British are wont to do with the Union Jack.

The Philippines flag is a piece of cloth that cannot be transformed into clothing. To do so would be deemed a sacrilege to

Filipinos. The flag is synonymous with patriotism and national reverence which is perhaps one reason why the Philippines' flag became an obvious theme in the centenary art exhibitions and competitions. Fifty of the 177 entries for the AAP Centennial Painting Competition used the flag as motif or source of the white, blue, and red libertarian colour scheme. Moreover, as I have mentioned above, the NCCA organized Watawat, an interpretation of the flag by art students from the University of the Philippines. Likewise, of the twenty-two artists featured in the Alabing Puso exhibition, seven incorporated the Philippines' flag in their works of art, either as centrepiece or model.

One of the three monumental outdoor installation works for the Sining Sentenaryo exhibition was made by contemporary artist Junyee. For his 'Isang

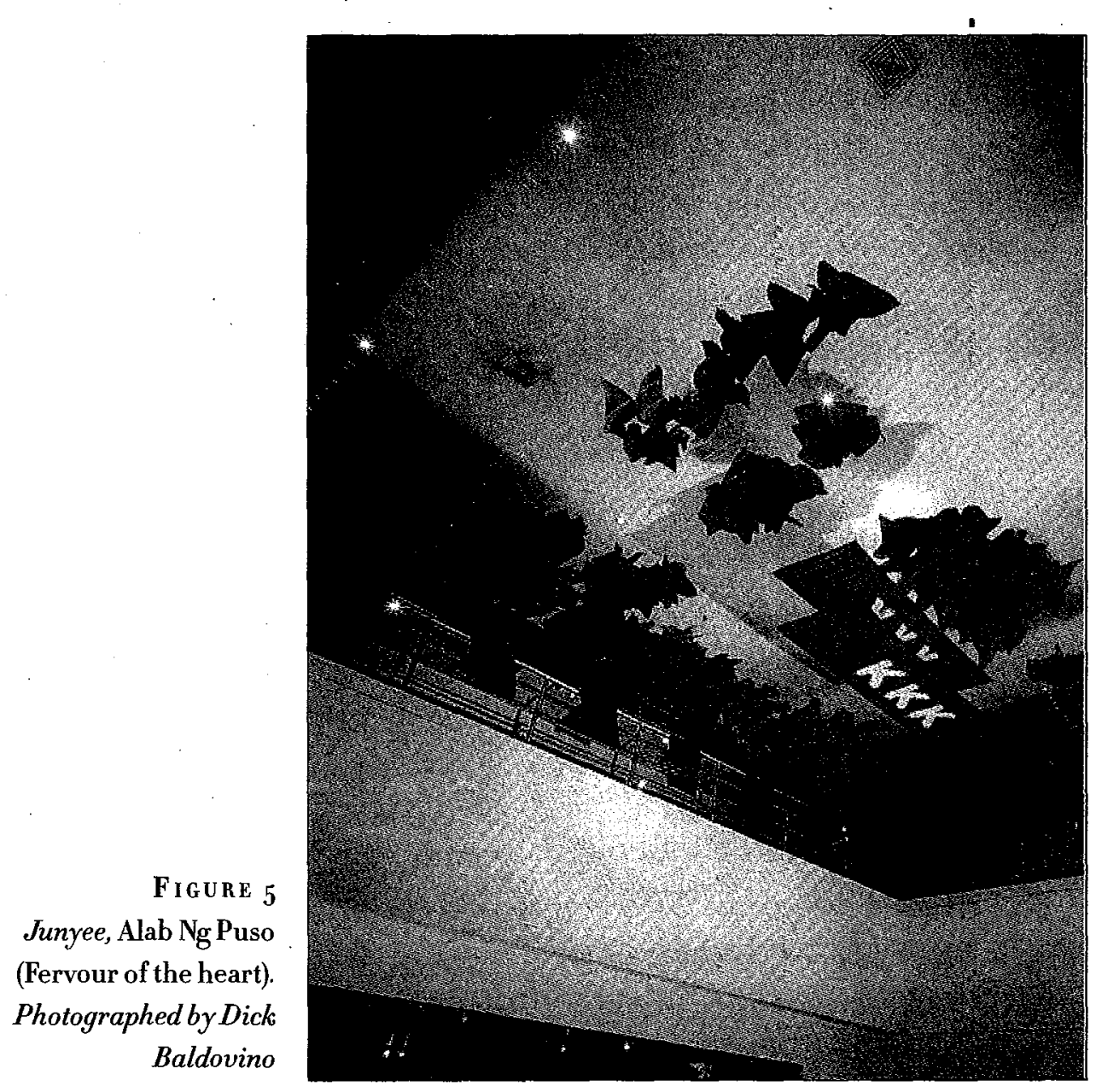


Daan' (One Hundred), he set up Ioo cloth flags inspired by the emblems of the revolution from roo years ago. The red flags with huge, white KKK letters used during the Philippines revolt, distinguished the front lawn of the CCP, amid traffic, tall buildings, and a magnificent water fountain. Junyee also took the revolutionary flag indoors at the Met exhibition, Alab ng Puso. There he cut out coloured tissue paper flags and banners and then suspended them on stretched nylon strings high on the railings of the Met's upper chambers. Rather than be constrained by the earnest flag fetish subscribed to by the NCC, Junyee chose to use the revolutionary flag as jubilant heraldry, akin to festival streamers. It is interesting to consider whether his work would have elicited a more emotive response had he used the contemporary Philippines flag. Although he used a blurry image of it juxtaposed against the KKK flag in his winning AAP entry, 'Dako Roon' (Over There), he did so only to set off the opposite categories between past and present (see figure 5 ).

In this act of incorporating the flag, the artists did not just endorse the nationalist narrative of the Philippine Centennial celebration, they also involved in their works a more complex assertion of primordial unearthing of self. Junyee chose to use the revolutionary KKK flag to give him more space to explore the meaning of flag as a banner of nationhood based on revolt against the colonial power. He chose it from amongst the other flags known to exist at the time of revolution because of its ties with the first recorded successful uprising and its symbolism of the tragic consequences of assertion for independence. Andres Bonifacio, the renowned founder of the Katipunan organization, which the K in the flag stands for, lost his life during a bitter power struggle over its leadership.

Nationalists consider him the embodiment of a true Filipino because they believe him to belong to the working class with few attachments to the mestizo (mixed blood) populations living in the Philippines.

Other artists preferred to use elements of the contemporary Philippines flag design in their work. Although it may seem that the motifs have become commonplace as a result of repetitive use of its colours and triangular design, the flag image's translation into other media represents a process of re-contextualization. The artists who used the elements from the present flag are, of course, subscribing to the accepted winning formula in order to gain centennial prizes and grants. But its transmission from standard cloth to oil, acrylic, or paper exonerates the artists from illegally altering the flag. The practice of painting, assembling, or sculpting the image of the flag perhaps changes the flag's significance more dramatically for the artists and consumers of the works of art than it would if it had just been seen displayed fluttering in its usual form. 
The works of art made during and for the centenary evoked the artists' efforts to get at the heart of what, indeed, is a Filipino. The pervasive images they constructed comprise far more meaningful reenactments than those devised by the NCC. These repetitive acts of creation and re-casting of images by visual artists are linked to rituals of belief and becoming.

\section{FIXATION ON NATIONALISM}

Anti-colonial nationalism characterized the totalizing narratives that ran through official Philippine Centennial events. Notwithstanding the lack of attention from politicians and the mismanagement of funds, ${ }^{\mathrm{II}}$ the centenary activities continued apace. These took place in different parts of the Philippines as well as in cities abroad that have big Filipino expatriate communities. In this essay, however, I have only taken into account the Manila art exhibitions.

NCC-financed projects focused on an official version of nation and nationalism, with an assumption that all Filipines must share their patriotic beliefs. But ideas of nationalism, like other aspects of people's existence, are a product of a combination of different cultures to which different people belong. The responses to nationalism or its reconstruction in art may be varied, contradictory, and subject to negotiation. The state, through its agents such as the NCC, tends to privilege a type of art that represents an anticolonial nationalism over other types of nationalism. In the Philippines the precedent for this in art were the forms promoted by the then President Ferdinand Marcos and his wife, Imelda. During their time, avant-garde Filipino art was given state support through exhibitions, museum spaces, and participation in international art competitions to project the conception of the new Filipino in the New Society promoted by the Marcoses. ${ }^{\text {t2 }}$ Only those who fitted their requirements were subsidized. This is true even today although it might be argued that current arts policy is much more constitutional.

The NCC's rather ambiguous criteria for selecting particular types of art projects allowed certain forms of tokenism to develop-as long as they did not deviate too much. For instance, in the outdoor installations at the Sining Sentenaryo at the CCP grounds, three artists were selected to convey the banner-fluttering of the celebration. Junyee's installation of Ioo flags was given the CCP front lawn rather than Sandra Torrijos's 'Templong araw para sa Kalayaan' (Sun temple for Freedom). Whereas Junyee's work of red KKK flags set on diagonal bamboo polés fitted the notion of action and stereotypical revolutionary fervour, Torrijos's was an art installation solemnizing repose. Multicoloured poles arranged in circular forms marked her work and, although their colours are akin to festival bunting, they are fixed as if poised to honour the sun. Torrijos's esoteric response to the curatorial brief seems to presume that the question of identity is larger than nationalism. But this 
may have been too metaphorical for the NCG curators, so her installation was placed on a less prominent site at the CCP grounds. It contrasted with the usual emotional appeal of official national celebrations. This is an example where the NCC found it difficult to control the outcome of most of their visual arts projects despite the public and corporate funds at its disposal. ${ }^{13}$

Culture became part of the national agenda and was prominent in diplomatic exchanges, manifested in programs that sought to renew the nationalism of Filipinos. The 'official' celebration that was managed by the NCC has been criticized as more prosaic than imaginative. Critics claim that most of its projects appeared as worn-out as the legislated wearing of Centennial costume each Monday in some government offices, or as tired as the compulsion to pledge allegiance to the Filipino flag at every chance the NCC was able to impose. Reviewing the activities celebrating the centenary of the past two years, it may seem that the rekindled enthusiasm for nationalism beyond the confines of banal devices is nearly at hand. It did not help that the NCC insisted on monumentalizing fleeting moments in the history of the Philippines through reproductions and re-enactments..$^{1 / 4}$ However, I would argue that the NCC did not have much control over most of their projects as many artists did not interpret the centenary celebrations according to the official version.
The NCC's supposed unimaginative programming, dissected and analysed in a number of Philippines' newspaper columns, created more controversy than the question of nationalism itself. Only a few journalists wondered about its anticolonial basis. In the Philippines, nationalism and national identity are generally regarded as unproblematic and to dispute anti-colonial nationalism is incomprehensible to the cultural and political elite (such as those members of the NCC). It is usually construed as a mark of treachery or a sign of 'colonial mentality'. This is one reason why the performances and exhibitions for the centenary celebrations rehearsed anticolonial sentiments. These activities featured what members of the NCC believe to be native Filipino practices, as distinct from colonial influences. Apart from the insistence on emphasizing Filipino agency in cultural production, such as in colonial architecture described above, certain arts activities were also selected on the basis of their identification as being primordial Filipino. This notion represents the Philippines as existing even before Spanish conquerors claimed the islands and named them, as a single entity, after King Philip II.

The discrepancy between historical accounts and local beliefs in the primeval nation created contradictions among Filipinos. These contradictions became sites of contest over rights, jurisdiction, and authenticity. The primordialists among the NCC members used the 
argument that indigenous groups who continued to engage in arts activities such as cloth-weaving and basket-making were evidence of the primacy of Filipino ingenuity over projects related to colonial civilization. Such an emotive postulation of a true Filipino culture was emphasized in most of the official centennial activities rather than an alternative conception of a Filipino identity that changes through time and whose authenticity is validated by practice and negotiation. For instance, the re-enactments were almost always focussed on the martyrdom of national heroes who fought for the right to become Filipinos. This seemed to uphold ideas that authentic Filipinos were born in the Philippines and could trace their roots among local indigenous groups. This appropriation contradicted the earlier label that Filipinos were the Spanish-born.

While the designation 'Filipino' has been taken for granted by citizens of the nationstate, it also brought into focus their differences in defining what is Filipino. Those in the lowland, Christian, and urban areas share ideas of being Filipino because of access to provisions made by the nationstate such as national universities and museums. On the other hand, those who live on the fringes far from access to those provisions have a more ambiguous image of themselves as Filipinos, tending, rather, to identify with their village or region. The Philippine centennial celebrations grew in importance at a time when Muslim groups in the south were pushing for secession and highland groups in the north remained indifferent to the nation-state.

The activities of the NCC expressed the desire for, rather than represented, a united nation. Anti-colonial sentiments seem to have fed into anti-colonial nationalism where official centennial celebrations insist upon a common Filipino history of war and oppression. The pledge of allegiance to the Filipino flag and the singing of the national anthem reinforce anti-colonial nationalism. As a result of this, the effort to assert the greatness of the Filipino remains pressing and expresses an aspiration to leave the marginal position of a former colony and enter the mainstream of national sovereignty. Yet Filipino identity remains for the moment a provisional condition where different definitions are constantly re-assessed and validated, like different sets of clothes being tried on until the majority finds one that fits all. In the process it is popular practice to raise the regard for Filipino culture at the expense of putting down other cultures, such as those of the Europeans. This may be perceived as a problem of insularity where the process of identity-formation is centripetal and colonialism is dismissed as an event rather than a process.

Alternatively, it could also be seen as a strategy implemented while other methods of defining national identity remain elusive.

Although the NCC agenda of instilling patriotic fervour among the citizens of the 
Philippines nation-state was emphasized, it was nevertheless construed in a number of 'unofficial' ways. The art exhibitions and competitions are evidence of artists' perceptions of their identities-national as well as those other elements that make up identities of persons, including gender, age, and ethnicity. The artists challenged figurative representation to the extent of resuscitating stereotypes from the past. As I have shown in this essay, the Filipiniana/ Centennial costume and the flag were two of the most favoured templates and inspirations. These were then reconstructed as an act of remembering and re-creating-much like Pacita Abad's cloth assemblage to fabricate a familiar, yet different, art form.

Art historian Patrick Flores analyses the power of artistic activity over other homologous political and cultural enterprises that are usually considered teleological. He observes that:

The act of painting constitutes not only a redescription of a world, but a certain world, a certain body of work and body politic. In itself a transformation of material into visual presence, it sets the condition of possibility of a world, and its world-ing in art. Art, however, makes sense only in the performance of its identity, in the manner in which it instantiates a determinate though reflexive practice of aesthetic education. ${ }^{15}$

In a sense, the NCC activities were part of a series of consensus-gathering activities designed to reify their official definition of a Filipino identity. Fortunately, the wall of nationalist discourse was rendered porous which enabled ideas to flow. These, in turn, provided the tension for renegotiating identities. Just like historian Vicente Rafael's assessment of religious conversion during Spanish colonialism, the official NCC celebration unintentionally devised a new idiom for contemporary Filipinos to recontextualize symbols of their identities through current practices and interpretations. Visual artists and even government employees who had to wear Centennial costumes every Monday sought ways to express their interpretations of what celebrating the centenary meant to them. On some occasions, such as group art exhibitions, there seemed to be a contingent consensus on what constituted Filipino national identity relative to the official NCC events. Most of the time, however, individuals brought forward tentative ideas of national identity that depended, in each case, upon their degree of access to the nation-state. In re-casting the elements of the national flag into works of art and assembling the Filipiniana costume into a contemporary Centennial ensemble, producers of this redefined cloth and clothing were able to imagine themselves as part of a nation. ${ }^{16}$ Their common identity was found not just on the basis of possessing similar forms of cloth but in an act of creativity during a propitious period of Filipino history. This may serve as a shared experience that will, in turn, lend itself to more meaningful acts of reproducing a national thread, linking other aspects of the identities of Filipinos. 
Bodies, memories, and body memories coincide to re-map agendas and ideologies. Seventeenth-century mathematician Blaise Pascal presaged the question of identity by looking into beliefs and practices. He observed that:

we are as much automatic as intellectual; and hence it comes that the instrument by which conviction is attained is not demonstrated alone. How few things are demonstrated! Proofs only convince the mind. Custom is the source of our strongest and most believed proofs. ${ }^{17}$

The Philippine Centennial celebration was distinguished by its use of local customs to rededicate the faith of Filipinos in a nation that is still in the process of defining its identity or identities. Its ambiguous position geographically (part of both Southeast Asia and the Pacific) and politically (neo-colonial and independent nation-state) may be deemed to be part of its strength but also its weakness. Yet we are reminded that the celebration of the Philippines' centenary, as well as the art exhibitions and competitions that accompanied it, were provisional compared to other practices in the Philippines. More significantly, they were secondary to the more important everyday activities of minding oneself and forging relationships with others. $\infty$

ANA P. LABRADOR

Ana P. Labrador is Assistant Professor of Art and Museum Studies at the University of the Philippines, Diliman. She has recently completed the requirements for a
Ph.D. in Social Anthropology at the

University of Cambridge, England.

\section{NOTES}

' I did not see most of the exhibitions cited in this essay as I was abroad on study while the activities for the centenary celebration took place. My data comes from interviews, photographs, and exhibition catalogues, some of which I cite here.

${ }^{2}$ This exhibition was accompanied by a book Nicanor G. Tiongson (ed.), Igkas-Arte: The Philippine arts during the Spanish period (Manila: Sentrong Pangkultura ng Pilipinas and Agencia Española de Cooperación (AECI), 1998).

${ }^{3}$ Images and Lifestyles: The Juan Luna paintings and the nineteenth century prints from the Far East Bank collection, I997.

4 Reynaldo C. Ileto, Pasyon and Revolution: Popular movements in the Philippines, $1840^{-}$ rgro (Quezon City: Ateneo de Manila University Press, 1979).

5 Vicente L. Rafael, Contracting Colonialism: Translation and Christian conversion in Tagalog society under early Spanish rule (Quezon City: Ateneo de Manila University Press, 1988), p. 7.

${ }^{6}$ Ramon N. Villegas, 'Culture and Empire in an Age of Liberation', in Tiongson, Igkas-Arte, P. $5^{2}$.

7 This is a contemporary interpretation of Villanueva's national identity. During his time, those identified as Filipinos were actually Spaniards who were born and bred in the Philippines. Villanueva was believed to be of mixed blood and thus belong to the mestizo category. Patrick Flores, 'Painting as Colonial Reconversion', in 'g8 Cien Años Después (Valencia: Generalitat Valenciana, 1998), for a discussion of Villanueva's Basi Revolt paintings. 
${ }^{8}$ The first school of art in Manila, the Academia de Dibujo, was founded by Damian Domingo in 1823 .

9 Emma Tarlo, Clothing Matters: Dress and identity in India (London: Hurst \& Co., I996), p. 16.

1o Thomas Carlyle, Sartor Resartus: The life and opinons of Herr Teufelsdröckh (London: Chapman \& Hall, 183 I), p. I43.

"At a museum conference in Manila in October r997, a spokesperson of the NCC actually gave these as reasons for the NCC's inability to meet project targets. See Amando Doronila, 'Still Nothing to Show for the Centennial', Philippine Daily Inquirer, 14 November 1997 . While writing this essay, a senate investigation hearing is underway.

${ }^{12}$ The New Society Movement was conceived when Martial Law was declared in 1972. The Marcoses used extra-judicial powers to allocate resources for specific projects. For an in-depth discussion of art in the Philippines during the Marcos years, see M.V. Herrera, 'Government Support for the Visual Arts: The Cultural Center of the Philippines and the Museum of Philippine Art from 1969 to $1985^{\prime}$, Unpublished M.A. Thesis, University of the Philippines, 1994 .
${ }^{13}$ At the time of this writing, the NCC was just about to end its term. There are not enough figures available to estimate the amount of public and corporate funds spent on centennial projects. The Clark Expo Project alone reportedly cost one billion pesos (or A $\left.\$ 39,37^{\circ}, 000\right)$

${ }^{14}$ Shrines of Filipino heroes have been refurbished as a result of massive funding from the NCC. Criticisms have been hurled at the NCC and the National Historical Institute for allegedly tampering with these hallowed spaces. These include the arrangements of displays based on fashionable museum designs with little thought being given to Filipino museum visitors' preferences and practices.

${ }^{15}$ Patrick Flores, 'g8 Cien Años Después , p. $29^{8}$.

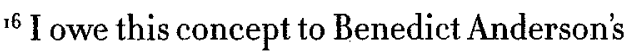
notion of nationalism as a modern phenomenon, focussing on it as a mode of political imagination. See B. Anderson, Imagined Communities: Reflections on the origins and spread of nationalism (London: Verso, $198_{3}$ ).

${ }^{7}$ Blaise Pascal, 'Pensées' (167o, translated by W.F. Trotter), in R.M. Hutchins (ed.), Great Books of the Western World (Chicago: William Benton, I952), p. 2 I9. 


\section{BEAM ME UP}

An interview by Sang Ye, translated by Geremie Barmé.

Born in Shanghai in 1937, he received a degree in International Trade from a university in Beijing in Ig62. He has been President of the Chinese UFO (Unidentified Flying Object)

Research Organization since 1986 and he will, in accordance with a 1995 decision of the Preparatory Committee for Human Contact with Extraterrestrials, be number five in a line up of dignitaries ready to make the first contact. The list is headed by Boutros-Boutros Ghali, the former Secretary-General of the United Nations, and former US President Jimmy Carter.Apart from his work as founder of China's National Federation of UFO organizations, he is also a university professor, an Honorary Member of the Executive Board of the National Association ofQigong Science, a Superior Assessor of the Institute of Paranormal Studies, a member of the Executive Board of the Association for the Investigation of the Hong Kong and Macao Economies, a permanent member of the Executive Council of the International Association of Cultural and Commercial Development, USA, etcetera. Over the past thirty years he has had various careers as a diplomat, interpreter, research scholar, and government bureaucrat.

M any people in China have been fortunate enough to see a UFO, myself included. I had my encounter in the darkest age of Chinese history. It was $197^{\circ}$, and I was at a May Seventh Cadre School in the countryside. ${ }^{\mathrm{I}}$ Only one year earlier I had been in the firmament myself acting as Chairman Mao's Spanish interpreter. I was one of the lucky few who spent some time in the presence of our own Red Sun. In I970, however, I'd very much returned to terra firma. I was undergoing selfrenewal through labour and thought reform.

Of course I didn't think that extraterrestrials would be our salvation. It never occurred to me; no one would think that. Anyway, there's no such thing as a saviour. ${ }^{2}$ The only person qualified to save us was Chairman Mao. He'd already delivered us and now we were working to save others, to liberate all of humanity. At the time we were incessantly warned that we were surrounded by enemies: American imperialism on the one hand, Soviet revisionism on the other. We faced the ever-present threat of a new world war. The Soviets encroached on our borders, so they were the more dangerous foe; they could launch an invasion any moment. That's why when I saw my UFO the last thing I thought of was extraterrestrials. I was convinced it was the Russians.

It was dark and the UFO was as bright as the moon, though smaller. It was roiling in the sky, maybe that's how it generated 
power. There are many was to generate power, after all. For example, you can wind an automatic watch just by moving your hand.

I don't know if that's how this particular UFO worked, but I believe we should be prepared to entertain such hypotheses. Our race, the human race, may be relatively familiar with our own immediate physical environment, one that we can access though our own senses and artificial extensions - various tools and instruments-but there is no conclusive proof to suggest that the universe conforms with our narrow perceptions of it. After all, it's only with the development of space technology in the last three decades that we've been able to investigate the possibility that other forms of life may exist. Of course, up until now these efforts have proved fruitless, but we must be willing to admit that we are hardly in an ideal position to explore the universe. Our efforts to learn the truth are frustrated by the limitations of modern science, but perhaps within a few generations significant advances will be made.

Telescopes extend our range of vision, just as spacecraft act as new means for physical movement. Humanity may have taken one giant step on the moon, but it was only one step after all. We are still a long way from understanding the world, let alone the universe. I attended a UFO conference in Brisbane not too long ago. I was there for a few days and saw a number of places, but on that basis alone I could hardly claim to know Australia.
Every year we hear of numerous eyewitness reports of sightings. There's been an increased frequency both of sightings and the discovery of physical evidence of visitations in recent years. Some people. have taken pictures of UFOs, others have actually been on board them, and people have even found the remains of space craft. However, scientists remain sceptical. All they can tell us about the remains is that some of the metal shards are special alloys. Although they maintain they're not from UFOs, they can't really say for sure. The point is that many unexplained phenomena are simply beyond the realm of general human experience. People's minds are closed to other possibilities and when they are confronted with something that's outside the bounds of the conventional they feel threatened. Even more problematic is the fact that a UFO experience cannot be repeated on demand. So, although there's some evidence of contact, we can't readily demonstrate it. Life is short and opportunities limited. If you say that the only way you'll be convinced about the existence of UFOs is if people can get on board and obtain concrete evidence then, given the present situation, we have a problem. UFOs simply aren't at your beck and call.

Our organization has numerous contacts with scientists, and our membership includes many top-ranking people. Take. Xue Chengwei, for example, the present head of the Beijing Branch. He's a noted rocket scientist. And Shen Shituan, our 
honorary chairperson, is the President of the Chinese Aeronautical University. We also welcome sceptics who are convinced that there's no such thing as extraterrestrial life. Zhou Yousuo, for instance, champions the view that UFOs are nothing more than atmospheric phenomena or balls of plasma. He claims that he can reproduce these so-called UFO phenomena in his laboratory on request.

That's to say, even top scientists have blind spots. We are confined by our contingent framework of knowledge. Our thinking is bound by objective conditions; our views and methodologies are similarly constrained. I am convinced by facts, not by the reproduction of plasma effects in a laboratory. Zhou may well argue that the UFOs people see are nothing more than balls of plasma, but that doesn't deter me. He can say whatever he likes. What I find convincing is something like the map of Piri Re'is. ${ }^{3}$ Once upon a time people treated that old parchment document as though it was little more than a joke, a wildly inaccurate fantasy. But as our knowledge has advanced it's proved to be extraordinarily accurate. Although the Antarctica looks out of place to us today, it was in the position marked on the map 8,000 years ago. Today we have to rely on satellites and spaceships to get such accurate pictures of the earth. I believe people 8,ooo years ago would have had to as well.

We have a membership of five thousand, most of whom have had a tertiary education. Our funding comes from a range of sources: membership fees,

financial support from local government technical and scientific associations, and grants that we've gone out and applied for ourselves. We've never been given a penny by the central government.

No, we don't get any help from extraterrestrials either! Though, to be more precise, I should say that we have no evidence that we've received support from extraterrestrials. Again, because of our limited perceptions it is impossible to say categorically whether we've been getting covert aid or not. Naturally, this brings us to the question of Men in Black. MIBs are extraterrestrials who live among us disguised as human beings. They're not only observers, since they also take part in human affairs. They have considerable power and play an important role in fostering, as well as actively discouraging and preventing, certain developments on earth.

As superior life forms they are a force for the good. They constantly inspire humanity and contribute to our collective wisdom, helping us move on to ever higher planes of civilization. Statistical studies done overseas have shown that some eighty percent of all discoveries throughout history were made semiconsciously or by people in a state of hypnotic suggestion. It's more than likely that these discoveries were actually inspired by aliens transmitting information through extrasensory perception. It's also possible that they've employed other media to relay messages. 
For example, some scientists admit they've received documents containing data that's far more advanced than contemporary scientific research. It's more advanced, but not so far ahead of our own science that it's beyond our comprehension. They've never been able to discover the genius behind any of it.

As to the question of how aliens have hindered certain developments on earth, we are convinced that MIBs have prevented us from pursuing in-depth research into certain mysterious phenomena. In some cases, they actively discourage people from their investigations. That's why, on one level, UFOs remain just that, Unidentified Flying Objects. The mystery may itself be the result of the direct intervention of MIBs. Manipulating politicians and scientific authorities to launch attacks on so-called pseudo-science is one of their most common tactics.

During his presidential campaign Jimmy Carter announced his commitment to make public all government information related to UFOs. When he got into office he reneged on that pledge. I believe that could have been the single most important political decision in the history of the human race. Because by revealing those secrets he could have sparked widespread social chaos, as well as creating a major threat to established religions and belief systems. But that was only one reason for his decision. There may well have been another: the aliens themselves decided they didn't want to reveal themselves.
Perhaps everything that has happened is part of an elaborate extraterrestrial ruse.

The time isn't ripe for aliens to establish open and sociable dealings with humanity. Although we've been in contact now for at least ten thousand years, the gap between our civilizations is still far too great. If relations were established today that led to people-to-alien exchanges and visits I fear it would be counterproductive for both sides. Evolution is like a relay race. We want to take the baton from those running ahead of us, but we're simply too slow. We need a training partner to help get us up to speed. Only when we're fast enough will the baton be handed over.

As for the origins of our species, people in China generally accept the DarwinianMarxist theory that we have evolved from apes through manual work. But if you look at it from another angle, you could just as well argue that the human race is part of an alien experiment. After all, modern science has proved that it must have taken longer than the known lifespan of the earth - calculated to be forty-six billion years-for humans to have evolved from the simplest organism. Thus, it is quite likely that aliens developed our human stock elsewhere and transferred it to the earth where we have gradually arrived to the stage at which we find ourselves today.

But I don't believe that aliens observe us in the same way, say, that we watch ants fighting with each other. Certainly, the earth has been supervised and controlled by extraterrestrials throughout human 
history, but that knowledge doesn't change my view of life itself. It hasn't made me particularly fatalistic or pessimistic.

Of course, I think Jesus Christ could have been an extraterrestrial. After all, he used telekinesis to cure illness and prevent disasters. He even modified the spiritual make-up of human kind. There are many accounts of his powers. As for the gods, spirits, and the bodhisattvas of the Far East, there is nothing mysterious about them at all. They are all agents of alien intelligence.

Chairman Mao? Chairman Mao was

Chairman Mao, plain and simple.

As for various other new age phenomena like astrology, fortune telling, the belief in advanced civilizations that existed before recorded history, and so on, it goes without saying that I'm interested in them all. However, I'm particularly fascinated by extrasensory perception and qigong. 4 UFO research is a vast field that inevitably leads to an investigation of all of these things. But, take my word for it, I'm not gullible; I don't believe everything. The deceptions of fake qigong masters and the like have a negative influence on our work, though they're not all that damaging. After all, our organization pursues aims that are closely related to the aims of modern science.

Ours is a serious enterprise that has nothing to do with the gamut of superstitious qigong beliefs, and all that talk about adepts who have trained secretly in the mountains for five hundred years, and such like.
False UFO sightings are reported for any number of reasons. Some are honest errors of judgement by people who have mistaken natural phenomena for UFOs. But there are also hoaxes concocted by individuals who have nothing better to do with their lives than make up wild stories for their own amusement. The perpetrators are usually crooks who are trying to work some swindle. They act in a secretive and covert fashion but despite their best efforts to fabricate fake aliens, alien medicines, alien representatives, intergalactic linguistics, and so on, their scams are easily exposed.

Just because you come across a few cheats is no reason to give up your own beliefs. There've been cases of itinerant workers in China pretending to be the children of high-level cadres. But they've only been able to get away with the deception because there really are high-level cadres. In general, the state maintains a hands-off attitude towards the issue of UFOs. This allows us to pursue our activities in an environment that's so relaxed that even our overseas colleagues are quite taken aback. Despite this, however, our legitimacy is still questioned: conventional science does not recognized the validity of our inquiry.

'You're just like a small group of religious fanatics. How can you be sure your beliefs aren't just another heresy?'

That's the kind of question I was asked by people after members of the Heaven's Gate 
cult in America committed suicide in the belief they'd be united with an alien mothership hidden in the tail of the HaleBopp Comet. 5 I said it was an excellent question, but that, no, we can't find anyone qualified to act as a guarantor of our beliefs. However, the cult members who committed suicide do not represent us or our beliefs. Indeed there may have been a quirky extraterrestrial among them with strong non-scientific fixations. Their leader may have been such a being and that explains how he attracted all those aberrant followers.

I told that reporter just to forget all about it. But enough of that, let's get back to what we were talking about.

I don't want to get involved in discussing the policies of the past. For the moment at least the government is concentrating its efforts on building up China's market economy. People fortunate enough to be living in this transitional age are easily overwhelmed by materialism; they lose sight of the important things in life. That's why I believe that our mission to explore a phenomenon that many people believe doesn't even exist, that's to say alien civilization, is of value in and of itself. We can claim that we have already achieved something: we provide food for thought for a society that craves intellectual sustenance.

I'm in a minority even at home. My sons don't believe in aliens, and their mother is even more sceptical. They're extremely critical of my views. That makes it three against one, and one of them is a high-level cadre: my wife is a bureau chief. If we were all in an American-style jury they'd have to work very hard to get me to agree with their verdict. In China, however, no one stands up for minority opinions; the minority has to defer to the will of the majority.

The thing is that there's no jury fit to adjudicate on these issues. If you don't agree it's just tough luck; there's no place for you to make your case. As for being allowed to arbitrate yourself, you couldn't imagine it even in your wildest dreams. The truth will never be put on the stand. People who take it upon themselves to judge others will be struck down as God laughs.

Human knowledge can no longer be simplistically categorized into opposing schools of materialism and idealism. ${ }^{6} \mathrm{We}$ have to contemplate the problems facing humanity from a more nuanced perspective. If you insist on labelling my approach in terms of some -ism or other, I suppose you could say that mine is a superior form of materialism. But even that's an artificial category. All attempts to draw a distinction between science and pseudo-science are dangerously subjective. If you are confronted by something that can't be found in any of your weighty tomes then you shouldn't presume that you're in a position to judge its validity impartially.

History has proved that most of the predictions that Nostradamus made three 
centuries ago were accurate, including the timing of the explosion of the first Chinese hydrogen bomb. The year 1999 is upon us. Whether the Armageddon he foresaw will come to pass is a pressing issue. But to obsess about such things only serves to undermine our commitment to life in the here and now. Our very existence on this planet is precarious and perhaps one day humanity will be confronted with a holocaust of its own making. That's when I believe aliens will come to our aid. And when they do appear on earth, our small group-The Preparatory Committee for Human Contact with Extraterrestrialswill be ready to carry out the task for which it was set up.

Of course, I'm a member of the Chinese Communist Party. $\propto$

\section{SANG YE}

Visiting Beijing in June I999 to secure the inflatable Hua Biao for the Brisbane Triennial, Sang Ye chanced again upon the President of the Chinese UFO Research Organization who gave him an update of his activities. The Chinese Communist Party was attempting to deal with the followers of the nationwide religious cult, the Buddhist Falungong, which boasted sixty million adherents on the mainland and had recently staged a surprise protest outside party headquarters. Meanwhile, there was more stirring news from the front for UFO activists. The president told Sang Ye that a higher form of intelligence previously covertly active in northeast China was preparing to move on Beijing. This being had already revealed that many politicians and social leaders were actually aliens. Despite this confirmation that perhaps even Chairman Mao had been an ET in disguise, the visitors to earth were experiencing financial difficulties. Increased economic pressures meant that finding new sources of funding had become a key issue for further UFO research; more importantly, the aliens active in human guise-the MIBs-needed more money themselves to deal with inflationary pressures that they were experiencing both in reformist China and elsewhere. Despite these problems the most startling news was that researchers in China had uncovered the secret of propulsion used by alien space craft, as well as having discovered an alien-sourced cure for cancer, among other diseases. 'As a by-product of our investigations into UFO phenomena,' the president remarked to Sang, 'these discoveries will have a profound impact not only on the economic well-being of China, but they will also have long-term payoffs for our nation in terms of energy resources, transportation, and medicine. This will put China at the forefront of the advanced nations early in the next millenium.' In parting he reminded Sang Ye that their activities were sanctioned by no less an authority than Vladimir Ilyich Lenin himself, for did not that great Russian revolutionary say: 'Contact with extraterrestrials will force mankind to radically revise all of its pre-existing philosophical and moral tenets? $\sim$ 
Sang Ye and Geremie R. Barmé have created an installation for the Asia-Pacific Triennial at the Queensland Art Gallery in

Brisbane entitled Hua Biao: A Chinese Pillar'. An outlandish decorated pillar this inflatable red column is like some intercontinental projectile crash-landed, or ready on its launch pad, and situated at the northern artistic Woomera of the APT. The UFO-logist talking to Sang Ye here has also visited Brisbane.

This is a chapter from Sang Ye's latest oral history project, Chairman Mao's Ark: the People on the People's Republic, edited by Geremie R. Barmé and to be published by the University of California Press in the year 2000 .

\section{NOTES}

${ }^{1}$ Cadre schools were set up in agricultural communes and state farms during the Cultural Revolution for the ostensible reeducation of government-employed white collar workers. Mao Zedong's directive on the need for cadres to engage in manual labour was made on 7 May 1966 , hence the name.

${ }^{2} \mathrm{~A}$ line from the Communist anthem 'The Internationale'.

3 The maps by Piri Re' is (Piri Ibn Haji Memmed) were discovered in Constantinople (now Istanbul) in $19^{2} 9$ and date from $\mathrm{AD}_{15} \mathbf{5}^{13}$.

4 Traditional Chinese yogic practices involving breath control, exercise, and meditation.

5 The Heaven's Gate cult, also known as Total Overcomers Anonymous Monastery, was led by Marshall Herff Applewhite. In March 1997, Applewhite and his followers committed mass suicide at Rancho Santa Fe, San Diego County, California.

${ }^{6}$ The basic epistemological categories of Marxist-Leninist ideology. 